\title{
Synthetic, Electrochemical, and Theoretical Studies of Tetrairidium Clusters Bearing Mono- and Bis-
}

\section{[60]Fullerene Ligands}

Bo Keun Park, ${ }^{\dagger}$ Gaehang Lee, ${ }^{\dagger}$ Kyoung Hoon Kim, ${ }^{\ddagger}$ Hongkyu Kang,,${ }^{\dagger}$ Chang Yeon Lee, ${ }^{\dagger}$ Md. Arzu Miah, ${ }^{\dagger}$ Jaehoon Jung, ${ }^{*}$ Young-Kyu Han, ${ }^{*,+}$ and Joon T. Park ${ }^{*}+$

Department of Chemistry and School of Molecular Science (BK 21), Korea Advanced Institute of Science and Technology (KAIST), Daejeon, 305-701, Korea

Computational Chemistry Laboratory, Advanced Materials R\&D, LG Chem, Ltd. Research Park, Daejeon, 305-380, Korea

Supporting Information 
Complete Reference 54: Frisch, M. J.; Trucks, G. W.; Schlegel, H. B.; Scuseria, G. E.; Robb, M. A.; Cheeseman, J. R.; Montgomery, Jr., J. A.; Vreven, T.; Kudin, K. N.; Burant, J. C.; Millam, J. M.; Iyengar, S. S.; Tomasi, J.; Barone, V.; Mennucci, B.; Cossi, M.; Scalmani, G.; Rega, N.; Petersson, G. A.; Nakatsuji, H.; Hada, M.; Ehara, M.; Toyota, K.; Fukuda, R.; Hasegawa, J.; Ishida, M.; Nakajima, T.; Honda, Y.; Kitao, O.; Nakai, H.; Klene, M.; Li, X.; Knox, J. E.; Hratchian, H. P.; Cross, J. B.; Bakken, V.; Adamo, C.; Jaramillo, J.; Gomperts, R.; Stratmann, R. E.; Yazyev, O.; Austin, A. J.; Cammi, R.; Pomelli, C.; Ochterski, J. W.; Ayala, P. Y.; Morokuma, K.; Voth, G. A.; Salvador, P.; Dannenberg, J. J.; Zakrzewski, V. G.; Dapprich, S.; Daniels, A. D.; Strain, M. C.; Farkas, O.; Malick, D. K.; Rabuck, A. D.; Raghavachari, K.; Foresman, J. B.; Ortiz, J. V.; Cui, Q.; Baboul, A. G.; Clifford, S.; Cioslowski, J.; Stefanov, B. B.; Liu, G.; Liashenko, A.; Piskorz, P.; Komaromi, I.; Martin, R. L.; Fox, D. J.; Keith, T.; Al-Laham, M. A.; Peng, C. Y.; Nanayakkara, A.; Challacombe, M.; Gill, P. M. W.; Johnson, B.; Chen, W.; Wong, M. W.; Gonzalez, C.; and Pople, J. A. Gaussian 03, Revision C.02; Gaussian, Inc.; Wallingford, CT, 2004 


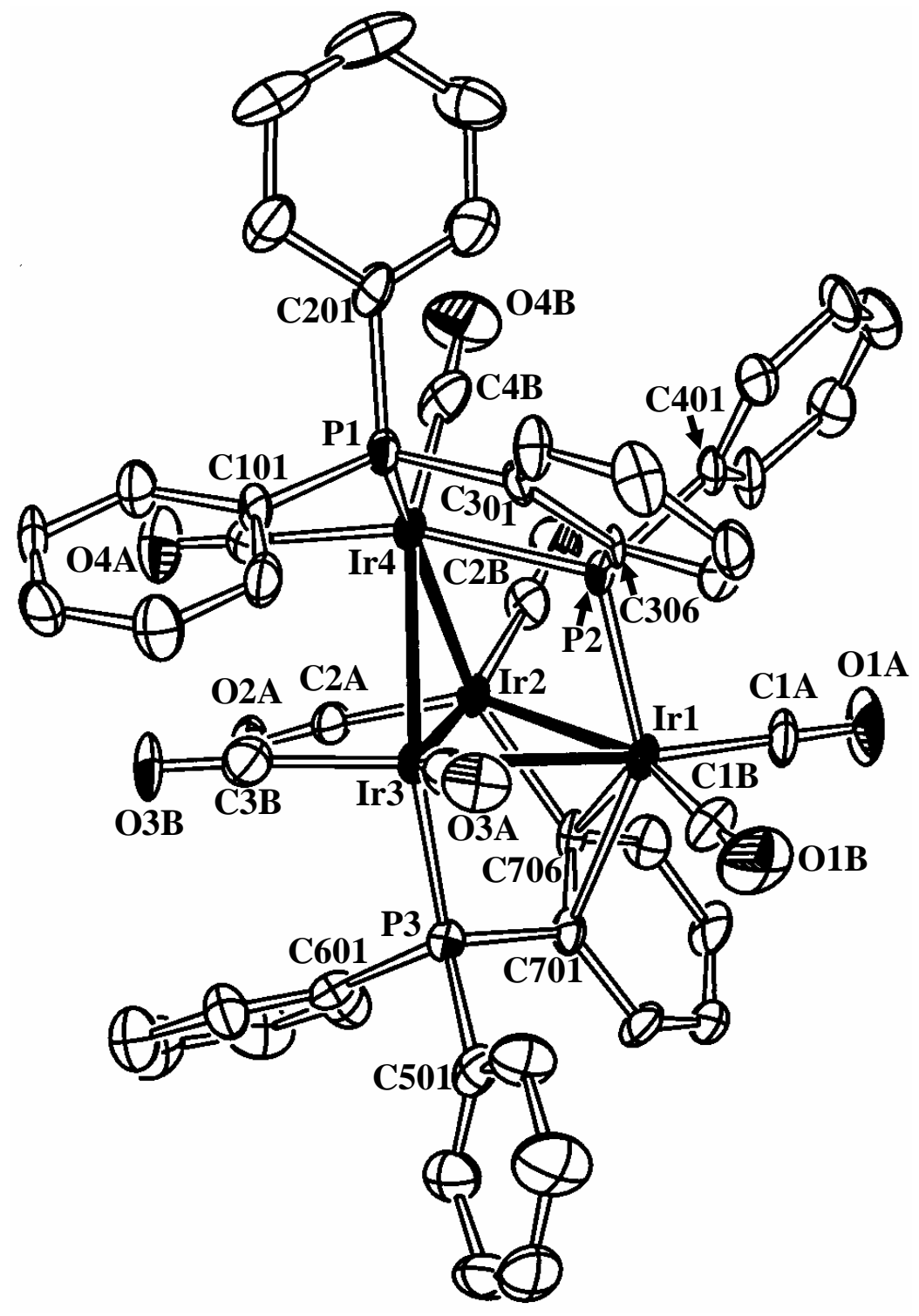

Figure S1. Molecular Structure of 2. 


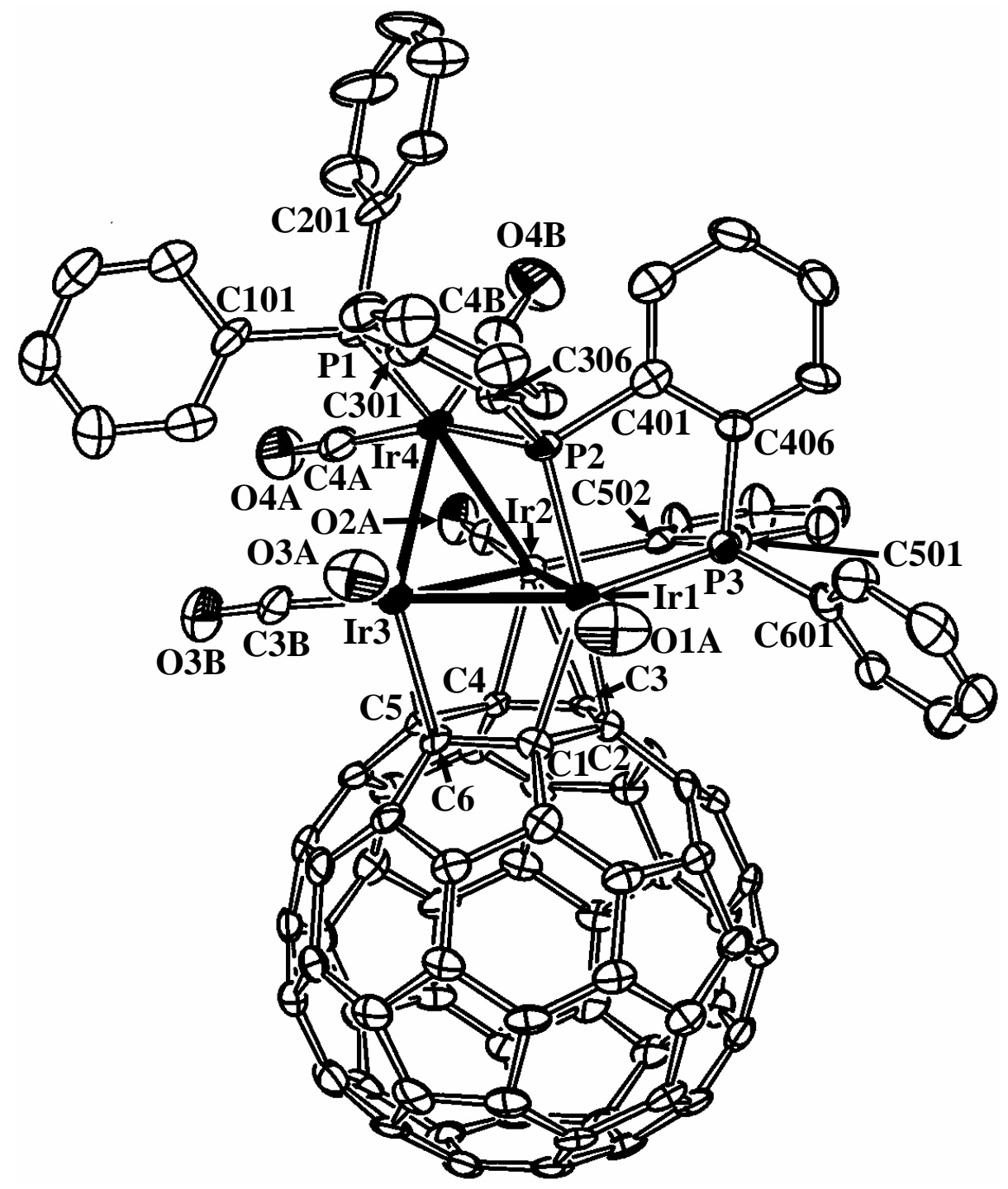

Figure S2. Molecular Structure of 3. 


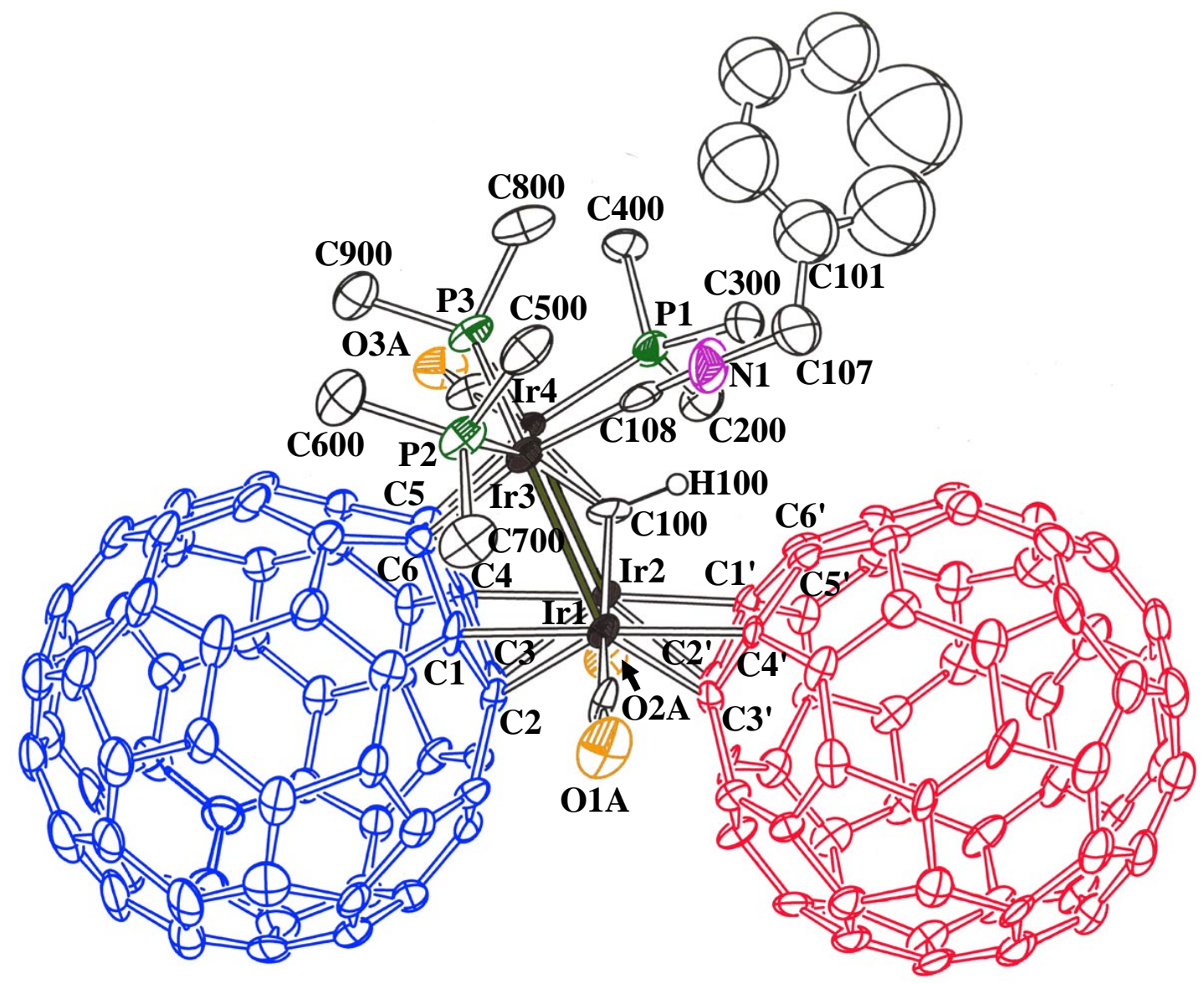

Figure S3. Molecular Structure of 5. 
Table S1. Atomic coordinates $\left(\times 10^{4}\right)$ and equivalent isotropic displacement parameters $\left(\AA^{2} \times 10^{3}\right)$ for 2. $\mathrm{U}(\mathrm{eq})$ is defined as one third of the trace of the orthogonalized Uij tensor.

\begin{tabular}{|c|c|c|c|c|}
\hline & $\mathrm{X}$ & $y$ & $\mathrm{z}$ & \\
\hline $\operatorname{Ir}(1)$ & $4422(1)$ & $2926(1)$ & $2218(1)$ & $22(1)$ \\
\hline $\operatorname{Ir}(2)$ & $2717(1)$ & $892(1)$ & $2713(1)$ & $20(1)$ \\
\hline $\operatorname{Ir}(3)$ & $4525(1)$ & 602(1) & $2154(1)$ & $20(1)$ \\
\hline $\operatorname{Ir}(4)$ & $5015(1)$ & $916(1)$ & $3491(1)$ & 19(1) \\
\hline $\mathrm{P}(1)$ & $7258(3)$ & $1228(3)$ & $3697(1)$ & $22(1)$ \\
\hline $\mathrm{P}(2)$ & $5809(3)$ & 2974(3) & $3177(1)$ & $21(1)$ \\
\hline $\mathrm{P}(3)$ & 2950(3) & $374(3)$ & 1232(1) & $23(1)$ \\
\hline$C(101)$ & $7551(12)$ & $-22(11)$ & $3309(6)$ & $22(2)$ \\
\hline$C(102)$ & $8255(13)$ & 161(12) & $2839(6)$ & $30(3)$ \\
\hline$C(103)$ & $8385(14)$ & $-836(13)$ & $2545(7)$ & $35(3)$ \\
\hline$C(104)$ & $7776(15)$ & $-2076(13)$ & $2696(6)$ & $36(3)$ \\
\hline$C(105)$ & $7016(13)$ & $-2329(12)$ & $3170(7)$ & $31(3)$ \\
\hline$C(106)$ & 6896(13) & $-1320(12)$ & $3477(6)$ & $31(3)$ \\
\hline$C(201)$ & $8131(13)$ & 1496(13) & $4537(6)$ & $28(3)$ \\
\hline$C(202)$ & $8637(16)$ & $655(15)$ & 4831(7) & $42(3)$ \\
\hline$C(203)$ & 9231(17) & 939(19) & $5484(8)$ & $54(5)$ \\
\hline$C(204)$ & $9300(18)$ & 1990(20) & $5848(8)$ & $62(5)$ \\
\hline$C(205)$ & $8853(16)$ & $2819(17)$ & $5566(7)$ & $47(4)$ \\
\hline$C(206)$ & $8227(17)$ & $2569(16)$ & $4918(7)$ & $45(4)$ \\
\hline $\mathrm{C}(301)$ & $8290(12)$ & $2740(10)$ & $3422(5)$ & $21(2)$ \\
\hline$C(302)$ & $9708(13)$ & $3203(12)$ & $3465(6)$ & $30(3)$ \\
\hline$C(303)$ & $10455(14)$ & 4311(14) & $3224(8)$ & $40(3)$ \\
\hline$C(304)$ & $9773(15)$ & $5017(13)$ & $2922(6)$ & $35(3)$ \\
\hline$C(305)$ & $8403(13)$ & $4628(12)$ & 2911(6) & $27(3)$ \\
\hline$C(306)$ & $7638(12)$ & $3496(10)$ & $3146(5)$ & $19(2)$ \\
\hline $\mathrm{C}(401)$ & $6097(12)$ & $4324(11)$ & $3778(5)$ & $22(2)$ \\
\hline$C(402)$ & $7393(15)$ & $5126(13)$ & $4179(6)$ & $33(3)$ \\
\hline$C(403)$ & $7575(17)$ & $6125(13)$ & $4637(6)$ & $38(3)$ \\
\hline$C(404)$ & $6501(16)$ & $6346(14)$ & $4692(7)$ & 41(4) \\
\hline$C(405)$ & $5190(15)$ & $5551(14)$ & $4293(7)$ & $36(3)$ \\
\hline$C(406)$ & $5004(15)$ & $4534(12)$ & $3863(7)$ & $34(3)$ \\
\hline $\mathrm{C}(501)$ & $3425(14)$ & 631(13) & $461(6)$ & $30(3)$ \\
\hline$C(502)$ & $4815(14)$ & $1416(15)$ & $452(7)$ & $40(3)$ \\
\hline$C(503)$ & $5143(18)$ & 1651(19) & $-138(8)$ & $59(5)$ \\
\hline$C(504)$ & $4110(20)$ & 1094(18) & $-704(8)$ & $55(4)$ \\
\hline$C(505)$ & 2778(18) & $364(17)$ & $-681(7)$ & $47(4)$ \\
\hline$C(506)$ & $2453(15)$ & $66(15)$ & $-94(6)$ & $38(3)$ \\
\hline$C(601)$ & $1435(13)$ & $-1215(13)$ & $1030(6)$ & $29(3)$ \\
\hline$C(602)$ & $1563(17)$ & $-2300(14)$ & $890(7)$ & $43(4)$ \\
\hline$C(603)$ & $450(20)$ & $-3571(17)$ & 786(9) & $61(5)$ \\
\hline$C(604)$ & $-815(18)$ & $-3729(18)$ & $801(8)$ & $59(5)$ \\
\hline$C(605)$ & $-993(15)$ & $-2622(18)$ & $915(7)$ & $49(4)$ \\
\hline$C(606)$ & $97(15)$ & $-1413(15)$ & $1038(7)$ & $40(3)$ \\
\hline$C(701)$ & $2263(11)$ & $1520(11)$ & 1341(6) & $22(2)$ \\
\hline$C(702)$ & 1804(13) & $2080(13)$ & $821(6)$ & $30(3)$ \\
\hline$C(703)$ & 999(16) & $2662(13)$ & $883(6)$ & $37(3)$ \\
\hline$C(704)$ & $638(14)$ & $2747(13)$ & $1469(7)$ & $36(3)$ \\
\hline$C(705)$ & $1096(13)$ & 2251(13) & $1965(7)$ & $33(3)$ \\
\hline$C(706)$ & 1944(12) & 1612(11) & 1939(6) & $24(2)$ \\
\hline $\mathrm{C}(1 \mathrm{~A})$ & 4011(14) & $4354(12)$ & $2383(7)$ & $33(3)$ \\
\hline $\mathrm{O}(1 \mathrm{~A})$ & $3794(13)$ & $5218(10)$ & 2481(6) & $63(3)$ \\
\hline $\mathrm{C}(1 \mathrm{~B})$ & $5740(14)$ & $3770(14)$ & $1730(6)$ & $35(3)$ \\
\hline $\mathrm{O}(1 \mathrm{~B})$ & $6555(12)$ & $4300(13)$ & $1468(5)$ & $63(4)$ \\
\hline
\end{tabular}




\begin{tabular}{|rrrrr|}
\hline $\mathrm{C}(2 \mathrm{~A})$ & $1573(12)$ & $-906(12)$ & $2625(6)$ & $28(3)$ \\
\hline $\mathrm{O}(2 \mathrm{~A})$ & $840(11)$ & $-1985(9)$ & $2535(5)$ & $43(2)$ \\
\hline $\mathrm{C}(2 \mathrm{~B})$ & $2089(13)$ & $1458(13)$ & $3348(6)$ & $30(3)$ \\
\hline $\mathrm{O}(2 \mathrm{~B})$ & $1767(11)$ & $1783(10)$ & $3766(5)$ & $43(2)$ \\
\hline $\mathrm{C}(3 \mathrm{~A})$ & $6266(13)$ & $1321(13)$ & $1955(6)$ & $31(3)$ \\
\hline $\mathrm{O}(3 \mathrm{~A})$ & $7315(9)$ & $1794(10)$ & $1821(5)$ & $40(2)$ \\
\hline $\mathrm{C}(3 \mathrm{~B})$ & $4190(14)$ & $-1180(14)$ & $2168(6)$ & $34(3)$ \\
\hline $\mathrm{O}(3 \mathrm{~B})$ & $3979(16)$ & $-2232(10)$ & $2143(6)$ & $66(4)$ \\
\hline $\mathrm{C}(4 \mathrm{~A})$ & $4037(14)$ & $-954(14)$ & $3498(6)$ & $36(3)$ \\
\hline $\mathrm{O}(4 \mathrm{~A})$ & $3474(11)$ & $-2043(10)$ & $3515(6)$ & $54(3)$ \\
\hline $\mathrm{C}(4 \mathrm{~B})$ & $4863(15)$ & $1396(15)$ & $4306(7)$ & $37(3)$ \\
\hline $\mathrm{O}(4 \mathrm{~B})$ & $4763(14)$ & $1654(14)$ & $4800(5)$ & $66(4)$ \\
\hline \multicolumn{5}{r}{}
\end{tabular}


Table S2. Bond lengths $[\AA]$ and angles [deg] for $\mathbf{2}$.

\begin{tabular}{|c|c|c|c|}
\hline $\operatorname{Ir}(1)-C(1 B)$ & $1.906(13)$ & $\mathrm{C}(104)-\mathrm{C}(105)$ & $1.413(19)$ \\
\hline $\operatorname{Ir}(1)-C(1 \mathrm{~A})$ & $1.924(13)$ & $\mathrm{C}(105)-\mathrm{C}(106)$ & $1.384(17)$ \\
\hline $\operatorname{Ir}(1)-\mathrm{P}(2)$ & $2.297(3)$ & $\mathrm{C}(201)-\mathrm{C}(206)$ & $1.409(19)$ \\
\hline $\operatorname{Ir}(1)-C(706)$ & $2.411(12)$ & $\mathrm{C}(201)-\mathrm{C}(202)$ & $1.421(18)$ \\
\hline $\operatorname{Ir}(1)-C(701)$ & $2.545(11)$ & $\mathrm{C}(202)-\mathrm{C}(203)$ & $1.39(2)$ \\
\hline $\operatorname{Ir}(1)-\operatorname{Ir}(2)$ & $2.6953(6)$ & $\mathrm{C}(203)-\mathrm{C}(204)$ & $1.38(3)$ \\
\hline $\operatorname{Ir}(1)-\operatorname{Ir}(3)$ & $2.7170(7)$ & $\mathrm{C}(204)-\mathrm{C}(205)$ & $1.36(2)$ \\
\hline $\operatorname{Ir}(2)-C(2 A)$ & $1.864(12)$ & $\mathrm{C}(205)-\mathrm{C}(206)$ & $1.39(2)$ \\
\hline $\operatorname{Ir}(2)-C(2 B)$ & $1.874(12)$ & $\mathrm{C}(301)-\mathrm{C}(302)$ & $1.402(16)$ \\
\hline $\operatorname{Ir}(2)-C(706)$ & $2.082(12)$ & $\mathrm{C}(301)-\mathrm{C}(306)$ & $1.429(15)$ \\
\hline $\operatorname{Ir}(2)-\operatorname{Ir}(3)$ & $2.6689(6)$ & $\mathrm{C}(302)-\mathrm{C}(303)$ & $1.365(19)$ \\
\hline $\operatorname{Ir}(2)-\operatorname{Ir}(4)$ & $2.7409(6)$ & $\mathrm{C}(303)-\mathrm{C}(304)$ & $1.42(2)$ \\
\hline $\operatorname{Ir}(3)-C(3 A)$ & $1.885(13)$ & $\mathrm{C}(304)-\mathrm{C}(305)$ & $1.377(18)$ \\
\hline $\operatorname{Ir}(3)-C(3 B)$ & $1.913(14)$ & $\mathrm{C}(305)-\mathrm{C}(306)$ & $1.383(16)$ \\
\hline $\operatorname{Ir}(3)-\mathrm{P}(3)$ & $2.286(3)$ & $\mathrm{C}(401)-\mathrm{C}(406)$ & $1.381(17)$ \\
\hline $\operatorname{Ir}(3)-\operatorname{Ir}(4)$ & $2.8054(6)$ & $\mathrm{C}(401)-\mathrm{C}(402)$ & $1.393(18)$ \\
\hline $\operatorname{Ir}(4)-C(4 B)$ & $1.887(14)$ & $\mathrm{C}(402)-\mathrm{C}(403)$ & $1.403(17)$ \\
\hline $\operatorname{Ir}(4)-C(4 A)$ & $1.935(14)$ & $\mathrm{C}(403)-\mathrm{C}(404)$ & $1.35(2)$ \\
\hline $\operatorname{Ir}(4)-P(1)$ & $2.295(3)$ & $\mathrm{C}(404)-\mathrm{C}(405)$ & $1.40(2)$ \\
\hline $\operatorname{Ir}(4)-P(2)$ & $2.309(3)$ & $\mathrm{C}(405)-\mathrm{C}(406)$ & $1.379(17)$ \\
\hline $\mathrm{P}(1)-\mathrm{C}(301)$ & $1.808(12)$ & $\mathrm{C}(501)-\mathrm{C}(506)$ & $1.352(19)$ \\
\hline $\mathrm{P}(1)-\mathrm{C}(101)$ & $1.817(11)$ & $\mathrm{C}(501)-\mathrm{C}(502)$ & $1.407(18)$ \\
\hline $\mathrm{P}(1)-\mathrm{C}(201)$ & $1.819(13)$ & $\mathrm{C}(502)-\mathrm{C}(503)$ & $1.40(2)$ \\
\hline $\mathrm{P}(2)-\mathrm{C}(401)$ & $1.854(11)$ & $\mathrm{C}(503)-\mathrm{C}(504)$ & $1.40(2)$ \\
\hline $\mathrm{P}(2)-\mathrm{C}(306)$ & $1.862(12)$ & $\mathrm{C}(504)-\mathrm{C}(505)$ & $1.35(2)$ \\
\hline $\mathrm{P}(3)-\mathrm{C}(601)$ & $1.814(13)$ & $\mathrm{C}(505)-\mathrm{C}(506)$ & $1.40(2)$ \\
\hline $\mathrm{P}(3)-\mathrm{C}(701)$ & $1.815(11)$ & $\mathrm{C}(601)-\mathrm{C}(602)$ & $1.344(19)$ \\
\hline $\mathrm{P}(3)-\mathrm{C}(501)$ & $1.839(13)$ & $\mathrm{C}(601)-\mathrm{C}(606)$ & $1.402(19)$ \\
\hline$C(101)-C(102)$ & $1.370(17)$ & $\mathrm{C}(602)-\mathrm{C}(603)$ & $1.41(2)$ \\
\hline$C(101)-C(106)$ & $1.437(16)$ & $\mathrm{C}(603)-\mathrm{C}(604)$ & $1.34(3)$ \\
\hline$C(102)-C(103)$ & $1.365(18)$ & $\mathrm{C}(604)-\mathrm{C}(605)$ & $1.39(3)$ \\
\hline$C(103)-C(104)$ & $1.365(19)$ & $\mathrm{C}(605)-\mathrm{C}(606)$ & $1.35(2)$ \\
\hline$C(701)-C(706)$ & $1.419(16)$ & $\mathrm{C}(1 \mathrm{~B})-\mathrm{O}(1 \mathrm{~B})$ & $1.120(16)$ \\
\hline$C(701)-C(702)$ & $1.426(16)$ & $\mathrm{C}(2 \mathrm{~A})-\mathrm{O}(2 \mathrm{~A})$ & $1.125(14)$ \\
\hline$C(702)-C(703)$ & $1.352(19)$ & $\mathrm{C}(2 \mathrm{~B})-\mathrm{O}(2 \mathrm{~B})$ & $1.142(15)$ \\
\hline$C(703)-C(704)$ & $1.41(2)$ & $\mathrm{C}(3 \mathrm{~A})-\mathrm{O}(3 \mathrm{~A})$ & $1.150(15)$ \\
\hline$C(704)-C(705)$ & $1.342(18)$ & $\mathrm{C}(3 \mathrm{~B})-\mathrm{O}(3 \mathrm{~B})$ & $1.121(17)$ \\
\hline$C(705)-C(706)$ & $1.432(17)$ & $\mathrm{C}(4 \mathrm{~A})-\mathrm{O}(4 \mathrm{~A})$ & $1.131(17)$ \\
\hline $\mathrm{C}(1 \mathrm{~A})-\mathrm{O}(1 \mathrm{~A})$ & $1.141(16)$ & $\mathrm{C}(4 \mathrm{~B})-\mathrm{O}(4 \mathrm{~B})$ & $1.138(16)$ \\
\hline
\end{tabular}

\begin{tabular}{|l|c|l|c|}
\hline $\mathrm{C}(1 \mathrm{~B})-\operatorname{Ir}(1)-\mathrm{C}(1 \mathrm{~A})$ & $97.3(6)$ & $\mathrm{Ir}(1)-\operatorname{Ir}(2)-\operatorname{Ir}(4)$ & $88.195(19)$ \\
\hline $\mathrm{C}(1 \mathrm{~B})-\operatorname{Ir}(1)-\mathrm{P}(2)$ & $102.2(4)$ & $\mathrm{C}(3 \mathrm{~A})-\operatorname{Ir}(3)-\mathrm{C}(3 \mathrm{~B})$ & $99.9(6)$ \\
\hline $\mathrm{C}(1 \mathrm{~A})-\operatorname{Ir}(1)-\mathrm{P}(2)$ & $103.1(4)$ & $\mathrm{C}(3 \mathrm{~A})-\operatorname{Ir}(3)-\mathrm{P}(3)$ & $106.2(4)$ \\
\hline $\mathrm{C}(1 \mathrm{~B})-\operatorname{Ir}(1)-\mathrm{C}(706)$ & $133.2(5)$ & $\mathrm{C}(3 \mathrm{~B})-\operatorname{Ir}(3)-\mathrm{P}(3)$ & $100.0(4)$ \\
\hline $\mathrm{C}(1 \mathrm{~A})-\operatorname{Ir}(1)-\mathrm{C}(706)$ & $84.5(5)$ & $\mathrm{C}(3 \mathrm{~A})-\operatorname{Ir}(3)-\operatorname{Ir}(2)$ & $149.7(4)$ \\
\hline $\mathrm{P}(2)-\operatorname{Ir}(1)-\mathrm{C}(706)$ & $123.1(3)$ & $\mathrm{C}(3 \mathrm{~B})-\operatorname{Ir}(3)-\operatorname{Ir}(2)$ & $106.6(4)$ \\
\hline $\mathrm{C}(1 \mathrm{~B})-\operatorname{Ir}(1)-\mathrm{C}(701)$ & $101.4(5)$ & $\mathrm{P}(3)-\operatorname{Ir}(3)-\operatorname{Ir}(2)$ & $83.51(8)$ \\
\hline $\mathrm{C}(1 \mathrm{~A})-\operatorname{Ir}(1)-\mathrm{C}(701)$ & $98.2(5)$ & $\mathrm{C}(3 \mathrm{~A})-\operatorname{Ir}(3)-\operatorname{Ir}(1)$ & $93.7(4)$ \\
\hline $\mathrm{P}(2)-\operatorname{Ir}(1)-\mathrm{C}(701)$ & $145.7(3)$ & $\mathrm{C}(3 \mathrm{~B})-\operatorname{Ir}(3)-\operatorname{Ir}(1)$ & $166.4(4)$ \\
\hline $\mathrm{C}(706)-\operatorname{Ir}(1)-\mathrm{C}(701)$ & $33.1(4)$ & $\mathrm{P}(3)-\operatorname{Ir}(3)-\operatorname{Ir}(1)$ & $76.62(8)$ \\
\hline $\mathrm{C}(1 \mathrm{~B})-\operatorname{Ir}(1)-\operatorname{Ir}(2)$ & $155.7(4)$ & $\mathrm{Ir}(2)-\operatorname{Ir}(3)-\operatorname{Ir}(1)$ & $60.049(16)$ \\
\hline $\mathrm{C}(1 \mathrm{~A})-\operatorname{Ir}(1)-\operatorname{Ir}(2)$ & $106.6(4)$ & $\mathrm{C}(3 \mathrm{~A})-\operatorname{Ir}(3)-\operatorname{Ir}(4)$ & $107.1(4)$ \\
\hline $\mathrm{P}(2)-\operatorname{Ir}(1)-\operatorname{Ir}(2)$ & $76.79(8)$ & $\mathrm{C}(3 \mathrm{~B})-\operatorname{Ir}(3)-\operatorname{Ir}(4)$ & $88.8(4)$ \\
\hline $\mathrm{C}(706)-\operatorname{Ir}(1)-\operatorname{Ir}(2)$ & $47.7(3)$ & $\mathrm{P}(3)-\operatorname{Ir}(3)-\operatorname{Ir}(4)$ & $143.44(8)$ \\
\hline
\end{tabular}




\begin{tabular}{|c|c|c|c|}
\hline$C(701)-\operatorname{Ir}(1)-\operatorname{Ir}(2)$ & $71.5(3)$ & $\operatorname{Ir}(2)-\operatorname{Ir}(3)-\operatorname{Ir}(4)$ & $60.029(16)$ \\
\hline $\mathrm{C}(1 \mathrm{~B})-\operatorname{Ir}(1)-\operatorname{Ir}(3)$ & $97.0(4)$ & $\operatorname{Ir}(1)-\operatorname{Ir}(3)-\operatorname{Ir}(4)$ & $86.462(17)$ \\
\hline $\mathrm{C}(1 \mathrm{~A})-\operatorname{Ir}(1)-\operatorname{Ir}(3)$ & $165.7(4)$ & $\mathrm{C}(4 \mathrm{~B})-\operatorname{Ir}(4)-\mathrm{C}(4 \mathrm{~A})$ & $95.6(6)$ \\
\hline $\mathrm{P}(2)-\operatorname{Ir}(1)-\operatorname{Ir}(3)$ & $74.04(7)$ & $\mathrm{C}(4 \mathrm{~B})-\operatorname{Ir}(4)-\mathrm{P}(1)$ & $102.3(4)$ \\
\hline$C(706)-\operatorname{Ir}(1)-\operatorname{Ir}(3)$ & $85.5(3)$ & $\mathrm{C}(4 \mathrm{~A})-\operatorname{Ir}(4)-\mathrm{P}(1)$ & $100.7(4)$ \\
\hline$C(701)-\operatorname{Ir}(1)-\operatorname{Ir}(3)$ & $78.6(3)$ & $\mathrm{C}(4 \mathrm{~B})-\operatorname{Ir}(4)-\mathrm{P}(2)$ & $97.1(5)$ \\
\hline $\operatorname{Ir}(2)-\operatorname{Ir}(1)-\operatorname{Ir}(3)$ & $59.089(16)$ & $\mathrm{C}(4 \mathrm{~A})-\operatorname{Ir}(4)-\mathrm{P}(2)$ & $163.3(4)$ \\
\hline $\mathrm{C}(2 \mathrm{~A})-\operatorname{Ir}(2)-\mathrm{C}(2 \mathrm{~B})$ & $99.2(6)$ & $\mathrm{P}(1)-\operatorname{Ir}(4)-\mathrm{P}(2)$ & $87.31(11)$ \\
\hline $\mathrm{C}(2 \mathrm{~A})-\operatorname{Ir}(2)-\mathrm{C}(706)$ & $107.9(5)$ & $\mathrm{C}(4 \mathrm{~B})-\operatorname{Ir}(4)-\operatorname{Ir}(2)$ & $101.6(4)$ \\
\hline $\mathrm{C}(2 \mathrm{~B})-\mathrm{Ir}(2)-\mathrm{C}(706)$ & $99.7(5)$ & $C(4 A)-\operatorname{Ir}(4)-\operatorname{Ir}(2)$ & 91.1(4) \\
\hline$C(2 A)-\operatorname{Ir}(2)-\operatorname{Ir}(3)$ & $93.6(4)$ & $P(1)-\operatorname{Ir}(4)-\operatorname{Ir}(2)$ & $152.18(8)$ \\
\hline $\mathrm{C}(2 \mathrm{~B})-\operatorname{Ir}(2)-\operatorname{Ir}(3)$ & $157.6(4)$ & $\mathrm{P}(2)-\operatorname{Ir}(4)-\operatorname{Ir}(2)$ & $75.66(8)$ \\
\hline$C(706)-\operatorname{Ir}(2)-\operatorname{Ir}(3)$ & $93.6(3)$ & C(4B)-Ir(4)-Ir(3) & $157.9(4)$ \\
\hline $\mathrm{C}(2 \mathrm{~A})-\operatorname{Ir}(2)-\operatorname{Ir}(1)$ & $147.8(4)$ & $C(4 A)-\operatorname{Ir}(4)-\operatorname{Ir}(3)$ & $92.2(4)$ \\
\hline$C(2 B)-\operatorname{Ir}(2)-\operatorname{Ir}(1)$ & $111.5(4)$ & $P(1)-\operatorname{Ir}(4)-\operatorname{Ir}(3)$ & $96.58(8)$ \\
\hline$C(706)-\operatorname{Ir}(2)-\operatorname{Ir}(1)$ & $59.0(3)$ & $P(2)-\operatorname{Ir}(4)-\operatorname{Ir}(3)$ & $72.12(7)$ \\
\hline $\operatorname{Ir}(3)-\operatorname{Ir}(2)-\operatorname{Ir}(1)$ & $60.862(17)$ & $\operatorname{Ir}(2)-\operatorname{Ir}(4)-\operatorname{Ir}(3)$ & $57.513(15)$ \\
\hline$C(2 A)-\operatorname{Ir}(2)-\operatorname{Ir}(4)$ & $97.1(4)$ & $\mathrm{C}(301)-\mathrm{P}(1)-\mathrm{C}(101)$ & $105.7(5)$ \\
\hline$C(2 B)-\operatorname{Ir}(2)-\operatorname{Ir}(4)$ & $97.6(4)$ & $\mathrm{C}(301)-\mathrm{P}(1)-\mathrm{C}(201)$ & $102.9(6)$ \\
\hline$C(706)-\operatorname{Ir}(2)-\operatorname{Ir}(4)$ & $146.7(3)$ & $\mathrm{C}(101)-\mathrm{P}(1)-\mathrm{C}(201)$ & $106.4(5)$ \\
\hline $\operatorname{Ir}(3)-\operatorname{Ir}(2)-\operatorname{Ir}(4)$ & $62.458(17)$ & $\mathrm{C}(301)-\mathrm{P}(1)-\operatorname{Ir}(4)$ & $108.3(4)$ \\
\hline $\mathrm{C}(101)-\mathrm{P}(1)-\operatorname{Ir}(4)$ & $116.6(4)$ & $\mathrm{C}(305)-\mathrm{C}(304)-\mathrm{C}(303)$ & $120.0(12)$ \\
\hline $\mathrm{C}(201)-\mathrm{P}(1)-\operatorname{Ir}(4)$ & $115.6(4)$ & $\mathrm{C}(304)-\mathrm{C}(305)-\mathrm{C}(306)$ & $121.0(12)$ \\
\hline $\mathrm{C}(401)-\mathrm{P}(2)-\mathrm{C}(306)$ & $98.8(5)$ & $\mathrm{C}(305)-\mathrm{C}(306)-\mathrm{C}(301)$ & $119.5(11)$ \\
\hline $\mathrm{C}(401)-\mathrm{P}(2)-\operatorname{Ir}(1)$ & $111.4(4)$ & $\mathrm{C}(305)-\mathrm{C}(306)-\mathrm{P}(2)$ & $122.5(8)$ \\
\hline $\mathrm{C}(306)-\mathrm{P}(2)-\operatorname{Ir}(1)$ & $113.2(4)$ & $\mathrm{C}(301)-\mathrm{C}(306)-\mathrm{P}(2)$ & $117.8(8)$ \\
\hline $\mathrm{C}(401)-\mathrm{P}(2)-\operatorname{Ir}(4)$ & $116.0(4)$ & $\mathrm{C}(406)-\mathrm{C}(401)-\mathrm{C}(402)$ & 117.1(11) \\
\hline $\mathrm{C}(306)-\mathrm{P}(2)-\operatorname{Ir}(4)$ & 106.4(3) & $\mathrm{C}(406)-\mathrm{C}(401)-\mathrm{P}(2)$ & $120.6(9)$ \\
\hline $\operatorname{Ir}(1)-P(2)-\operatorname{Ir}(4)$ & $110.46(12)$ & $\mathrm{C}(402)-\mathrm{C}(401)-\mathrm{P}(2)$ & $122.3(9)$ \\
\hline $\mathrm{C}(601)-\mathrm{P}(3)-\mathrm{C}(701)$ & 104.3(6) & $\mathrm{C}(401)-\mathrm{C}(402)-\mathrm{C}(403)$ & 121.0(13) \\
\hline $\mathrm{C}(601)-\mathrm{P}(3)-\mathrm{C}(501)$ & $101.7(6)$ & $\mathrm{C}(404)-\mathrm{C}(403)-\mathrm{C}(402)$ & $120.8(14)$ \\
\hline $\mathrm{C}(701)-\mathrm{P}(3)-\mathrm{C}(501)$ & $104.2(6)$ & $\mathrm{C}(403)-\mathrm{C}(404)-\mathrm{C}(405)$ & 119.1(12) \\
\hline $\mathrm{C}(601)-\mathrm{P}(3)-\operatorname{Ir}(3)$ & $114.6(4)$ & $\mathrm{C}(406)-\mathrm{C}(405)-\mathrm{C}(404)$ & 119.9(13) \\
\hline $\mathrm{C}(701)-\mathrm{P}(3)-\operatorname{Ir}(3)$ & 108.3(4) & $\mathrm{C}(405)-\mathrm{C}(406)-\mathrm{C}(401)$ & $122.0(13)$ \\
\hline $\mathrm{C}(501)-\mathrm{P}(3)-\operatorname{Ir}(3)$ & $121.9(4)$ & $\mathrm{C}(506)-\mathrm{C}(501)-\mathrm{C}(502)$ & $119.9(12)$ \\
\hline$C(102)-C(101)-C(106)$ & 118.1(11) & $\mathrm{C}(506)-\mathrm{C}(501)-\mathrm{P}(3)$ & $120.5(11)$ \\
\hline $\mathrm{C}(102)-\mathrm{C}(101)-\mathrm{P}(1)$ & $124.8(9)$ & $\mathrm{C}(502)-\mathrm{C}(501)-\mathrm{P}(3)$ & $119.6(10)$ \\
\hline $\mathrm{C}(106)-\mathrm{C}(101)-\mathrm{P}(1)$ & $116.9(9)$ & $\mathrm{C}(503)-\mathrm{C}(502)-\mathrm{C}(501)$ & $118.6(14)$ \\
\hline $\mathrm{C}(103)-\mathrm{C}(102)-\mathrm{C}(101)$ & $122.0(12)$ & $\mathrm{C}(502)-\mathrm{C}(503)-\mathrm{C}(504)$ & 120.1(15) \\
\hline $\mathrm{C}(104)-\mathrm{C}(103)-\mathrm{C}(102)$ & $121.0(12)$ & $\mathrm{C}(505)-\mathrm{C}(504)-\mathrm{C}(503)$ & $120.0(14)$ \\
\hline $\mathrm{C}(103)-\mathrm{C}(104)-\mathrm{C}(105)$ & $119.5(12)$ & $\mathrm{C}(504)-\mathrm{C}(505)-\mathrm{C}(506)$ & $120.0(15)$ \\
\hline $\mathrm{C}(106)-\mathrm{C}(105)-\mathrm{C}(104)$ & $119.8(12)$ & $\mathrm{C}(501)-\mathrm{C}(506)-\mathrm{C}(505)$ & $120.8(14)$ \\
\hline$C(105)-C(106)-C(101)$ & $119.5(12)$ & $\mathrm{C}(602)-\mathrm{C}(601)-\mathrm{C}(606)$ & $115.9(13)$ \\
\hline $\mathrm{C}(206)-\mathrm{C}(201)-\mathrm{C}(202)$ & $119.0(13)$ & $\mathrm{C}(602)-\mathrm{C}(601)-\mathrm{P}(3)$ & $120.3(11)$ \\
\hline $\mathrm{C}(206)-\mathrm{C}(201)-\mathrm{P}(1)$ & $116.6(10)$ & $\mathrm{C}(606)-\mathrm{C}(601)-\mathrm{P}(3)$ & $123.8(11)$ \\
\hline $\mathrm{C}(202)-\mathrm{C}(201)-\mathrm{P}(1)$ & $124.2(10)$ & $\mathrm{C}(601)-\mathrm{C}(602)-\mathrm{C}(603)$ & $122.8(16)$ \\
\hline $\mathrm{C}(203)-\mathrm{C}(202)-\mathrm{C}(201)$ & $118.5(15)$ & $\mathrm{C}(604)-\mathrm{C}(603)-\mathrm{C}(602)$ & $119.8(18)$ \\
\hline $\mathrm{C}(204)-\mathrm{C}(203)-\mathrm{C}(202)$ & $121.4(15)$ & $\mathrm{C}(603)-\mathrm{C}(604)-\mathrm{C}(605)$ & $118.6(15)$ \\
\hline$C(205)-C(204)-C(203)$ & $120.3(15)$ & $\mathrm{C}(606)-\mathrm{C}(605)-\mathrm{C}(604)$ & $120.8(15)$ \\
\hline $\mathrm{C}(204)-\mathrm{C}(205)-\mathrm{C}(206)$ & $120.7(16)$ & $\mathrm{C}(605)-\mathrm{C}(606)-\mathrm{C}(601)$ & $121.9(15)$ \\
\hline $\mathrm{C}(205)-\mathrm{C}(206)-\mathrm{C}(201)$ & $119.9(14)$ & $C(706)-C(701)-C(702)$ & $121.2(11)$ \\
\hline $\mathrm{C}(302)-\mathrm{C}(301)-\mathrm{C}(306)$ & $118.3(10)$ & $\mathrm{C}(706)-\mathrm{C}(701)-\mathrm{P}(3)$ & $115.5(8)$ \\
\hline $\mathrm{C}(302)-\mathrm{C}(301)-\mathrm{P}(1)$ & $122.8(9)$ & $\mathrm{C}(702)-\mathrm{C}(701)-\mathrm{P}(3)$ & $122.0(9)$ \\
\hline $\mathrm{C}(306)-\mathrm{C}(301)-\mathrm{P}(1)$ & $118.9(9)$ & $C(706)-C(701)-\operatorname{Ir}(1)$ & $68.2(6)$ \\
\hline $\mathrm{C}(303)-\mathrm{C}(302)-\mathrm{C}(301)$ & $122.0(12)$ & $C(702)-C(701)-\operatorname{Ir}(1)$ & $120.8(8)$ \\
\hline $\mathrm{C}(302)-\mathrm{C}(303)-\mathrm{C}(304)$ & $119.0(12)$ & $\mathrm{P}(3)-\mathrm{C}(701)-\operatorname{Ir}(1)$ & $89.8(4)$ \\
\hline $\mathrm{C}(703)-\mathrm{C}(702)-\mathrm{C}(701)$ & $120.1(12)$ & $\operatorname{Ir}(2)-C(706)-\operatorname{Ir}(1)$ & 73.3(4) \\
\hline
\end{tabular}




\begin{tabular}{|l|c|l|l|}
\hline $\mathrm{C}(702)-\mathrm{C}(703)-\mathrm{C}(704)$ & $120.1(12)$ & $\mathrm{O}(1 \mathrm{~A})-\mathrm{C}(1 \mathrm{~A})-\operatorname{Ir}(1)$ & $178.6(13)$ \\
\hline $\mathrm{C}(705)-\mathrm{C}(704)-\mathrm{C}(703)$ & $120.0(12)$ & $\mathrm{O}(1 \mathrm{~B})-\mathrm{C}(1 \mathrm{~B})-\operatorname{Ir}(1)$ & $176.8(14)$ \\
\hline $\mathrm{C}(704)-\mathrm{C}(705)-\mathrm{C}(706)$ & $123.5(12)$ & $\mathrm{O}(2 \mathrm{~A})-\mathrm{C}(2 \mathrm{~A})-\operatorname{Ir}(2)$ & $175.6(11)$ \\
\hline $\mathrm{C}(701)-\mathrm{C}(706)-\mathrm{C}(705)$ & $115.0(11)$ & $\mathrm{O}(2 \mathrm{~B})-\mathrm{C}(2 \mathrm{~B})-\operatorname{Ir}(2)$ & $175.3(12)$ \\
\hline $\mathrm{C}(701)-\mathrm{C}(706)-\operatorname{Ir}(2)$ & $121.0(8)$ & $\mathrm{O}(3 \mathrm{~A})-\mathrm{C}(3 \mathrm{~A})-\operatorname{Ir}(3)$ & $177.3(13)$ \\
\hline $\mathrm{C}(705)-\mathrm{C}(706)-\operatorname{Ir}(2)$ & $124.0(9)$ & $\mathrm{O}(3 \mathrm{~B})-\mathrm{C}(3 \mathrm{~B})-\operatorname{Ir}(3)$ & $176.5(12)$ \\
\hline $\mathrm{C}(701)-\mathrm{C}(706)-\operatorname{Ir}(1)$ & $78.6(7)$ & $\mathrm{O}(4 \mathrm{~A})-\mathrm{C}(4 \mathrm{~A})-\operatorname{Ir}(4)$ & $178.7(13)$ \\
\hline $\mathrm{C}(705)-\mathrm{C}(706)-\operatorname{Ir}(1)$ & $118.4(8)$ & $\mathrm{O}(4 \mathrm{~B})-\mathrm{C}(4 \mathrm{~B})-\operatorname{Ir}(4)$ & $178.2(14)$ \\
\hline
\end{tabular}

Symmetry transformations used to generate equivalent atoms: 
Table S3. Anisotropic displacement parameters $\left(\AA^{2} \times 10^{3}\right)$ for 2 . The anisotropic displacement factor exponent takes the form : $-2 \mathrm{pi}^{2}\left[\mathrm{~h}^{2} \mathrm{a}^{2} \mathrm{U} 11+\ldots+2 \mathrm{hka} * \mathrm{~b} * \mathrm{U} 12\right]$

\begin{tabular}{|c|c|c|c|c|c|c|}
\hline & U11 & U22 & U33 & $\mathrm{U} 23$ & U13 & U12 \\
\hline $\operatorname{Ir}(1)$ & $25(1)$ & $15(1)$ & $27(1)$ & $8(1)$ & $7(1)$ & 11(1) \\
\hline $\operatorname{Ir}(2)$ & $23(1)$ & $17(1)$ & $25(1)$ & $7(1)$ & $8(1)$ & $12(1)$ \\
\hline $\operatorname{Ir}(3)$ & $25(1)$ & $18(1)$ & $23(1)$ & $4(1)$ & $7(1)$ & 14(1) \\
\hline $\operatorname{Ir}(4)$ & $23(1)$ & $15(1)$ & $23(1)$ & $6(1)$ & $7(1)$ & $12(1)$ \\
\hline $\mathrm{P}(1)$ & $26(1)$ & $15(1)$ & $26(1)$ & $4(1)$ & $6(1)$ & $12(1)$ \\
\hline $\mathrm{P}(2)$ & $28(2)$ & $13(1)$ & $26(1)$ & $5(1)$ & $7(1)$ & $13(1)$ \\
\hline $\mathrm{P}(3)$ & $28(2)$ & $19(2)$ & $24(1)$ & $5(1)$ & $6(1)$ & 11(1) \\
\hline $\mathrm{C}(101)$ & $24(6)$ & $18(6)$ & $33(6)$ & 1(5) & $6(5)$ & $17(5)$ \\
\hline $\mathrm{C}(102)$ & $31(6)$ & $16(6)$ & $38(7)$ & $7(5)$ & $3(5)$ & $9(5)$ \\
\hline$C(103)$ & $35(7)$ & $28(7)$ & $48(8)$ & $6(6)$ & $20(6)$ & $15(6)$ \\
\hline$C(104)$ & $46(8)$ & $27(7)$ & $37(7)$ & $-5(6)$ & $3(6)$ & $23(6)$ \\
\hline$C(105)$ & $32(7)$ & $12(6)$ & $51(8)$ & $4(5)$ & $7(6)$ & $12(5)$ \\
\hline $\mathrm{C}(106)$ & $36(7)$ & $18(6)$ & $39(7)$ & $7(5)$ & $13(6)$ & $10(5)$ \\
\hline$C(201)$ & $34(7)$ & $28(7)$ & $34(6)$ & $12(5)$ & $12(5)$ & $24(6)$ \\
\hline$C(202)$ & $50(9)$ & $36(8)$ & $42(8)$ & $18(6)$ & $6(7)$ & $22(7)$ \\
\hline$C(203)$ & $51(10)$ & $80(13)$ & $40(8)$ & $29(9)$ & $3(7)$ & $39(9)$ \\
\hline$C(204)$ & $53(10)$ & 107(17) & $35(8)$ & $40(10)$ & $18(7)$ & $39(11)$ \\
\hline$C(205)$ & $46(9)$ & $63(11)$ & $36(8)$ & $-9(7)$ & $3(6)$ & $32(8)$ \\
\hline$C(206)$ & $59(10)$ & $45(9)$ & $44(8)$ & $10(7)$ & $8(7)$ & $36(8)$ \\
\hline$C(301)$ & $30(6)$ & $9(5)$ & $22(5)$ & $-1(4)$ & $8(4)$ & $6(4)$ \\
\hline$C(302)$ & $28(6)$ & 19(6) & $49(8)$ & $7(5)$ & $14(6)$ & $14(5)$ \\
\hline$C(303)$ & $23(6)$ & $29(7)$ & $67(10)$ & $-1(7)$ & $14(6)$ & $10(6)$ \\
\hline $\mathrm{C}(304)$ & $50(8)$ & $17(6)$ & $36(7)$ & $6(5)$ & $20(6)$ & $9(6)$ \\
\hline $\mathrm{C}(305)$ & $33(6)$ & $24(6)$ & $29(6)$ & 6(5) & $6(5)$ & $17(5)$ \\
\hline $\mathrm{C}(306)$ & $33(6)$ & $9(5)$ & $22(5)$ & $0(4)$ & $6(4)$ & $16(5)$ \\
\hline $\mathrm{C}(401)$ & $30(6)$ & $12(5)$ & $29(6)$ & 4(4) & 11(5) & $12(5)$ \\
\hline $\mathrm{C}(402)$ & $49(8)$ & $24(7)$ & $32(7)$ & 1(5) & $8(6)$ & $22(6)$ \\
\hline $\mathrm{C}(403)$ & 64(9) & $20(7)$ & $34(7)$ & $-4(5)$ & 19(7) & $19(6)$ \\
\hline $\mathrm{C}(404)$ & $59(9)$ & $28(7)$ & $39(8)$ & $-3(6)$ & $28(7)$ & $16(7)$ \\
\hline $\mathrm{C}(405)$ & $47(8)$ & $35(8)$ & $43(8)$ & $9(6)$ & $24(6)$ & $28(7)$ \\
\hline $\mathrm{C}(406)$ & $49(8)$ & 14(6) & $46(8)$ & $7(5)$ & $25(6)$ & $14(6)$ \\
\hline $\mathrm{C}(501)$ & $39(7)$ & $34(7)$ & $34(7)$ & $13(5)$ & $16(5)$ & $29(6)$ \\
\hline $\mathrm{C}(502)$ & $36(7)$ & 51(9) & $32(7)$ & $5(6)$ & 16(6) & $17(7)$ \\
\hline $\mathrm{C}(503)$ & $54(10)$ & $67(13)$ & $47(9)$ & 11(8) & $27(8)$ & $12(9)$ \\
\hline $\mathrm{C}(504)$ & $89(13)$ & $57(11)$ & $38(8)$ & $16(8)$ & $33(9)$ & $41(10)$ \\
\hline $\mathrm{C}(505)$ & $65(10)$ & $59(11)$ & $27(7)$ & $0(7)$ & $9(7)$ & $37(9)$ \\
\hline $\mathrm{C}(506)$ & $41(8)$ & $44(9)$ & $36(7)$ & $2(6)$ & $10(6)$ & $26(7)$ \\
\hline $\mathrm{C}(601)$ & $38(7)$ & $31(7)$ & $20(6)$ & $10(5)$ & $5(5)$ & $17(6)$ \\
\hline $\mathrm{C}(602)$ & $60(10)$ & $25(7)$ & $41(8)$ & 2(6) & 12(7) & $16(7)$ \\
\hline $\mathrm{C}(603)$ & $80(13)$ & $29(9)$ & $60(11)$ & $6(8)$ & $8(9)$ & $16(9)$ \\
\hline $\mathrm{C}(604)$ & $48(10)$ & $44(10)$ & $60(11)$ & $21(8)$ & $14(8)$ & $-2(8)$ \\
\hline $\mathrm{C}(605)$ & $25(7)$ & $59(11)$ & $45(9)$ & $4(8)$ & $7(6)$ & $4(7)$ \\
\hline $\mathrm{C}(606)$ & $39(8)$ & $35(8)$ & $41(8)$ & $0(6)$ & $10(6)$ & 11(6) \\
\hline $\mathrm{C}(701)$ & $21(5)$ & $17(6)$ & $32(6)$ & 4(5) & $4(4)$ & $12(5)$ \\
\hline $\mathrm{C}(702)$ & $36(7)$ & $31(7)$ & $28(6)$ & 14(5) & $3(5)$ & $21(6)$ \\
\hline $\mathrm{C}(703)$ & 63(9) & $30(7)$ & $27(6)$ & $6(5)$ & $3(6)$ & $31(7)$ \\
\hline $\mathrm{C}(704)$ & $32(7)$ & $33(7)$ & $49(8)$ & 13(6) & $-2(6)$ & $25(6)$ \\
\hline $\mathrm{C}(705)$ & $36(7)$ & $35(8)$ & $41(7)$ & $7(6)$ & $19(6)$ & $22(6)$ \\
\hline $\mathrm{C}(706)$ & $26(6)$ & $14(5)$ & $35(6)$ & 11(5) & $13(5)$ & $10(5)$ \\
\hline $\mathrm{C}(1 \mathrm{~A})$ & $35(7)$ & 14(6) & $50(8)$ & $8(5)$ & $4(6)$ & 13(5) \\
\hline $\mathrm{O}(1 \mathrm{~A})$ & $71(8)$ & $26(6)$ & $97(10)$ & $6(6)$ & $0(7)$ & $36(6)$ \\
\hline $\mathrm{C}(1 \mathrm{~B})$ & $36(7)$ & $35(8)$ & $36(7)$ & $18(6)$ & 11(6) & $18(6)$ \\
\hline $\mathrm{O}(1 \mathrm{~B})$ & $59(7)$ & $63(8)$ & $52(7)$ & $25(6)$ & $27(6)$ & $7(6)$ \\
\hline
\end{tabular}




\begin{tabular}{|ccccccc|}
\hline $\mathrm{C}(2 \mathrm{~A})$ & $28(6)$ & $18(6)$ & $27(6)$ & $6(5)$ & $2(5)$ & $3(5)$ \\
\hline $\mathrm{O}(2 \mathrm{~A})$ & $57(6)$ & $22(5)$ & $53(6)$ & $13(4)$ & $21(5)$ & $19(5)$ \\
\hline $\mathrm{C}(2 \mathrm{~B})$ & $28(6)$ & $32(7)$ & $40(7)$ & $2(6)$ & $7(5)$ & $23(6)$ \\
\hline $\mathrm{O}(2 \mathrm{~B})$ & $60(7)$ & $44(6)$ & $39(5)$ & $7(5)$ & $23(5)$ & $30(5)$ \\
\hline $\mathrm{C}(3 \mathrm{~A})$ & $30(7)$ & $34(7)$ & $30(6)$ & $1(5)$ & $7(5)$ & $16(6)$ \\
\hline $\mathrm{O}(3 \mathrm{~A})$ & $28(5)$ & $52(7)$ & $41(5)$ & $5(5)$ & $13(4)$ & $16(5)$ \\
\hline $\mathrm{C}(3 \mathrm{~B})$ & $40(7)$ & $35(8)$ & $32(7)$ & $7(6)$ & $10(6)$ & $21(6)$ \\
\hline $\mathrm{O}(3 \mathrm{~B})$ & $125(11)$ & $25(6)$ & $60(7)$ & $7(5)$ & $13(7)$ & $49(7)$ \\
\hline $\mathrm{C}(4 \mathrm{~A})$ & $37(7)$ & $31(8)$ & $32(7)$ & $7(6)$ & $7(6)$ & $11(6)$ \\
\hline $\mathrm{O}(4 \mathrm{~A})$ & $51(7)$ & $26(6)$ & $84(8)$ & $18(5)$ & $22(6)$ & $14(5)$ \\
\hline $\mathrm{C}(4 \mathrm{~B})$ & $45(8)$ & $50(9)$ & $42(8)$ & $19(7)$ & $17(6)$ & $40(7)$ \\
\hline $\mathrm{O}(4 \mathrm{~B})$ & $88(9)$ & $85(10)$ & $36(6)$ & $4(6)$ & $31(6)$ & $43(8)$ \\
\hline
\end{tabular}


Table S4. Atomic coordinates $\left(\times 10^{4}\right)$ and equivalent isotropic displacement parameters $\left(\AA^{2} \times 10^{3}\right)$ for 3 . $\mathrm{U}(\mathrm{eq})$ is defined as one third of the trace of the orthogonalized $\mathrm{U}_{\mathrm{ij}}$ tensor.

\begin{tabular}{|c|c|c|c|c|}
\hline & $\mathrm{x}$ & $\mathrm{y}$ & $\mathrm{z}$ & $\mathrm{U}(\mathrm{eq})$ \\
\hline $\operatorname{Ir}(1)$ & $2828(1)$ & $-394(1)$ & $1739(1)$ & $20(1)$ \\
\hline $\operatorname{Ir}(2)$ & 2594(1) & $900(1)$ & $2075(1)$ & 19(1) \\
\hline $\operatorname{Ir}(3)$ & $3414(1)$ & $4(1)$ & 2913(1) & $22(1)$ \\
\hline $\operatorname{Ir}(4)$ & 4188(1) & $970(1)$ & $2345(1)$ & $22(1)$ \\
\hline $\mathrm{P}(1)$ & $5462(1)$ & $594(1)$ & $2576(1)$ & $27(1)$ \\
\hline $\mathrm{P}(2)$ & 3981(1) & $103(1)$ & $1669(1)$ & $22(1)$ \\
\hline $\mathrm{P}(3)$ & $2437(1)$ & $-29(1)$ & $775(1)$ & $23(1)$ \\
\hline $\mathrm{C}(1 \mathrm{~A})$ & $3068(5)$ & $-1295(5)$ & 1611(4) & $32(2)$ \\
\hline $\mathrm{O}(1 \mathrm{~A})$ & $3241(5)$ & $-1834(4)$ & $1539(4)$ & $63(2)$ \\
\hline $\mathrm{C}(2 \mathrm{~A})$ & $2604(5)$ & 1780(4) & $2354(4)$ & $25(2)$ \\
\hline $\mathrm{O}(2 \mathrm{~A})$ & $2617(4)$ & $2310(3)$ & $2529(3)$ & $42(2)$ \\
\hline $\mathrm{C}(3 \mathrm{~A})$ & 4061(5) & $-755(5)$ & $2946(5)$ & $38(3)$ \\
\hline $\mathrm{O}(3 \mathrm{~A})$ & $4409(4)$ & $-1240(4)$ & 2971(4) & $55(2)$ \\
\hline $\mathrm{C}(3 \mathrm{~B})$ & $3716(5)$ & $319(5)$ & 3701(4) & $33(2)$ \\
\hline $\mathrm{O}(3 \mathrm{~B})$ & $3879(5)$ & $472(4)$ & 4195(3) & $65(2)$ \\
\hline $\mathrm{C}(4 \mathrm{~A})$ & $4190(5)$ & $1512(5)$ & $3043(5)$ & $33(2)$ \\
\hline $\mathrm{O}(4 \mathrm{~A})$ & $4224(4)$ & $1830(4)$ & $3464(3)$ & $56(2)$ \\
\hline$C(4 B)$ & $4319(6)$ & $1644(5)$ & 1793(5) & $37(2)$ \\
\hline $\mathrm{O}(4 \mathrm{~B})$ & $4399(5)$ & $2056(4)$ & $1466(4)$ & 71(3) \\
\hline$C(101)$ & $5980(5)$ & $512(5)$ & $3351(4)$ & $36(2)$ \\
\hline$C(102)$ & $5627(7)$ & $184(8)$ & $3762(6)$ & $82(5)$ \\
\hline$C(103)$ & $6001(8)$ & $100(9)$ & $4354(6)$ & $98(6)$ \\
\hline$C(104)$ & 6701(7) & $357(7)$ & $4535(5)$ & $65(4)$ \\
\hline$C(105)$ & 7089(7) & $617(7)$ & $4138(6)$ & $72(4)$ \\
\hline$C(106)$ & $6745(6)$ & 704(7) & $3549(5)$ & $65(4)$ \\
\hline$C(201)$ & $6139(5)$ & $1086(5)$ & $2210(4)$ & $33(2)$ \\
\hline$C(202)$ & $6233(6)$ & $1749(5)$ & $2360(5)$ & $52(3)$ \\
\hline$C(203)$ & 6704(7) & $2146(6)$ & 2099(6) & $61(4)$ \\
\hline$C(204)$ & 7090(7) & $1880(6)$ & $1665(6)$ & $64(4)$ \\
\hline$C(205)$ & 6998(6) & $1221(5)$ & $1527(5)$ & $49(3)$ \\
\hline$C(206)$ & $6527(5)$ & $824(5)$ & 1792(4) & $34(2)$ \\
\hline$C(301)$ & 5501(5) & $-236(4)$ & $2250(4)$ & $29(2)$ \\
\hline$C(302)$ & $6142(5)$ & $-649(5)$ & 2392(5) & $35(2)$ \\
\hline$C(303)$ & $6159(6)$ & $-1242(5)$ & 2092(5) & $46(3)$ \\
\hline$C(304)$ & $5542(5)$ & $-1437(5)$ & $1650(5)$ & $39(2)$ \\
\hline$C(305)$ & 4902(5) & $-1022(4)$ & $1510(4)$ & $29(2)$ \\
\hline$C(306)$ & 4851(5) & $-432(4)$ & 1813(4) & $25(2)$ \\
\hline$C(401)$ & $3961(5)$ & $309(4)$ & $879(4)$ & $26(2)$ \\
\hline$C(402)$ & 4601(6) & $580(5)$ & $678(5)$ & $40(3)$ \\
\hline$C(403)$ & $4574(6)$ & $706(5)$ & $81(5)$ & 44(3) \\
\hline $\mathrm{C}(404)$ & $3904(6)$ & $542(5)$ & $-338(4)$ & 41(3) \\
\hline $\mathrm{C}(405)$ & $3262(5)$ & $280(5)$ & $-148(4)$ & $33(2)$ \\
\hline$C(406)$ & $3289(5)$ & $172(4)$ & $465(4)$ & $22(2)$ \\
\hline $\mathrm{C}(501)$ & 1977(5) & 783(4) & $715(4)$ & $23(2)$ \\
\hline$C(502)$ & 2093(4) & $1213(4)$ & $1210(4)$ & $22(2)$ \\
\hline$C(503)$ & 1797(5) & 1861(4) & 1094(4) & $32(2)$ \\
\hline$C(504)$ & $1440(6)$ & 2071(5) & $537(4)$ & $40(3)$ \\
\hline$C(505)$ & 1341(5) & $1642(5)$ & $50(4)$ & $35(2)$ \\
\hline$C(506)$ & $1599(5)$ & $998(5)$ & $139(4)$ & $32(2)$ \\
\hline$C(601)$ & $1846(5)$ & $-593(4)$ & $252(4)$ & $26(2)$ \\
\hline$C(602)$ & $2216(6)$ & $-1126(5)$ & $23(4)$ & $39(3)$ \\
\hline$C(603)$ & $1774(7)$ & $-1609(5)$ & $-336(5)$ & $49(3)$ \\
\hline$C(604)$ & 974(7) & $-1539(5)$ & $-465(5)$ & $46(3)$ \\
\hline
\end{tabular}




\begin{tabular}{|c|c|c|c|c|}
\hline $\mathrm{C}(605)$ & $615(6)$ & $-1026(5)$ & $-247(4)$ & $41(3)$ \\
\hline $\mathrm{C}(606)$ & 1044(5) & $-552(4)$ & 107(4) & $28(2)$ \\
\hline $\mathrm{C}(1)$ & $2010(5)$ & $-757(4)$ & $2332(4)$ & $20(2)$ \\
\hline $\mathrm{C}(2)$ & $1600(5)$ & $-334(4)$ & $1868(4)$ & $20(2)$ \\
\hline $\mathrm{C}(3)$ & $1450(4)$ & $374(4)$ & $2009(3)$ & $19(2)$ \\
\hline $\mathrm{C}(4)$ & 1727(4) & $635(4)$ & 2593(3) & $16(2)$ \\
\hline $\mathrm{C}(5)$ & $2166(5)$ & 197(4) & $3066(4)$ & $21(2)$ \\
\hline $\mathrm{C}(6)$ & 2324(4) & $-487(4)$ & 2951(4) & $19(2)$ \\
\hline $\mathrm{C}(7)$ & $2167(4)$ & $-995(4)$ & $3375(4)$ & $21(2)$ \\
\hline $\mathrm{C}(8)$ & $1822(5)$ & $-1567(4)$ & $3044(4)$ & $24(2)$ \\
\hline $\mathrm{C}(9)$ & $1706(5)$ & $-1421(4)$ & $2410(4)$ & $24(2)$ \\
\hline $\mathrm{C}(10)$ & $1054(5)$ & $-1664(4)$ & $2029(4)$ & $24(2)$ \\
\hline $\mathrm{C}(11)$ & $627(5)$ & $-1238(4)$ & $1558(4)$ & $21(2)$ \\
\hline $\mathrm{C}(12)$ & $884(5)$ & $-595(4)$ & $1503(3)$ & $20(2)$ \\
\hline $\mathrm{C}(13)$ & $322(5)$ & $-50(4)$ & 1397(4) & $22(2)$ \\
\hline $\mathrm{C}(14)$ & $650(5)$ & $535(4)$ & 1709(3) & $22(2)$ \\
\hline $\mathrm{C}(15)$ & $188(5)$ & $956(4)$ & 1969(4) & $23(2)$ \\
\hline $\mathrm{C}(16)$ & $465(5)$ & $1228(4)$ & $2567(4)$ & $25(2)$ \\
\hline $\mathrm{C}(17)$ & $1203(5)$ & 1056(4) & 2871(4) & $21(2)$ \\
\hline $\mathrm{C}(18)$ & $1327(5)$ & $891(4)$ & $3508(4)$ & $25(2)$ \\
\hline $\mathrm{C}(19)$ & 1892(5) & $359(4)$ & $3622(4)$ & $23(2)$ \\
\hline $\mathrm{C}(20)$ & 1807(5) & $-131(5)$ & $4050(4)$ & $28(2)$ \\
\hline $\mathrm{C}(21)$ & 1952(5) & $-825(5)$ & $3926(4)$ & $26(2)$ \\
\hline $\mathrm{C}(22)$ & 1384(5) & $-1222(4)$ & $4150(4)$ & $25(2)$ \\
\hline $\mathrm{C}(23)$ & $1060(5)$ & $-1786(4)$ & $3839(4)$ & $29(2)$ \\
\hline $\mathrm{C}(24)$ & $1283(5)$ & $-1967(4)$ & $3273(4)$ & $23(2)$ \\
\hline $\mathrm{C}(25)$ & $608(5)$ & $-2221(4)$ & 2871(4) & $27(2)$ \\
\hline $\mathrm{C}(26)$ & $509(5)$ & $-2075(4)$ & $2269(4)$ & $26(2)$ \\
\hline $\mathrm{C}(27)$ & $-278(5)$ & $-1891(4)$ & $1948(4)$ & $28(2)$ \\
\hline $\mathrm{C}(28)$ & $-181(5)$ & $-1381(4)$ & $1512(4)$ & $27(2)$ \\
\hline $\mathrm{C}(29)$ & $-735(5)$ & $-865(4)$ & 1392(4) & $27(2)$ \\
\hline $\mathrm{C}(30)$ & $-475(5)$ & $-191(4)$ & $1337(4)$ & $25(2)$ \\
\hline $\mathrm{C}(31)$ & $-966(5)$ & 252(4) & $1608(4)$ & $28(2)$ \\
\hline $\mathrm{C}(32)$ & $-636(5)$ & $814(4)$ & 1927(4) & $26(2)$ \\
\hline $\mathrm{C}(33)$ & $-859(5)$ & $990(4)$ & $2480(4)$ & $26(2)$ \\
\hline $\mathrm{C}(34)$ & $-187(5)$ & 1251(4) & $2878(4)$ & $26(2)$ \\
\hline $\mathrm{C}(35)$ & $-64(5)$ & $1095(4)$ & $3493(4)$ & $29(2)$ \\
\hline $\mathrm{C}(36)$ & $700(5)$ & 919(4) & $3816(4)$ & $27(2)$ \\
\hline $\mathrm{C}(37)$ & $621(5)$ & $410(4)$ & $4249(4)$ & $28(2)$ \\
\hline $\mathrm{C}(38)$ & $1163(5)$ & $-114(5)$ & $4357(4)$ & $27(2)$ \\
\hline $\mathrm{C}(39)$ & $903(5)$ & $-779(5)$ & $4430(4)$ & $28(2)$ \\
\hline $\mathrm{C}(40)$ & 111(5) & $-924(5)$ & $4376(4)$ & $33(2)$ \\
\hline $\mathrm{C}(41)$ & $-227(5)$ & $-1494(4)$ & $4051(4)$ & $27(2)$ \\
\hline $\mathrm{C}(42)$ & $235(5)$ & $-1917(4)$ & $3780(4)$ & $32(2)$ \\
\hline $\mathrm{C}(43)$ & $-43(5)$ & $-2199(4)$ & $3194(4)$ & $29(2)$ \\
\hline $\mathrm{C}(44)$ & $-790(5)$ & $-2032(4)$ & $2886(4)$ & $28(2)$ \\
\hline $\mathrm{C}(45)$ & $-908(5)$ & $-1867(4)$ & $2247(4)$ & $27(2)$ \\
\hline $\mathrm{C}(46)$ & $-1460(5)$ & $-1334(5)$ & $2135(4)$ & $29(2)$ \\
\hline $\mathrm{C}(47)$ & $-1382(5)$ & $-842(4)$ & $1717(4)$ & $28(2)$ \\
\hline $\mathrm{C}(48)$ & $-1524(5)$ & $-151(5)$ & $1839(4)$ & $29(2)$ \\
\hline $\mathrm{C}(49)$ & $-1738(5)$ & $24(5)$ & $2387(4)$ & $29(2)$ \\
\hline $\mathrm{C}(50)$ & $-1399(5)$ & $612(5)$ & $2718(4)$ & $31(2)$ \\
\hline $\mathrm{C}(51)$ & $-1280(5)$ & $449(5)$ & $3347(4)$ & $31(2)$ \\
\hline $\mathrm{C}(52)$ & $-626(5)$ & $689(4)$ & $3733(4)$ & $31(2)$ \\
\hline $\mathrm{C}(53)$ & $-209(5)$ & $264(5)$ & 4193(4) & $31(2)$ \\
\hline $\mathrm{C}(54)$ & $-447(5)$ & $-383(5)$ & $4260(4)$ & $31(2)$ \\
\hline C(55) & $-1128(5)$ & $-631(5)$ & $3850(4)$ & $30(2)$ \\
\hline
\end{tabular}




\begin{tabular}{|ccccc|}
\hline C(56) & $-1000(5)$ & $-1336(4)$ & $3727(4)$ & $29(2)$ \\
\hline C(57) & $-1262(5)$ & $-1579(4)$ & $3149(4)$ & $28(2)$ \\
\hline C(58) & $-1684(5)$ & $-1155(4)$ & $2686(4)$ & $31(2)$ \\
\hline C(59) & $-1814(5)$ & $-493(5)$ & $2820(4)$ & $31(2)$ \\
\hline C(60) & $-1536(5)$ & $-231(5)$ & $3415(4)$ & $33(2)$ \\
\hline CA & $1094(6)$ & $-2789(6)$ & $754(6)$ & $69(4)$ \\
\hline SA & $1920(3)$ & $-2848(3)$ & $1142(4)$ & $185(4)$ \\
\hline SAA & $237(3)$ & $-2724(2)$ & $464(2)$ & $92(1)$ \\
\hline CB & $3929(18)$ & $-2033(11)$ & $4832(8)$ & $217(15)$ \\
\hline SB & $3881(6)$ & $-2384(5)$ & $5444(5)$ & $257(5)$ \\
\hline SBB & $4314(9)$ & $-1628(6)$ & $4361(5)$ & $367(8)$ \\
\hline CC & $3089(10)$ & $2647(9)$ & $4488(6)$ & $130(7)$ \\
\hline SC & $3726(7)$ & $2708(5)$ & $5049(4)$ & $331(8)$ \\
\hline SCC & $2480(4)$ & $2579(4)$ & $3913(3)$ & $177(3)$ \\
\hline CD & $2777(8)$ & $3599(7)$ & $670(5)$ & $77(4)$ \\
\hline SD & $3250(3)$ & $3447(3)$ & $1302(2)$ & $120(2)$ \\
\hline SDD & $2251(3)$ & $3733(2)$ & $62(2)$ & $101(1)$ \\
\hline
\end{tabular}


Table S5. Bond lengths $[\AA]$ and angles [deg] for 3 .

\begin{tabular}{|c|c|c|c|}
\hline $\operatorname{Ir}(1)-C(1 \mathrm{~A})$ & $1.890(10)$ & $\mathrm{C}(3 \mathrm{~A})-\mathrm{O}(3 \mathrm{~A})$ & $1.144(11)$ \\
\hline $\operatorname{Ir}(1)-C(2)$ & $2.222(8)$ & $\mathrm{C}(3 \mathrm{~B})-\mathrm{O}(3 \mathrm{~B})$ & $1.142(11)$ \\
\hline $\operatorname{Ir}(1)-C(1)$ & $2.256(8)$ & $\mathrm{C}(4 \mathrm{~A})-\mathrm{O}(4 \mathrm{~A})$ & $1.138(11)$ \\
\hline $\operatorname{Ir}(1)-\mathrm{P}(2)$ & $2.281(2)$ & $\mathrm{C}(4 \mathrm{~B})-\mathrm{O}(4 \mathrm{~B})$ & $1.136(11)$ \\
\hline $\operatorname{Ir}(1)-P(3)$ & $2.282(2)$ & $\mathrm{C}(101)-\mathrm{C}(102)$ & $1.375(15)$ \\
\hline $\operatorname{Ir}(1)-\operatorname{Ir}(2)$ & $2.7598(8)$ & $\mathrm{C}(101)-\mathrm{C}(106)$ & $1.383(13)$ \\
\hline $\operatorname{Ir}(1)-\operatorname{Ir}(3)$ & $2.7827(8)$ & $\mathrm{C}(102)-\mathrm{C}(103)$ & $1.388(16)$ \\
\hline $\operatorname{Ir}(2)-C(2 A)$ & $1.875(9)$ & $\mathrm{C}(103)-\mathrm{C}(104)$ & $1.320(17)$ \\
\hline $\operatorname{Ir}(2)-C(502)$ & $2.089(8)$ & $\mathrm{C}(104)-\mathrm{C}(105)$ & $1.330(16)$ \\
\hline $\operatorname{Ir}(2)-C(4)$ & $2.150(8)$ & $\mathrm{C}(105)-\mathrm{C}(106)$ & $1.367(15)$ \\
\hline $\operatorname{Ir}(2)-C(3)$ & $2.241(8)$ & $\mathrm{C}(201)-\mathrm{C}(206)$ & $1.368(13)$ \\
\hline $\operatorname{Ir}(2)-\operatorname{Ir}(4)$ & $2.7401(9)$ & $\mathrm{C}(201)-\mathrm{C}(202)$ & $1.376(13)$ \\
\hline $\operatorname{Ir}(2)-\operatorname{Ir}(3)$ & $2.8059(7)$ & $\mathrm{C}(202)-\mathrm{C}(203)$ & $1.357(15)$ \\
\hline $\operatorname{Ir}(3)-C(3 B)$ & $1.873(9)$ & $\mathrm{C}(203)-\mathrm{C}(204)$ & $1.397(16)$ \\
\hline $\operatorname{Ir}(3)-C(3 A)$ & 1.891(10) & $\mathrm{C}(204)-\mathrm{C}(205)$ & $1.363(15)$ \\
\hline $\operatorname{Ir}(3)-C(6)$ & $2.161(8)$ & $\mathrm{C}(205)-\mathrm{C}(206)$ & $1.360(13)$ \\
\hline $\operatorname{Ir}(3)-C(5)$ & $2.303(8)$ & $\mathrm{C}(301)-\mathrm{C}(302)$ & $1.383(12)$ \\
\hline $\operatorname{Ir}(3)-\operatorname{Ir}(4)$ & $2.8094(7)$ & $\mathrm{C}(301)-\mathrm{C}(306)$ & $1.416(12)$ \\
\hline $\operatorname{Ir}(4)-C(4 B)$ & $1.884(10)$ & $\mathrm{C}(302)-\mathrm{C}(303)$ & $1.373(14)$ \\
\hline $\operatorname{Ir}(4)-C(4 A)$ & $1.918(11)$ & $\mathrm{C}(303)-\mathrm{C}(304)$ & $1.383(13)$ \\
\hline $\operatorname{Ir}(4)-P(2)$ & $2.300(2)$ & $\mathrm{C}(304)-\mathrm{C}(305)$ & $1.383(12)$ \\
\hline $\operatorname{Ir}(4)-\mathrm{P}(1)$ & $2.318(2)$ & $\mathrm{C}(305)-\mathrm{C}(306)$ & $1.379(12)$ \\
\hline $\mathrm{P}(1)-\mathrm{C}(301)$ & $1.826(9)$ & $\mathrm{C}(401)-\mathrm{C}(406)$ & $1.387(11)$ \\
\hline $\mathrm{P}(1)-\mathrm{C}(101)$ & $1.827(9)$ & $\mathrm{C}(401)-\mathrm{C}(402)$ & $1.393(13)$ \\
\hline $\mathrm{P}(1)-\mathrm{C}(201)$ & $1.851(10)$ & $\mathrm{C}(402)-\mathrm{C}(403)$ & $1.367(14)$ \\
\hline $\mathrm{P}(2)-\mathrm{C}(401)$ & $1.831(9)$ & $\mathrm{C}(403)-\mathrm{C}(404)$ & $1.402(13)$ \\
\hline $\mathrm{P}(2)-\mathrm{C}(306)$ & $1.841(8)$ & $\mathrm{C}(404)-\mathrm{C}(405)$ & $1.378(13)$ \\
\hline $\mathrm{P}(3)-\mathrm{C}(406)$ & $1.807(9)$ & $\mathrm{C}(405)-\mathrm{C}(406)$ & $1.396(12)$ \\
\hline $\mathrm{P}(3)-\mathrm{C}(501)$ & $1.812(9)$ & $\mathrm{C}(501)-\mathrm{C}(502)$ & $1.397(12)$ \\
\hline $\mathrm{P}(3)-\mathrm{C}(601)$ & $1.815(9)$ & $\mathrm{C}(501)-\mathrm{C}(506)$ & $1.416(11)$ \\
\hline $\mathrm{C}(1 \mathrm{~A})-\mathrm{O}(1 \mathrm{~A})$ & $1.144(11)$ & $\mathrm{C}(502)-\mathrm{C}(503)$ & $1.406(12)$ \\
\hline $\mathrm{C}(2 \mathrm{~A})-\mathrm{O}(2 \mathrm{~A})$ & $1.133(10)$ & $\mathrm{C}(503)-\mathrm{C}(504)$ & $1.366(12)$ \\
\hline $\mathrm{C}(504)-\mathrm{C}(505)$ & $1.384(13)$ & $\mathrm{C}(16)-\mathrm{C}(17)$ & $1.388(12)$ \\
\hline$C(505)-C(506)$ & $1.369(12)$ & $\mathrm{C}(16)-\mathrm{C}(34)$ & $1.448(12)$ \\
\hline $\mathrm{C}(601)-\mathrm{C}(606)$ & $1.380(12)$ & $\mathrm{C}(17)-\mathrm{C}(18)$ & $1.456(12)$ \\
\hline $\mathrm{C}(601)-\mathrm{C}(602)$ & $1.398(13)$ & $\mathrm{C}(18)-\mathrm{C}(36)$ & $1.404(12)$ \\
\hline$C(602)-C(603)$ & $1.400(13)$ & $\mathrm{C}(18)-\mathrm{C}(19)$ & $1.443(11)$ \\
\hline $\mathrm{C}(603)-\mathrm{C}(604)$ & $1.381(15)$ & $\mathrm{C}(19)-\mathrm{C}(20)$ & $1.408(12)$ \\
\hline$C(604)-C(605)$ & $1.346(14)$ & $\mathrm{C}(20)-\mathrm{C}(38)$ & $1.428(13)$ \\
\hline$C(605)-C(606)$ & $1.373(12)$ & $\mathrm{C}(20)-\mathrm{C}(21)$ & $1.453(12)$ \\
\hline$C(1)-C(2)$ & $1.435(11)$ & $\mathrm{C}(21)-\mathrm{C}(22)$ & $1.437(12)$ \\
\hline$C(1)-C(9)$ & $1.458(11)$ & $\mathrm{C}(22)-\mathrm{C}(23)$ & $1.396(12)$ \\
\hline$C(1)-C(6)$ & $1.507(11)$ & $\mathrm{C}(22)-\mathrm{C}(39)$ & $1.447(13)$ \\
\hline $\mathrm{C}(2)-\mathrm{C}(12)$ & $1.463(11)$ & $\mathrm{C}(23)-\mathrm{C}(42)$ & $1.448(12)$ \\
\hline$C(2)-C(3)$ & $1.491(11)$ & $\mathrm{C}(23)-\mathrm{C}(24)$ & $1.452(13)$ \\
\hline$C(3)-C(4)$ & $1.420(11)$ & $C(24)-C(25)$ & $1.442(12)$ \\
\hline $\mathrm{C}(3)-\mathrm{C}(14)$ & 1.471(11) & $\mathrm{C}(25)-\mathrm{C}(26)$ & $1.373(12)$ \\
\hline $\mathrm{C}(4)-\mathrm{C}(17)$ & $1.468(11)$ & $\mathrm{C}(25)-\mathrm{C}(43)$ & $1.463(13)$ \\
\hline$C(4)-C(5)$ & $1.483(11)$ & $\mathrm{C}(26)-\mathrm{C}(27)$ & $1.478(12)$ \\
\hline$C(5)-C(6)$ & $1.434(11)$ & $\mathrm{C}(27)-\mathrm{C}(45)$ & $1.396(12)$ \\
\hline $\mathrm{C}(5)-\mathrm{C}(19)$ & $1.465(12)$ & $\mathrm{C}(27)-\mathrm{C}(28)$ & $1.453(12)$ \\
\hline$C(6)-C(7)$ & $1.460(11)$ & $\mathrm{C}(28)-\mathrm{C}(29)$ & $1.409(12)$ \\
\hline $\mathrm{C}(7)-\mathrm{C}(21)$ & $1.410(12)$ & $\mathrm{C}(29)-\mathrm{C}(30)$ & $1.439(12)$ \\
\hline$C(7)-C(8)$ & $1.440(11)$ & $\mathrm{C}(29)-\mathrm{C}(47)$ & $1.460(13)$ \\
\hline
\end{tabular}




\begin{tabular}{|l|l|l|l|}
\hline $\mathrm{C}(8)-\mathrm{C}(24)$ & $1.409(12)$ & $\mathrm{C}(30)-\mathrm{C}(31)$ & $1.447(13)$ \\
\hline $\mathrm{C}(8)-\mathrm{C}(9)$ & $1.440(12)$ & $\mathrm{C}(31)-\mathrm{C}(32)$ & $1.405(12)$ \\
\hline $\mathrm{C}(9)-\mathrm{C}(10)$ & $1.383(11)$ & $\mathrm{C}(31)-\mathrm{C}(48)$ & $1.438(12)$ \\
\hline $\mathrm{C}(10)-\mathrm{C}(26)$ & $1.439(12)$ & $\mathrm{C}(32)-\mathrm{C}(33)$ & $1.422(13)$ \\
\hline $\mathrm{C}(10)-\mathrm{C}(11)$ & $1.458(12)$ & $\mathrm{C}(33)-\mathrm{C}(50)$ & $1.396(12)$ \\
\hline $\mathrm{C}(11)-\mathrm{C}(12)$ & $1.380(11)$ & $\mathrm{C}(33)-\mathrm{C}(34)$ & $1.439(12)$ \\
\hline $\mathrm{C}(11)-\mathrm{C}(28)$ & $1.426(11)$ & $\mathrm{C}(34)-\mathrm{C}(35)$ & $1.403(12)$ \\
\hline $\mathrm{C}(12)-\mathrm{C}(13)$ & $1.460(11)$ & $\mathrm{C}(35)-\mathrm{C}(36)$ & $1.441(12)$ \\
\hline $\mathrm{C}(13)-\mathrm{C}(30)$ & $1.404(11)$ & $\mathrm{C}(35)-\mathrm{C}(52)$ & $1.457(12)$ \\
\hline $\mathrm{C}(13)-\mathrm{C}(14)$ & $1.434(11)$ & $\mathrm{C}(36)-\mathrm{C}(37)$ & $1.441(12)$ \\
\hline $\mathrm{C}(14)-\mathrm{C}(15)$ & $1.374(12)$ & $\mathrm{C}(37)-\mathrm{C}(38)$ & $1.405(12)$ \\
\hline $\mathrm{C}(15)-\mathrm{C}(32)$ & $1.453(12)$ & $\mathrm{C}(37)-\mathrm{C}(53)$ & $1.461(12)$ \\
\hline $\mathrm{C}(15)-\mathrm{C}(16)$ & $1.456(12)$ & $\mathrm{C}(38)-\mathrm{C}(39)$ & $1.431(12)$ \\
\hline $\mathrm{C}(39)-\mathrm{C}(40)$ & $1.396(12)$ & $\mathrm{C}(52)-\mathrm{C}(53)$ & $1.436(13)$ \\
\hline $\mathrm{C}(40)-\mathrm{C}(41)$ & $1.428(13)$ & $\mathrm{C}(53)-\mathrm{C}(54)$ & $1.381(13)$ \\
\hline $\mathrm{C}(40)-\mathrm{C}(54)$ & $1.450(13)$ & $\mathrm{C}(54)-\mathrm{C}(55)$ & $1.454(12)$ \\
\hline $\mathrm{C}(41)-\mathrm{C}(42)$ & $1.389(13)$ & $\mathrm{C}(55)-\mathrm{C}(60)$ & $1.362(13)$ \\
\hline $\mathrm{C}(41)-\mathrm{C}(56)$ & $1.447(12)$ & $\mathrm{C}(55)-\mathrm{C}(56)$ & $1.467(13)$ \\
\hline $\mathrm{C}(42)-\mathrm{C}(43)$ & $1.442(12)$ & $\mathrm{C}(56)-\mathrm{C}(57)$ & $1.392(12)$ \\
\hline $\mathrm{C}(43)-\mathrm{C}(44)$ & $1.400(12)$ & $\mathrm{C}(57)-\mathrm{C}(58)$ & $1.441(13)$ \\
\hline $\mathrm{C}(44)-\mathrm{C}(57)$ & $1.429(12)$ & $\mathrm{C}(58)-\mathrm{C}(59)$ & $1.390(13)$ \\
\hline $\mathrm{C}(44)-\mathrm{C}(45)$ & $1.461(12)$ & $\mathrm{C}(59)-\mathrm{C}(60)$ & $1.444(13)$ \\
\hline $\mathrm{C}(45)-\mathrm{C}(46)$ & $1.432(12)$ & $\mathrm{CA}-\mathrm{SAA}$ & $1.524(11)$ \\
\hline $\mathrm{C}(46)-\mathrm{C}(47)$ & $1.391(13)$ & $\mathrm{CA}-\mathrm{SA}$ & $1.548(11)$ \\
\hline $\mathrm{C}(46)-\mathrm{C}(58)$ & $1.422(13)$ & $\mathrm{CB}-\mathrm{SB}$ & $1.570(14)$ \\
\hline $\mathrm{C}(47)-\mathrm{C}(48)$ & $1.445(12)$ & $\mathrm{CB}-\mathrm{SBB}$ & $1.587(16)$ \\
\hline $\mathrm{C}(48)-\mathrm{C}(49)$ & $1.406(13)$ & $\mathrm{CC}-\mathrm{SCC}$ & $1.526(13)$ \\
\hline $\mathrm{C}(49)-\mathrm{C}(59)$ & $1.448(13)$ & $\mathrm{CC}-\mathrm{SC}$ & $1.530(13)$ \\
\hline $\mathrm{C}(49)-\mathrm{C}(50)$ & $1.463(13)$ & $\mathrm{CD}-\mathrm{SDD}$ & $1.529(10)$ \\
\hline $\mathrm{C}(50)-\mathrm{C}(51)$ & $1.438(13)$ & $\mathrm{CD}-\mathrm{SD}$ & $1.543(10)$ \\
\hline $\mathrm{C}(51)-\mathrm{C}(52)$ & $1.389(12)$ & $\mathrm{CD}-\mathrm{SD}$ & $1.543(10)$ \\
\hline $\mathrm{C}(51)-\mathrm{C}(60)$ & $1.454(13)$ & $\mathrm{CD}-\mathrm{SD}$ & \\
\hline & & & \\
\hline
\end{tabular}

\begin{tabular}{|l|c|l|c|}
\hline $\mathrm{C}(1 \mathrm{~A})-\operatorname{Ir}(1)-\mathrm{C}(2)$ & $108.6(3)$ & $\mathrm{Ir}(4)-\operatorname{Ir}(2)-\operatorname{Ir}(1)$ & $85.022(14)$ \\
\hline $\mathrm{C}(1 \mathrm{~A})-\operatorname{Ir}(1)-\mathrm{C}(1)$ & $88.0(3)$ & $\mathrm{C}(2 \mathrm{~A})-\operatorname{Ir}(2)-\operatorname{Ir}(3)$ & $113.9(2)$ \\
\hline $\mathrm{C}(2)-\operatorname{Ir}(1)-\mathrm{C}(1)$ & $37.4(3)$ & $\mathrm{C}(502)-\operatorname{Ir}(2)-\operatorname{Ir}(3)$ & $154.0(2)$ \\
\hline $\mathrm{C}(1 \mathrm{~A})-\operatorname{Ir}(1)-\mathrm{P}(2)$ & $100.6(3)$ & $\mathrm{C}(4)-\operatorname{Ir}(2)-\operatorname{Ir}(3)$ & $78.2(2)$ \\
\hline $\mathrm{C}(2)-\operatorname{Ir}(1)-\mathrm{P}(2)$ & $150.7(2)$ & $\mathrm{C}(3)-\operatorname{Ir}(2)-\operatorname{Ir}(3)$ & $94.6(2)$ \\
\hline $\mathrm{C}(1)-\operatorname{Ir}(1)-\mathrm{P}(2)$ & $148.0(2)$ & $\mathrm{Ir}(4)-\operatorname{Ir}(2)-\operatorname{Ir}(3)$ & $60.856(14)$ \\
\hline $\mathrm{C}(1 \mathrm{~A})-\operatorname{Ir}(1)-\mathrm{P}(3)$ & $101.3(3)$ & $\mathrm{Ir}(1)-\operatorname{Ir}(2)-\operatorname{Ir}(3)$ & $59.990(19)$ \\
\hline $\mathrm{C}(2)-\operatorname{Ir}(1)-\mathrm{P}(3)$ & $89.0(2)$ & $\mathrm{C}(3 \mathrm{~B})-\operatorname{Ir}(3)-\mathrm{C}(3 \mathrm{~A})$ & $100.0(4)$ \\
\hline $\mathrm{C}(1)-\operatorname{Ir}(1)-\mathrm{P}(3)$ & $124.2(2)$ & $\mathrm{C}(3 \mathrm{~B})-\operatorname{Ir}(3)-\mathrm{C}(6)$ & $102.1(4)$ \\
\hline $\mathrm{P}(2)-\operatorname{Ir}(1)-\mathrm{P}(3)$ & $84.53(8)$ & $\mathrm{C}(3 \mathrm{~A})-\operatorname{Ir}(3)-\mathrm{C}(6)$ & $99.0(4)$ \\
\hline $\mathrm{C}(1 \mathrm{~A})-\operatorname{Ir}(1)-\operatorname{Ir}(2)$ & $172.5(3)$ & $\mathrm{C}(3 \mathrm{~B})-\operatorname{Ir}(3)-\mathrm{C}(5)$ & $84.7(3)$ \\
\hline $\mathrm{C}(2)-\operatorname{Ir}(1)-\operatorname{Ir}(2)$ & $73.5(2)$ & $\mathrm{C}(3 \mathrm{~A})-\operatorname{Ir}(3)-\mathrm{C}(5)$ & $134.9(4)$ \\
\hline $\mathrm{C}(1)-\operatorname{Ir}(1)-\operatorname{Ir}(2)$ & $89.82(19)$ & $\mathrm{C}(6)-\operatorname{Ir}(3)-\mathrm{C}(5)$ & $37.3(3)$ \\
\hline $\mathrm{P}(2)-\operatorname{Ir}(1)-\operatorname{Ir}(2)$ & $77.56(6)$ & $\mathrm{C}(3 \mathrm{~B})-\operatorname{Ir}(3)-\operatorname{Ir}(1)$ & $174.3(3)$ \\
\hline $\mathrm{P}(3)-\operatorname{Ir}(1)-\operatorname{Ir}(2)$ & $85.87(6)$ & $\mathrm{C}(3 \mathrm{~A})-\operatorname{Ir}(3)-\operatorname{Ir}(1)$ & $85.2(3)$ \\
\hline $\mathrm{C}(1 \mathrm{~A})-\operatorname{Ir}(1)-\operatorname{Ir}(3)$ & $111.7(3)$ & $\mathrm{C}(6)-\operatorname{Ir}(3)-\operatorname{Ir}(1)$ & $74.7(2)$ \\
\hline $\mathrm{C}(2)-\operatorname{Ir}(1)-\operatorname{Ir}(3)$ & $92.9(2)$ & $\mathrm{C}(5)-\operatorname{Ir}(3)-\operatorname{Ir}(1)$ & $90.1(2)$ \\
\hline $\mathrm{C}(1)-\operatorname{Ir}(1)-\operatorname{Ir}(3)$ & $71.6(2)$ & $\mathrm{C}(3 \mathrm{~B})-\operatorname{Ir}(3)-\operatorname{Ir}(2)$ & $116.5(3)$ \\
\hline $\mathrm{P}(2)-\operatorname{Ir}(1)-\operatorname{Ir}(3)$ & $76.57(6)$ & $\mathrm{C}(3 \mathrm{~A})-\operatorname{Ir}(3)-\operatorname{Ir}(2)$ & $140.3(3)$ \\
\hline $\mathrm{P}(3)-\operatorname{Ir}(1)-\operatorname{Ir}(3)$ & $144.33(6)$ & $\mathrm{C}(6)-\operatorname{Ir}(3)-\operatorname{Ir}(2)$ & $88.7(2)$ \\
\hline $\mathrm{Ir}(2)-\operatorname{Ir}(1)-\operatorname{Ir}(3)$ & $60.827(12)$ & $\mathrm{C}(5)-\operatorname{Ir}(3)-\operatorname{Ir}(2)$ & $67.4(2)$ \\
\hline $\mathrm{C}(2 \mathrm{~A})-\operatorname{Ir}(2)-\mathrm{C}(502)$ & $90.5(3)$ & $\mathrm{Ir}(1)-\operatorname{Ir}(3)-\operatorname{Ir}(2)$ & $59.183(19)$ \\
\hline $\mathrm{C}(2 \mathrm{~A})-\operatorname{Ir}(2)-\mathrm{C}(4)$ & $90.8(3)$ & $\mathrm{C}(3 \mathrm{~B})-\operatorname{Ir}(3)-\operatorname{Ir}(4)$ & $97.4(3)$ \\
\hline $\mathrm{C}(502)-\operatorname{Ir}(2)-\mathrm{C}(4)$ & $111.8(3)$ & $\mathrm{C}(3 \mathrm{~A})-\operatorname{Ir}(3)-\operatorname{Ir}(4)$ & $103.8(3)$ \\
\hline
\end{tabular}




\begin{tabular}{|c|c|c|c|}
\hline $\mathrm{C}(2 \mathrm{~A})-\operatorname{Ir}(2)-\mathrm{C}(3)$ & $114.7(3)$ & $C(6)-\operatorname{Ir}(3)-\operatorname{Ir}(4)$ & $146.7(2)$ \\
\hline$C(502)-\operatorname{Ir}(2)-C(3)$ & $82.3(3)$ & $C(5)-\operatorname{Ir}(3)-\operatorname{Ir}(4)$ & $120.2(2)$ \\
\hline $\mathrm{C}(4)-\operatorname{Ir}(2)-\mathrm{C}(3)$ & $37.7(3)$ & $\operatorname{Ir}(1)-\operatorname{Ir}(3)-\operatorname{Ir}(4)$ & $83.30(2)$ \\
\hline $\mathrm{C}(2 \mathrm{~A})-\operatorname{Ir}(2)-\operatorname{Ir}(4)$ & $86.1(3)$ & $\operatorname{Ir}(2)-\operatorname{Ir}(3)-\operatorname{Ir}(4)$ & $58.42(2)$ \\
\hline$C(502)-\operatorname{Ir}(2)-\operatorname{Ir}(4)$ & $115.1(2)$ & $\mathrm{C}(4 \mathrm{~B})-\operatorname{Ir}(4)-\mathrm{C}(4 \mathrm{~A})$ & 99.1(4) \\
\hline $\mathrm{C}(4)-\operatorname{Ir}(2)-\operatorname{Ir}(4)$ & $132.99(19)$ & $\mathrm{C}(4 \mathrm{~B})-\operatorname{Ir}(4)-\mathrm{P}(2)$ & $97.2(3)$ \\
\hline $\mathrm{C}(3)-\operatorname{Ir}(2)-\operatorname{Ir}(4)$ & $153.6(2)$ & $\mathrm{C}(4 \mathrm{~A})-\operatorname{Ir}(4)-\mathrm{P}(2)$ & $162.3(3)$ \\
\hline $\mathrm{C}(2 \mathrm{~A})-\operatorname{Ir}(2)-\operatorname{Ir}(1)$ & $170.9(3)$ & $\mathrm{C}(4 \mathrm{~B})-\operatorname{Ir}(4)-\mathrm{P}(1)$ & $98.8(3)$ \\
\hline$C(502)-\operatorname{Ir}(2)-\operatorname{Ir}(1)$ & $94.7(2)$ & $\mathrm{C}(4 \mathrm{~A})-\operatorname{Ir}(4)-\mathrm{P}(1)$ & 98.3(3) \\
\hline $\mathrm{C}(4)-\operatorname{Ir}(2)-\operatorname{Ir}(1)$ & $94.2(2)$ & $\mathrm{P}(2)-\operatorname{Ir}(4)-\mathrm{P}(1)$ & $85.87(8)$ \\
\hline$C(3)-\operatorname{Ir}(2)-\operatorname{Ir}(1)$ & $73.4(2)$ & $\mathrm{C}(4 \mathrm{~B})-\operatorname{Ir}(4)-\operatorname{Ir}(2)$ & $97.7(3)$ \\
\hline $\mathrm{C}(4 \mathrm{~A})-\operatorname{Ir}(4)-\operatorname{Ir}(2)$ & $93.4(3)$ & $\mathrm{C}(101)-\mathrm{C}(102)-\mathrm{C}(103)$ & $121.5(11)$ \\
\hline$P(2)-\operatorname{Ir}(4)-\operatorname{Ir}(2)$ & $77.67(6)$ & $C(104)-C(103)-C(102)$ & $119.6(13)$ \\
\hline$P(1)-\operatorname{Ir}(4)-\operatorname{Ir}(2)$ & $158.00(6)$ & $\mathrm{C}(103)-\mathrm{C}(104)-\mathrm{C}(105)$ & $120.2(12)$ \\
\hline $\mathrm{C}(4 \mathrm{~B})-\operatorname{Ir}(4)-\operatorname{Ir}(3)$ & $158.1(3)$ & $\mathrm{C}(104)-\mathrm{C}(105)-\mathrm{C}(106)$ & $121.5(11)$ \\
\hline$C(4 A)-\operatorname{Ir}(4)-\operatorname{Ir}(3)$ & $86.6(3)$ & $\mathrm{C}(105)-\mathrm{C}(106)-\mathrm{C}(101)$ & $120.2(11)$ \\
\hline $\mathrm{P}(2)-\operatorname{Ir}(4)-\operatorname{Ir}(3)$ & $75.72(6)$ & $\mathrm{C}(206)-\mathrm{C}(201)-\mathrm{C}(202)$ & $119.4(10)$ \\
\hline $\mathrm{P}(1)-\operatorname{Ir}(4)-\operatorname{Ir}(3)$ & $101.28(6)$ & $\mathrm{C}(206)-\mathrm{C}(201)-\mathrm{P}(1)$ & $123.1(7)$ \\
\hline $\operatorname{Ir}(2)-\operatorname{Ir}(4)-\operatorname{Ir}(3)$ & $60.729(15)$ & $\mathrm{C}(202)-\mathrm{C}(201)-\mathrm{P}(1)$ & $117.5(8)$ \\
\hline $\mathrm{C}(301)-\mathrm{P}(1)-\mathrm{C}(101)$ & $104.9(4)$ & $\mathrm{C}(203)-\mathrm{C}(202)-\mathrm{C}(201)$ & $121.0(11)$ \\
\hline $\mathrm{C}(301)-\mathrm{P}(1)-\mathrm{C}(201)$ & $103.4(4)$ & $\mathrm{C}(202)-\mathrm{C}(203)-\mathrm{C}(204)$ & $119.5(11)$ \\
\hline$C(101)-P(1)-C(201)$ & $103.6(4)$ & $C(205)-C(204)-C(203)$ & $118.7(10)$ \\
\hline $\mathrm{C}(301)-\mathrm{P}(1)-\operatorname{Ir}(4)$ & 108.2(3) & $\mathrm{C}(206)-\mathrm{C}(205)-\mathrm{C}(204)$ & $121.5(11)$ \\
\hline $\mathrm{C}(101)-\mathrm{P}(1)-\operatorname{Ir}(4)$ & $122.0(3)$ & $\mathrm{C}(205)-\mathrm{C}(206)-\mathrm{C}(201)$ & $119.9(9)$ \\
\hline $\mathrm{C}(201)-\mathrm{P}(1)-\operatorname{Ir}(4)$ & $113.1(3)$ & $\mathrm{C}(302)-\mathrm{C}(301)-\mathrm{C}(306)$ & $120.2(8)$ \\
\hline $\mathrm{C}(401)-\mathrm{P}(2)-\mathrm{C}(306)$ & $99.8(4)$ & $\mathrm{C}(302)-\mathrm{C}(301)-\mathrm{P}(1)$ & $122.8(7)$ \\
\hline $\mathrm{C}(401)-\mathrm{P}(2)-\operatorname{Ir}(1)$ & 108.1(3) & $\mathrm{C}(306)-\mathrm{C}(301)-\mathrm{P}(1)$ & $116.8(6)$ \\
\hline $\mathrm{C}(306)-\mathrm{P}(2)-\operatorname{Ir}(1)$ & $116.3(3)$ & $\mathrm{C}(303)-\mathrm{C}(302)-\mathrm{C}(301)$ & $119.8(9)$ \\
\hline $\mathrm{C}(401)-\mathrm{P}(2)-\operatorname{Ir}(4)$ & $116.8(3)$ & $\mathrm{C}(302)-\mathrm{C}(303)-\mathrm{C}(304)$ & 121.2(9) \\
\hline $\mathrm{C}(306)-\mathrm{P}(2)-\operatorname{Ir}(4)$ & $107.6(3)$ & $\mathrm{C}(303)-\mathrm{C}(304)-\mathrm{C}(305)$ & 118.9(9) \\
\hline $\operatorname{Ir}(1)-\mathrm{P}(2)-\operatorname{Ir}(4)$ & $108.45(9)$ & $\mathrm{C}(306)-\mathrm{C}(305)-\mathrm{C}(304)$ & $121.8(9)$ \\
\hline $\mathrm{C}(406)-\mathrm{P}(3)-\mathrm{C}(501)$ & $99.0(4)$ & $\mathrm{C}(305)-\mathrm{C}(306)-\mathrm{C}(301)$ & $118.0(8)$ \\
\hline $\mathrm{C}(406)-\mathrm{P}(3)-\mathrm{C}(601)$ & $107.2(4)$ & $\mathrm{C}(305)-\mathrm{C}(306)-\mathrm{P}(2)$ & $122.7(7)$ \\
\hline $\mathrm{C}(501)-\mathrm{P}(3)-\mathrm{C}(601)$ & $108.8(4)$ & $\mathrm{C}(301)-\mathrm{C}(306)-\mathrm{P}(2)$ & $119.2(7)$ \\
\hline $\mathrm{C}(406)-\mathrm{P}(3)-\operatorname{Ir}(1)$ & $108.8(3)$ & $\mathrm{C}(406)-\mathrm{C}(401)-\mathrm{C}(402)$ & $119.2(9)$ \\
\hline $\mathrm{C}(501)-\mathrm{P}(3)-\operatorname{Ir}(1)$ & $114.2(3)$ & $\mathrm{C}(406)-\mathrm{C}(401)-\mathrm{P}(2)$ & $118.4(7)$ \\
\hline $\mathrm{C}(601)-\mathrm{P}(3)-\operatorname{Ir}(1)$ & $117.2(3)$ & $\mathrm{C}(402)-\mathrm{C}(401)-\mathrm{P}(2)$ & $122.4(7)$ \\
\hline $\mathrm{O}(1 \mathrm{~A})-\mathrm{C}(1 \mathrm{~A})-\operatorname{Ir}(1)$ & $177.5(9)$ & $\mathrm{C}(403)-\mathrm{C}(402)-\mathrm{C}(401)$ & $120.8(9)$ \\
\hline $\mathrm{O}(2 \mathrm{~A})-\mathrm{C}(2 \mathrm{~A})-\operatorname{Ir}(2)$ & $179.1(8)$ & $\mathrm{C}(402)-\mathrm{C}(403)-\mathrm{C}(404)$ & $119.8(10)$ \\
\hline $\mathrm{O}(3 \mathrm{~A})-\mathrm{C}(3 \mathrm{~A})-\operatorname{Ir}(3)$ & $175.3(9)$ & $\mathrm{C}(405)-\mathrm{C}(404)-\mathrm{C}(403)$ & $120.2(9)$ \\
\hline $\mathrm{O}(3 \mathrm{~B})-\mathrm{C}(3 \mathrm{~B})-\operatorname{Ir}(3)$ & $175.3(9)$ & $C(404)-C(405)-C(406)$ & $119.5(9)$ \\
\hline $\mathrm{O}(4 \mathrm{~A})-\mathrm{C}(4 \mathrm{~A})-\operatorname{Ir}(4)$ & $177.2(8)$ & $\mathrm{C}(401)-\mathrm{C}(406)-\mathrm{C}(405)$ & $120.5(8)$ \\
\hline $\mathrm{O}(4 \mathrm{~B})-\mathrm{C}(4 \mathrm{~B})-\operatorname{Ir}(4)$ & $179.1(10)$ & $\mathrm{C}(401)-\mathrm{C}(406)-\mathrm{P}(3)$ & $115.9(7)$ \\
\hline$C(102)-C(101)-C(106)$ & $116.3(10)$ & $\mathrm{C}(405)-\mathrm{C}(406)-\mathrm{P}(3)$ & $123.0(6)$ \\
\hline $\mathrm{C}(102)-\mathrm{C}(101)-\mathrm{P}(1)$ & $119.3(8)$ & $\mathrm{C}(502)-\mathrm{C}(501)-\mathrm{C}(506)$ & $121.5(8)$ \\
\hline $\mathrm{C}(106)-\mathrm{C}(101)-\mathrm{P}(1)$ & $124.2(9)$ & $\mathrm{C}(502)-\mathrm{C}(501)-\mathrm{P}(3)$ & $119.9(6)$ \\
\hline $\mathrm{C}(506)-\mathrm{C}(501)-\mathrm{P}(3)$ & $117.9(6)$ & $C(3)-C(4)-C(5)$ & $119.6(7)$ \\
\hline $\mathrm{C}(501)-\mathrm{C}(502)-\mathrm{C}(503)$ & $115.4(7)$ & $C(17)-C(4)-C(5)$ & $108.2(7)$ \\
\hline $\mathrm{C}(501)-\mathrm{C}(502)-\operatorname{Ir}(2)$ & $122.6(6)$ & $\mathrm{C}(3)-\mathrm{C}(4)-\operatorname{Ir}(2)$ & $74.7(5)$ \\
\hline $\mathrm{C}(503)-\mathrm{C}(502)-\operatorname{Ir}(2)$ & $121.8(6)$ & $\mathrm{C}(17)-\mathrm{C}(4)-\operatorname{Ir}(2)$ & $130.5(6)$ \\
\hline $\mathrm{C}(504)-\mathrm{C}(503)-\mathrm{C}(502)$ & $123.1(8)$ & $C(5)-C(4)-\operatorname{Ir}(2)$ & $102.6(5)$ \\
\hline $\mathrm{C}(503)-\mathrm{C}(504)-\mathrm{C}(505)$ & $120.8(9)$ & $\mathrm{C}(6)-\mathrm{C}(5)-\mathrm{C}(19)$ & $118.3(7)$ \\
\hline $\mathrm{C}(506)-\mathrm{C}(505)-\mathrm{C}(504)$ & $118.7(9)$ & $C(6)-C(5)-C(4)$ & $121.8(7)$ \\
\hline $\mathrm{C}(505)-\mathrm{C}(506)-\mathrm{C}(501)$ & $120.5(8)$ & $\mathrm{C}(19)-\mathrm{C}(5)-\mathrm{C}(4)$ & 106.3(7) \\
\hline $\mathrm{C}(606)-\mathrm{C}(601)-\mathrm{C}(602)$ & $118.5(8)$ & $\mathrm{C}(6)-\mathrm{C}(5)-\operatorname{Ir}(3)$ & $65.9(4)$ \\
\hline $\mathrm{C}(606)-\mathrm{C}(601)-\mathrm{P}(3)$ & $123.1(7)$ & $\mathrm{C}(19)-\mathrm{C}(5)-\operatorname{Ir}(3)$ & $129.6(6)$ \\
\hline $\mathrm{C}(602)-\mathrm{C}(601)-\mathrm{P}(3)$ & $118.2(7)$ & $\mathrm{C}(4)-\mathrm{C}(5)-\operatorname{Ir}(3)$ & $111.6(6)$ \\
\hline
\end{tabular}




\begin{tabular}{|c|c|c|c|}
\hline $\mathrm{C}(601)-\mathrm{C}(602)-\mathrm{C}(603)$ & $120.1(10)$ & $C(5)-C(6)-C(7)$ & $118.9(7)$ \\
\hline $\mathrm{C}(604)-\mathrm{C}(603)-\mathrm{C}(602)$ & $118.6(10)$ & $C(5)-C(6)-C(1)$ & $117.7(7)$ \\
\hline $\mathrm{C}(605)-\mathrm{C}(604)-\mathrm{C}(603)$ & $121.5(10)$ & $C(7)-C(6)-C(1)$ & 106.2(7) \\
\hline $\mathrm{C}(604)-\mathrm{C}(605)-\mathrm{C}(606)$ & $120.2(10)$ & $C(5)-C(6)-\operatorname{Ir}(3)$ & $76.8(5)$ \\
\hline $\mathrm{C}(605)-\mathrm{C}(606)-\mathrm{C}(601)$ & 121.1(9) & $C(7)-C(6)-\operatorname{Ir}(3)$ & $128.3(5)$ \\
\hline $\mathrm{C}(2)-\mathrm{C}(1)-\mathrm{C}(9)$ & 119.1(7) & $\mathrm{C}(1)-\mathrm{C}(6)-\operatorname{Ir}(3)$ & $107.3(5)$ \\
\hline$C(2)-C(1)-C(6)$ & $120.9(7)$ & $\mathrm{C}(21)-\mathrm{C}(7)-\mathrm{C}(8)$ & $119.9(8)$ \\
\hline$C(9)-C(1)-C(6)$ & $107.1(7)$ & $\mathrm{C}(21)-\mathrm{C}(7)-\mathrm{C}(6)$ & $121.7(8)$ \\
\hline$C(2)-C(1)-\operatorname{Ir}(1)$ & $70.0(5)$ & $C(8)-C(7)-C(6)$ & $109.0(7)$ \\
\hline$C(9)-C(1)-\operatorname{Ir}(1)$ & $130.8(6)$ & $\mathrm{C}(24)-\mathrm{C}(8)-\mathrm{C}(9)$ & $120.2(8)$ \\
\hline$C(6)-C(1)-\operatorname{Ir}(1)$ & $106.1(5)$ & $\mathrm{C}(24)-\mathrm{C}(8)-\mathrm{C}(7)$ & $120.4(8)$ \\
\hline $\mathrm{C}(1)-\mathrm{C}(2)-\mathrm{C}(12)$ & $117.4(7)$ & $\mathrm{C}(9)-\mathrm{C}(8)-\mathrm{C}(7)$ & 108.9(7) \\
\hline$C(1)-C(2)-C(3)$ & $119.4(7)$ & $\mathrm{C}(10)-\mathrm{C}(9)-\mathrm{C}(8)$ & $119.8(8)$ \\
\hline $\mathrm{C}(12)-\mathrm{C}(2)-\mathrm{C}(3)$ & $107.2(7)$ & $\mathrm{C}(10)-\mathrm{C}(9)-\mathrm{C}(1)$ & $121.5(8)$ \\
\hline$C(1)-C(2)-\operatorname{Ir}(1)$ & $72.6(5)$ & $\mathrm{C}(8)-\mathrm{C}(9)-\mathrm{C}(1)$ & $108.6(7)$ \\
\hline$C(12)-C(2)-\operatorname{Ir}(1)$ & $130.7(6)$ & $\mathrm{C}(9)-\mathrm{C}(10)-\mathrm{C}(26)$ & $119.4(8)$ \\
\hline$C(3)-C(2)-\operatorname{Ir}(1)$ & $107.0(5)$ & $\mathrm{C}(9)-\mathrm{C}(10)-\mathrm{C}(11)$ & $120.0(8)$ \\
\hline$C(4)-C(3)-C(14)$ & $118.6(7)$ & $C(26)-C(10)-C(11)$ & 109.1(7) \\
\hline$C(4)-C(3)-C(2)$ & $120.5(7)$ & $\mathrm{C}(12)-\mathrm{C}(11)-\mathrm{C}(28)$ & $121.0(8)$ \\
\hline$C(14)-C(3)-C(2)$ & $107.5(7)$ & $\mathrm{C}(12)-\mathrm{C}(11)-\mathrm{C}(10)$ & $118.9(7)$ \\
\hline$C(4)-C(3)-\operatorname{Ir}(2)$ & $67.7(4)$ & $\mathrm{C}(28)-\mathrm{C}(11)-\mathrm{C}(10)$ & $107.5(7)$ \\
\hline$C(14)-C(3)-\operatorname{Ir}(2)$ & $133.3(6)$ & $\mathrm{C}(11)-\mathrm{C}(12)-\mathrm{C}(13)$ & $119.8(7)$ \\
\hline$C(2)-C(3)-\operatorname{Ir}(2)$ & $105.8(5)$ & $\mathrm{C}(11)-\mathrm{C}(12)-\mathrm{C}(2)$ & $122.9(7)$ \\
\hline $\mathrm{C}(3)-\mathrm{C}(4)-\mathrm{C}(17)$ & $118.6(7)$ & $\mathrm{C}(13)-\mathrm{C}(12)-\mathrm{C}(2)$ & $107.6(7)$ \\
\hline $\mathrm{C}(30)-\mathrm{C}(13)-\mathrm{C}(14)$ & $120.8(8)$ & $\mathrm{C}(25)-\mathrm{C}(24)-\mathrm{C}(23)$ & $108.9(8)$ \\
\hline $\mathrm{C}(30)-\mathrm{C}(13)-\mathrm{C}(12)$ & $119.3(7)$ & $\mathrm{C}(26)-\mathrm{C}(25)-\mathrm{C}(24)$ & $119.2(8)$ \\
\hline $\mathrm{C}(14)-\mathrm{C}(13)-\mathrm{C}(12)$ & $109.8(7)$ & $\mathrm{C}(26)-\mathrm{C}(25)-\mathrm{C}(43)$ & $121.6(8)$ \\
\hline $\mathrm{C}(15)-\mathrm{C}(14)-\mathrm{C}(13)$ & $120.1(8)$ & $\mathrm{C}(24)-\mathrm{C}(25)-\mathrm{C}(43)$ & $107.2(8)$ \\
\hline $\mathrm{C}(15)-\mathrm{C}(14)-\mathrm{C}(3)$ & $121.4(7)$ & $\mathrm{C}(25)-\mathrm{C}(26)-\mathrm{C}(10)$ & $121.8(8)$ \\
\hline $\mathrm{C}(13)-\mathrm{C}(14)-\mathrm{C}(3)$ & 107.8(7) & $\mathrm{C}(25)-\mathrm{C}(26)-\mathrm{C}(27)$ & $118.4(8)$ \\
\hline $\mathrm{C}(14)-\mathrm{C}(15)-\mathrm{C}(32)$ & $120.4(8)$ & $\mathrm{C}(10)-\mathrm{C}(26)-\mathrm{C}(27)$ & $106.9(7)$ \\
\hline $\mathrm{C}(14)-\mathrm{C}(15)-\mathrm{C}(16)$ & $120.5(7)$ & $\mathrm{C}(45)-\mathrm{C}(27)-\mathrm{C}(28)$ & $120.5(8)$ \\
\hline $\mathrm{C}(32)-\mathrm{C}(15)-\mathrm{C}(16)$ & 106.7(8) & $\mathrm{C}(45)-\mathrm{C}(27)-\mathrm{C}(26)$ & $121.0(8)$ \\
\hline $\mathrm{C}(17)-\mathrm{C}(16)-\mathrm{C}(34)$ & $120.6(8)$ & $\mathrm{C}(28)-\mathrm{C}(27)-\mathrm{C}(26)$ & $107.1(8)$ \\
\hline $\mathrm{C}(17)-\mathrm{C}(16)-\mathrm{C}(15)$ & $119.0(8)$ & $\mathrm{C}(29)-\mathrm{C}(28)-\mathrm{C}(11)$ & $120.1(8)$ \\
\hline $\mathrm{C}(34)-\mathrm{C}(16)-\mathrm{C}(15)$ & 108.0(7) & $\mathrm{C}(29)-\mathrm{C}(28)-\mathrm{C}(27)$ & $119.1(8)$ \\
\hline $\mathrm{C}(16)-\mathrm{C}(17)-\mathrm{C}(18)$ & $120.0(8)$ & $\mathrm{C}(11)-\mathrm{C}(28)-\mathrm{C}(27)$ & $109.3(8)$ \\
\hline $\mathrm{C}(16)-\mathrm{C}(17)-\mathrm{C}(4)$ & $121.7(7)$ & $\mathrm{C}(28)-\mathrm{C}(29)-\mathrm{C}(30)$ & $119.5(8)$ \\
\hline $\mathrm{C}(18)-\mathrm{C}(17)-\mathrm{C}(4)$ & 107.7(7) & $\mathrm{C}(28)-\mathrm{C}(29)-\mathrm{C}(47)$ & $119.6(8)$ \\
\hline $\mathrm{C}(36)-\mathrm{C}(18)-\mathrm{C}(19)$ & $120.7(8)$ & $\mathrm{C}(30)-\mathrm{C}(29)-\mathrm{C}(47)$ & $107.5(8)$ \\
\hline $\mathrm{C}(36)-\mathrm{C}(18)-\mathrm{C}(17)$ & $119.8(8)$ & $\mathrm{C}(13)-\mathrm{C}(30)-\mathrm{C}(29)$ & $120.3(8)$ \\
\hline $\mathrm{C}(19)-\mathrm{C}(18)-\mathrm{C}(17)$ & 108.4(7) & $\mathrm{C}(13)-\mathrm{C}(30)-\mathrm{C}(31)$ & $119.4(8)$ \\
\hline $\mathrm{C}(20)-\mathrm{C}(19)-\mathrm{C}(18)$ & $119.0(8)$ & $\mathrm{C}(29)-\mathrm{C}(30)-\mathrm{C}(31)$ & $108.6(8)$ \\
\hline $\mathrm{C}(20)-\mathrm{C}(19)-\mathrm{C}(5)$ & $122.0(8)$ & $\mathrm{C}(32)-\mathrm{C}(31)-\mathrm{C}(48)$ & $120.3(9)$ \\
\hline $\mathrm{C}(18)-\mathrm{C}(19)-\mathrm{C}(5)$ & 109.4(7) & $\mathrm{C}(32)-\mathrm{C}(31)-\mathrm{C}(30)$ & $119.5(8)$ \\
\hline $\mathrm{C}(19)-\mathrm{C}(20)-\mathrm{C}(38)$ & $120.7(8)$ & $\mathrm{C}(48)-\mathrm{C}(31)-\mathrm{C}(30)$ & $107.7(8)$ \\
\hline $\mathrm{C}(19)-\mathrm{C}(20)-\mathrm{C}(21)$ & $119.5(8)$ & $\mathrm{C}(31)-\mathrm{C}(32)-\mathrm{C}(33)$ & $119.9(8)$ \\
\hline $\mathrm{C}(38)-\mathrm{C}(20)-\mathrm{C}(21)$ & 107.4(8) & $\mathrm{C}(31)-\mathrm{C}(32)-\mathrm{C}(15)$ & $119.8(8)$ \\
\hline$C(7)-C(21)-C(22)$ & $119.7(8)$ & $\mathrm{C}(33)-\mathrm{C}(32)-\mathrm{C}(15)$ & $108.9(7)$ \\
\hline$C(7)-C(21)-C(20)$ & $119.2(8)$ & $\mathrm{C}(50)-\mathrm{C}(33)-\mathrm{C}(32)$ & $121.4(8)$ \\
\hline $\mathrm{C}(22)-\mathrm{C}(21)-\mathrm{C}(20)$ & $107.8(8)$ & $\mathrm{C}(50)-\mathrm{C}(33)-\mathrm{C}(34)$ & $119.2(8)$ \\
\hline $\mathrm{C}(23)-\mathrm{C}(22)-\mathrm{C}(21)$ & $120.7(8)$ & $\mathrm{C}(32)-\mathrm{C}(33)-\mathrm{C}(34)$ & $108.5(8)$ \\
\hline $\mathrm{C}(23)-\mathrm{C}(22)-\mathrm{C}(39)$ & $120.4(8)$ & $\mathrm{C}(35)-\mathrm{C}(34)-\mathrm{C}(33)$ & $119.8(8)$ \\
\hline $\mathrm{C}(21)-\mathrm{C}(22)-\mathrm{C}(39)$ & $108.1(8)$ & $C(35)-C(34)-C(16)$ & $119.2(8)$ \\
\hline $\mathrm{C}(22)-\mathrm{C}(23)-\mathrm{C}(42)$ & $119.7(9)$ & $\mathrm{C}(33)-\mathrm{C}(34)-\mathrm{C}(16)$ & $107.9(8)$ \\
\hline $\mathrm{C}(22)-\mathrm{C}(23)-\mathrm{C}(24)$ & $119.9(8)$ & $\mathrm{C}(34)-\mathrm{C}(35)-\mathrm{C}(36)$ & $120.9(8)$ \\
\hline $\mathrm{C}(42)-\mathrm{C}(23)-\mathrm{C}(24)$ & $107.5(8)$ & $\mathrm{C}(34)-\mathrm{C}(35)-\mathrm{C}(52)$ & $120.3(8)$ \\
\hline
\end{tabular}




\begin{tabular}{|c|c|c|c|}
\hline $\mathrm{C}(8)-\mathrm{C}(24)-\mathrm{C}(25)$ & $119.6(8)$ & $\mathrm{C}(36)-\mathrm{C}(35)-\mathrm{C}(52)$ & $107.4(8)$ \\
\hline $\mathrm{C}(8)-\mathrm{C}(24)-\mathrm{C}(23)$ & $119.4(8)$ & $\mathrm{C}(18)-\mathrm{C}(36)-\mathrm{C}(37)$ & $119.4(8)$ \\
\hline$C(18)-C(36)-C(35)$ & $119.5(8)$ & $\mathrm{C}(49)-\mathrm{C}(48)-\mathrm{C}(31)$ & $119.5(8)$ \\
\hline $\mathrm{C}(37)-\mathrm{C}(36)-\mathrm{C}(35)$ & $108.8(8)$ & $\mathrm{C}(49)-\mathrm{C}(48)-\mathrm{C}(47)$ & $119.4(8)$ \\
\hline $\mathrm{C}(38)-\mathrm{C}(37)-\mathrm{C}(36)$ & $120.1(8)$ & $\mathrm{C}(31)-\mathrm{C}(48)-\mathrm{C}(47)$ & $108.5(8)$ \\
\hline $\mathrm{C}(38)-\mathrm{C}(37)-\mathrm{C}(53)$ & 119.4(8) & $\mathrm{C}(48)-\mathrm{C}(49)-\mathrm{C}(59)$ & $119.5(8)$ \\
\hline $\mathrm{C}(36)-\mathrm{C}(37)-\mathrm{C}(53)$ & $107.6(8)$ & $\mathrm{C}(48)-\mathrm{C}(49)-\mathrm{C}(50)$ & 120.3(9) \\
\hline $\mathrm{C}(37)-\mathrm{C}(38)-\mathrm{C}(20)$ & $120.1(8)$ & $\mathrm{C}(59)-\mathrm{C}(49)-\mathrm{C}(50)$ & 108.1(8) \\
\hline $\mathrm{C}(37)-\mathrm{C}(38)-\mathrm{C}(39)$ & $120.0(8)$ & $\mathrm{C}(33)-\mathrm{C}(50)-\mathrm{C}(51)$ & $121.5(8)$ \\
\hline $\mathrm{C}(20)-\mathrm{C}(38)-\mathrm{C}(39)$ & 109.2(8) & $\mathrm{C}(33)-\mathrm{C}(50)-\mathrm{C}(49)$ & $118.7(9)$ \\
\hline $\mathrm{C}(40)-\mathrm{C}(39)-\mathrm{C}(38)$ & $121.0(8)$ & $\mathrm{C}(51)-\mathrm{C}(50)-\mathrm{C}(49)$ & 107.1(8) \\
\hline$C(40)-C(39)-C(22)$ & $118.7(8)$ & $\mathrm{C}(52)-\mathrm{C}(51)-\mathrm{C}(50)$ & 119.6(9) \\
\hline $\mathrm{C}(38)-\mathrm{C}(39)-\mathrm{C}(22)$ & $107.4(8)$ & $\mathrm{C}(52)-\mathrm{C}(51)-\mathrm{C}(60)$ & $119.5(8)$ \\
\hline$C(39)-C(40)-C(41)$ & $121.3(9)$ & $\mathrm{C}(50)-\mathrm{C}(51)-\mathrm{C}(60)$ & $109.2(8)$ \\
\hline$C(39)-C(40)-C(54)$ & $118.8(9)$ & $\mathrm{C}(51)-\mathrm{C}(52)-\mathrm{C}(53)$ & $119.8(8)$ \\
\hline $\mathrm{C}(41)-\mathrm{C}(40)-\mathrm{C}(54)$ & $107.9(8)$ & $\mathrm{C}(51)-\mathrm{C}(52)-\mathrm{C}(35)$ & $119.5(9)$ \\
\hline $\mathrm{C}(42)-\mathrm{C}(41)-\mathrm{C}(40)$ & 119.9(8) & $\mathrm{C}(53)-\mathrm{C}(52)-\mathrm{C}(35)$ & $108.5(8)$ \\
\hline$C(42)-C(41)-C(56)$ & 118.3(8) & $\mathrm{C}(54)-\mathrm{C}(53)-\mathrm{C}(52)$ & $121.0(8)$ \\
\hline $\mathrm{C}(40)-\mathrm{C}(41)-\mathrm{C}(56)$ & $110.0(8)$ & $\mathrm{C}(54)-\mathrm{C}(53)-\mathrm{C}(37)$ & $119.5(9)$ \\
\hline $\mathrm{C}(41)-\mathrm{C}(42)-\mathrm{C}(43)$ & $121.5(8)$ & $\mathrm{C}(52)-\mathrm{C}(53)-\mathrm{C}(37)$ & $107.8(8)$ \\
\hline$C(41)-C(42)-C(23)$ & $119.9(8)$ & $\mathrm{C}(53)-\mathrm{C}(54)-\mathrm{C}(40)$ & 121.2(9) \\
\hline$C(43)-C(42)-C(23)$ & 108.3(8) & $\mathrm{C}(53)-\mathrm{C}(54)-\mathrm{C}(55)$ & $118.6(8)$ \\
\hline $\mathrm{C}(44)-\mathrm{C}(43)-\mathrm{C}(42)$ & $119.2(9)$ & $\mathrm{C}(40)-\mathrm{C}(54)-\mathrm{C}(55)$ & $107.6(8)$ \\
\hline $\mathrm{C}(44)-\mathrm{C}(43)-\mathrm{C}(25)$ & $119.8(8)$ & $C(60)-C(55)-C(54)$ & $121.0(9)$ \\
\hline$C(42)-C(43)-C(25)$ & $108.2(8)$ & $C(60)-C(55)-C(56)$ & $120.6(8)$ \\
\hline $\mathrm{C}(43)-\mathrm{C}(44)-\mathrm{C}(57)$ & $120.1(8)$ & $\mathrm{C}(54)-\mathrm{C}(55)-\mathrm{C}(56)$ & 108.3(8) \\
\hline $\mathrm{C}(43)-\mathrm{C}(44)-\mathrm{C}(45)$ & $119.6(8)$ & $C(57)-C(56)-C(41)$ & $120.8(9)$ \\
\hline$C(57)-C(44)-C(45)$ & $106.4(8)$ & $C(57)-C(56)-C(55)$ & $118.8(8)$ \\
\hline$C(27)-C(45)-C(46)$ & $120.4(8)$ & $C(41)-C(56)-C(55)$ & 106.1(8) \\
\hline $\mathrm{C}(27)-\mathrm{C}(45)-\mathrm{C}(44)$ & $119.7(8)$ & $\mathrm{C}(56)-\mathrm{C}(57)-\mathrm{C}(44)$ & $120.0(8)$ \\
\hline $\mathrm{C}(46)-\mathrm{C}(45)-\mathrm{C}(44)$ & $108.1(8)$ & $\mathrm{C}(56)-\mathrm{C}(57)-\mathrm{C}(58)$ & $120.6(8)$ \\
\hline $\mathrm{C}(47)-\mathrm{C}(46)-\mathrm{C}(58)$ & $119.6(9)$ & $\mathrm{C}(44)-\mathrm{C}(57)-\mathrm{C}(58)$ & 109.3(8) \\
\hline $\mathrm{C}(47)-\mathrm{C}(46)-\mathrm{C}(45)$ & $120.2(8)$ & $\mathrm{C}(59)-\mathrm{C}(58)-\mathrm{C}(46)$ & $121.0(9)$ \\
\hline $\mathrm{C}(58)-\mathrm{C}(46)-\mathrm{C}(45)$ & $108.7(8)$ & $\mathrm{C}(59)-\mathrm{C}(58)-\mathrm{C}(57)$ & $119.3(9)$ \\
\hline$C(46)-C(47)-C(48)$ & $120.7(9)$ & $\mathrm{C}(46)-\mathrm{C}(58)-\mathrm{C}(57)$ & $107.5(8)$ \\
\hline $\mathrm{C}(46)-\mathrm{C}(47)-\mathrm{C}(29)$ & $120.2(8)$ & $\mathrm{C}(58)-\mathrm{C}(59)-\mathrm{C}(60)$ & $120.6(8)$ \\
\hline $\mathrm{C}(48)-\mathrm{C}(47)-\mathrm{C}(29)$ & $107.6(8)$ & $\mathrm{C}(58)-\mathrm{C}(59)-\mathrm{C}(49)$ & $119.8(9)$ \\
\hline $\mathrm{C}(60)-\mathrm{C}(59)-\mathrm{C}(49)$ & $108.3(8)$ & SAA-CA-SA & $171.2(11)$ \\
\hline$C(55)-C(60)-C(59)$ & $120.0(9)$ & SB-CB-SBB & $157(2)$ \\
\hline$C(55)-C(60)-C(51)$ & $120.0(8)$ & SCC-CC-SC & $177.6(16)$ \\
\hline $\mathrm{C}(59)-\mathrm{C}(60)-\mathrm{C}(51)$ & $107.3(8)$ & SDD-CD-SD & $175.5(12)$ \\
\hline
\end{tabular}

Symmetry transformations used to generate equivalent atoms: 
Table S6. Anisotropic displacement parameters $\left(\AA^{2} \times 10^{3}\right)$ for 3 . The anisotropic displacement factor exponent takes the form : $-2 \mathrm{pi}^{2}\left[\mathrm{~h}^{2} \mathrm{a}^{2} \mathrm{U} 11+\ldots+2 \mathrm{hka} * \mathrm{~b} * \mathrm{U} 12\right]$

\begin{tabular}{|c|c|c|c|c|c|c|}
\hline & U11 & U22 & U33 & U23 & U13 & U12 \\
\hline $\operatorname{Ir}(1)$ & $16(1)$ & $21(1)$ & $23(1)$ & $-1(1)$ & $5(1)$ & $1(1)$ \\
\hline $\operatorname{Ir}(2)$ & 15(1) & $20(1)$ & 21(1) & $0(1)$ & $4(1)$ & $-1(1)$ \\
\hline $\operatorname{Ir}(3)$ & 15(1) & $27(1)$ & $23(1)$ & $2(1)$ & 1(1) & $-1(1)$ \\
\hline $\operatorname{Ir}(4)$ & $15(1)$ & $24(1)$ & $28(1)$ & $-1(1)$ & $4(1)$ & $-2(1)$ \\
\hline $\mathrm{P}(1)$ & $16(1)$ & $35(1)$ & $31(1)$ & $0(1)$ & $3(1)$ & $-2(1)$ \\
\hline $\mathrm{P}(2)$ & $15(1)$ & $27(1)$ & $27(1)$ & $-1(1)$ & 7(1) & 1(1) \\
\hline $\mathrm{P}(3)$ & $22(1)$ & $24(1)$ & $23(1)$ & $-2(1)$ & $5(1)$ & $-1(1)$ \\
\hline $\mathrm{C}(1 \mathrm{~A})$ & $33(6)$ & $32(6)$ & $36(6)$ & $0(5)$ & $18(4)$ & $-10(5)$ \\
\hline $\mathrm{O}(1 \mathrm{~A})$ & $69(6)$ & $29(4)$ & 101(7) & $-11(4)$ & $43(5)$ & $6(4)$ \\
\hline $\mathrm{C}(2 \mathrm{~A})$ & $25(5)$ & $25(5)$ & $23(5)$ & $-1(4)$ & $1(4)$ & 1(4) \\
\hline $\mathrm{O}(2 \mathrm{~A})$ & $50(5)$ & $29(4)$ & $42(4)$ & $-11(3)$ & $-2(3)$ & 6(3) \\
\hline $\mathrm{C}(3 \mathrm{~A})$ & 11(5) & $55(7)$ & $50(7)$ & $14(5)$ & $9(4)$ & $9(5)$ \\
\hline $\mathrm{O}(3 \mathrm{~A})$ & $38(4)$ & $51(5)$ & $79(6)$ & $17(4)$ & $17(4)$ & $24(4)$ \\
\hline $\mathrm{C}(3 \mathrm{~B})$ & $28(5)$ & $39(6)$ & $30(6)$ & $-9(5)$ & $-1(4)$ & $-11(4)$ \\
\hline $\mathrm{O}(3 \mathrm{~B})$ & $61(6)$ & $89(6)$ & $40(5)$ & $-16(5)$ & $-1(4)$ & $-18(5)$ \\
\hline $\mathrm{C}(4 \mathrm{~A})$ & $21(5)$ & $36(6)$ & $39(6)$ & 4(5) & $2(4)$ & $-3(4)$ \\
\hline $\mathrm{O}(4 \mathrm{~A})$ & $65(5)$ & $56(5)$ & $48(5)$ & $-24(4)$ & 14(4) & $-8(4)$ \\
\hline $\mathrm{C}(4 \mathrm{~B})$ & $41(6)$ & $27(5)$ & $45(6)$ & $5(5)$ & $13(5)$ & $0(5)$ \\
\hline $\mathrm{O}(4 \mathrm{~B})$ & $86(7)$ & $60(5)$ & $67(6)$ & $35(5)$ & $16(5)$ & $-7(5)$ \\
\hline $\mathrm{C}(101)$ & $18(5)$ & $46(6)$ & $40(6)$ & $-2(5)$ & $-5(4)$ & $-7(4)$ \\
\hline$C(102)$ & $42(8)$ & $145(14)$ & $58(9)$ & 21(9) & $6(6)$ & $-40(8)$ \\
\hline$C(103)$ & $52(9)$ & 193(18) & $43(8)$ & $34(10)$ & $-8(7)$ & $-26(10)$ \\
\hline$C(104)$ & $43(7)$ & $110(11)$ & $38(7)$ & $9(7)$ & $-3(6)$ & $-1(7)$ \\
\hline$C(105)$ & $33(7)$ & $117(12)$ & $62(9)$ & $-6(8)$ & $-7(6)$ & $-24(7)$ \\
\hline$C(106)$ & $34(7)$ & $109(11)$ & $52(8)$ & $9(7)$ & $4(6)$ & $-21(7)$ \\
\hline $\mathrm{C}(201)$ & $16(5)$ & $33(6)$ & $48(6)$ & $-7(5)$ & $-1(4)$ & $-8(4)$ \\
\hline $\mathrm{C}(202)$ & $52(7)$ & $48(7)$ & $64(8)$ & $-17(6)$ & $28(6)$ & $-12(6)$ \\
\hline$C(203)$ & $50(7)$ & $48(7)$ & $93(10)$ & $-17(7)$ & $31(7)$ & $-31(6)$ \\
\hline $\mathrm{C}(204)$ & $64(8)$ & $58(8)$ & $81(10)$ & $4(7)$ & 43(7) & $-31(7)$ \\
\hline$C(205)$ & $43(7)$ & $43(7)$ & $69(8)$ & $-8(6)$ & $28(6)$ & $-6(5)$ \\
\hline$C(206)$ & $25(5)$ & $37(6)$ & $44(6)$ & $-1(5)$ & $15(4)$ & 1(4) \\
\hline $\mathrm{C}(301)$ & $25(5)$ & $26(5)$ & $36(6)$ & $3(4)$ & $4(4)$ & $-4(4)$ \\
\hline $\mathrm{C}(302)$ & $19(5)$ & $38(6)$ & $48(6)$ & $5(5)$ & $3(4)$ & $4(4)$ \\
\hline $\mathrm{C}(303)$ & $39(6)$ & $39(6)$ & $60(8)$ & $14(6)$ & $7(6)$ & $13(5)$ \\
\hline$C(304)$ & $35(6)$ & $29(5)$ & $55(7)$ & $-10(5)$ & $16(5)$ & $3(5)$ \\
\hline $\mathrm{C}(305)$ & $26(5)$ & $29(5)$ & $36(6)$ & $-4(4)$ & $14(4)$ & $3(4)$ \\
\hline $\mathrm{C}(306)$ & $22(5)$ & $22(5)$ & $30(5)$ & $6(4)$ & $4(4)$ & $3(4)$ \\
\hline $\mathrm{C}(401)$ & $24(5)$ & $18(5)$ & $36(6)$ & $-6(4)$ & $6(4)$ & $2(4)$ \\
\hline $\mathrm{C}(402)$ & $27(5)$ & $46(6)$ & $47(7)$ & $-1(5)$ & $5(5)$ & $-1(5)$ \\
\hline $\mathrm{C}(403)$ & $38(6)$ & $54(7)$ & $44(7)$ & $8(5)$ & $22(5)$ & $-6(5)$ \\
\hline $\mathrm{C}(404)$ & $43(6)$ & $56(7)$ & $26(5)$ & $1(5)$ & $12(5)$ & $6(5)$ \\
\hline $\mathrm{C}(405)$ & $25(5)$ & $43(6)$ & $34(6)$ & $2(5)$ & $16(4)$ & $-1(4)$ \\
\hline $\mathrm{C}(406)$ & $21(5)$ & 19(4) & $26(5)$ & 1(4) & $7(4)$ & $0(3)$ \\
\hline $\mathrm{C}(501)$ & $20(5)$ & $26(5)$ & $21(5)$ & $-1(4)$ & $1(4)$ & $-1(4)$ \\
\hline $\mathrm{C}(502)$ & $10(4)$ & $29(5)$ & $27(5)$ & $2(4)$ & $5(4)$ & $1(4)$ \\
\hline $\mathrm{C}(503)$ & $49(6)$ & $25(5)$ & $20(5)$ & $-3(4)$ & $0(4)$ & $-3(4)$ \\
\hline $\mathrm{C}(504)$ & $57(7)$ & $27(5)$ & $31(6)$ & $6(5)$ & $-4(5)$ & $12(5)$ \\
\hline $\mathrm{C}(505)$ & $39(6)$ & $35(6)$ & $30(6)$ & $5(5)$ & $1(4)$ & $6(5)$ \\
\hline $\mathrm{C}(506)$ & $34(5)$ & $36(6)$ & $25(5)$ & $-5(4)$ & $2(4)$ & $-2(4)$ \\
\hline $\mathrm{C}(601)$ & $40(6)$ & $21(5)$ & $17(5)$ & $5(4)$ & $4(4)$ & $-2(4)$ \\
\hline$C(602)$ & $43(6)$ & $34(6)$ & $41(6)$ & $-7(5)$ & $13(5)$ & $-2(5)$ \\
\hline $\mathrm{C}(603)$ & $75(9)$ & $34(6)$ & $42(7)$ & $-11(5)$ & $24(6)$ & $-1(6)$ \\
\hline $\mathrm{C}(604)$ & $62(8)$ & $39(6)$ & $35(6)$ & $-8(5)$ & $4(5)$ & $-21(6)$ \\
\hline
\end{tabular}




\begin{tabular}{|c|c|c|c|c|c|c|}
\hline $\mathrm{C}(605)$ & $44(6)$ & $41(6)$ & $37(6)$ & $9(5)$ & $1(5)$ & $-10(5)$ \\
\hline $\mathrm{C}(606)$ & $33(5)$ & $29(5)$ & $21(5)$ & $-2(4)$ & $5(4)$ & $-3(4)$ \\
\hline$C(1)$ & $23(5)$ & 13(4) & $25(5)$ & $0(4)$ & $8(4)$ & $5(3)$ \\
\hline $\mathrm{C}(2)$ & $22(5)$ & $21(5)$ & 18(4) & $-2(4)$ & $3(4)$ & $-3(4)$ \\
\hline $\mathrm{C}(3)$ & $16(4)$ & $23(4)$ & $20(4)$ & $3(4)$ & $10(3)$ & $-2(4)$ \\
\hline C(4) & $13(4)$ & $15(4)$ & 19(4) & $-2(3)$ & $3(3)$ & $-1(3)$ \\
\hline$C(5)$ & $14(4)$ & $23(5)$ & $24(5)$ & $-2(4)$ & $0(4)$ & $-6(3)$ \\
\hline$C(6)$ & $5(4)$ & $28(5)$ & $22(4)$ & $-1(4)$ & 1(3) & $5(3)$ \\
\hline $\mathrm{C}(7)$ & $12(4)$ & $22(4)$ & $27(5)$ & $8(4)$ & $-3(4)$ & $0(4)$ \\
\hline$C(8)$ & $20(5)$ & $20(5)$ & $32(5)$ & $5(4)$ & $3(4)$ & $4(4)$ \\
\hline$C(9)$ & $19(5)$ & 21(4) & $31(5)$ & $-2(4)$ & $3(4)$ & 9(4) \\
\hline$C(10)$ & $20(5)$ & $22(5)$ & $33(5)$ & $-7(4)$ & $12(4)$ & $-1(4)$ \\
\hline $\mathrm{C}(11)$ & $21(5)$ & $25(5)$ & $20(5)$ & $-15(4)$ & $10(4)$ & $-4(4)$ \\
\hline $\mathrm{C}(12)$ & 21(4) & $27(5)$ & 11(4) & $-6(4)$ & 6(3) & $4(4)$ \\
\hline $\mathrm{C}(13)$ & $23(5)$ & $26(5)$ & $17(4)$ & $3(4)$ & 6(4) & $-6(4)$ \\
\hline $\mathrm{C}(14)$ & 20(4) & $34(5)$ & $11(4)$ & $11(4)$ & $4(3)$ & $3(4)$ \\
\hline $\mathrm{C}(15)$ & 18(4) & 19(4) & $31(5)$ & $13(4)$ & 2(4) & $8(4)$ \\
\hline$C(16)$ & $35(5)$ & $18(4)$ & $26(5)$ & $-1(4)$ & $14(4)$ & $3(4)$ \\
\hline $\mathrm{C}(17)$ & $23(5)$ & $15(4)$ & $26(5)$ & $-7(4)$ & $5(4)$ & $0(3)$ \\
\hline $\mathrm{C}(18)$ & $22(5)$ & $21(5)$ & $31(5)$ & $-10(4)$ & $7(4)$ & $-6(4)$ \\
\hline$C(19)$ & $16(4)$ & $26(5)$ & $27(5)$ & $-5(4)$ & $5(4)$ & $-7(4)$ \\
\hline$C(20)$ & $20(5)$ & $40(6)$ & $21(5)$ & $-2(4)$ & $-8(4)$ & $-7(4)$ \\
\hline $\mathrm{C}(21)$ & $16(5)$ & $41(6)$ & 19(5) & $5(4)$ & $-4(4)$ & $5(4)$ \\
\hline $\mathrm{C}(22)$ & $26(5)$ & $28(5)$ & $19(5)$ & $11(4)$ & $-2(4)$ & $1(4)$ \\
\hline $\mathrm{C}(23)$ & $23(5)$ & $30(5)$ & $33(6)$ & $17(4)$ & $3(4)$ & $7(4)$ \\
\hline$C(24)$ & $25(5)$ & $15(4)$ & $31(5)$ & $9(4)$ & $9(4)$ & $6(4)$ \\
\hline$C(25)$ & $29(5)$ & $13(4)$ & $42(6)$ & $5(4)$ & 11(4) & $-5(4)$ \\
\hline$C(26)$ & $26(5)$ & $19(5)$ & $36(6)$ & $-6(4)$ & $12(4)$ & $-2(4)$ \\
\hline $\mathrm{C}(27)$ & $36(6)$ & $15(4)$ & $33(5)$ & $-6(4)$ & $5(4)$ & $-9(4)$ \\
\hline $\mathrm{C}(28)$ & $23(5)$ & $30(5)$ & $26(5)$ & $-8(4)$ & $3(4)$ & $-8(4)$ \\
\hline $\mathrm{C}(29)$ & $26(5)$ & $32(5)$ & $24(5)$ & $-3(4)$ & 2(4) & $-16(4)$ \\
\hline $\mathrm{C}(30)$ & $18(5)$ & $39(5)$ & $15(4)$ & $3(4)$ & $-5(4)$ & $-6(4)$ \\
\hline $\mathrm{C}(31)$ & $15(5)$ & $37(5)$ & $29(5)$ & $15(4)$ & $-7(4)$ & 1(4) \\
\hline $\mathrm{C}(32)$ & $20(5)$ & $27(5)$ & $27(5)$ & $16(4)$ & $-5(4)$ & $9(4)$ \\
\hline $\mathrm{C}(33)$ & $17(5)$ & $22(5)$ & $42(6)$ & $8(4)$ & $13(4)$ & $12(4)$ \\
\hline $\mathrm{C}(34)$ & $33(5)$ & $13(4)$ & $37(6)$ & $2(4)$ & $15(4)$ & $3(4)$ \\
\hline$C(35)$ & $23(5)$ & $27(5)$ & $41(6)$ & $-11(4)$ & $13(4)$ & $-5(4)$ \\
\hline$C(36)$ & $27(5)$ & $23(5)$ & $31(5)$ & $-11(4)$ & $3(4)$ & $2(4)$ \\
\hline $\mathrm{C}(37)$ & $36(5)$ & $36(5)$ & $13(4)$ & $-6(4)$ & $10(4)$ & $-3(4)$ \\
\hline $\mathrm{C}(38)$ & $22(5)$ & $45(6)$ & $12(4)$ & $-3(4)$ & $0(4)$ & $0(4)$ \\
\hline $\mathrm{C}(39)$ & $25(5)$ & $40(6)$ & $18(5)$ & $7(4)$ & $-1(4)$ & $-1(4)$ \\
\hline $\mathrm{C}(40)$ & $32(5)$ & $44(6)$ & $23(5)$ & $12(5)$ & $8(4)$ & $6(5)$ \\
\hline $\mathrm{C}(41)$ & $23(5)$ & $32(5)$ & $30(5)$ & $12(4)$ & $12(4)$ & $-7(4)$ \\
\hline $\mathrm{C}(42)$ & $40(6)$ & $23(5)$ & $32(6)$ & $21(4)$ & $5(4)$ & 1(4) \\
\hline $\mathrm{C}(43)$ & $33(5)$ & $15(4)$ & $40(6)$ & $8(4)$ & $11(4)$ & $-4(4)$ \\
\hline $\mathrm{C}(44)$ & $22(5)$ & $27(5)$ & $37(6)$ & 2(4) & $10(4)$ & $-13(4)$ \\
\hline $\mathrm{C}(45)$ & $17(5)$ & $24(5)$ & $40(6)$ & $-6(4)$ & 2(4) & $-9(4)$ \\
\hline $\mathrm{C}(46)$ & $15(5)$ & $37(6)$ & $35(6)$ & $-4(5)$ & 4(4) & $-12(4)$ \\
\hline $\mathrm{C}(47)$ & 21(5) & $34(5)$ & $27(5)$ & $-7(4)$ & $-4(4)$ & $-8(4)$ \\
\hline $\mathrm{C}(48)$ & $13(5)$ & $40(6)$ & $30(5)$ & $9(4)$ & $-8(4)$ & $6(4)$ \\
\hline $\mathrm{C}(49)$ & $13(5)$ & $33(5)$ & $40(6)$ & $5(5)$ & $3(4)$ & $6(4)$ \\
\hline $\mathrm{C}(50)$ & 12(4) & $36(5)$ & $42(6)$ & $6(5)$ & 1(4) & $12(4)$ \\
\hline $\mathrm{C}(51)$ & $20(5)$ & $40(6)$ & $37(6)$ & $-5(5)$ & $14(4)$ & $5(4)$ \\
\hline $\mathrm{C}(52)$ & $28(5)$ & $27(5)$ & $45(6)$ & $-6(5)$ & $25(5)$ & 2(4) \\
\hline $\mathrm{C}(53)$ & $28(5)$ & $46(6)$ & $23(5)$ & $-9(4)$ & $18(4)$ & $-5(4)$ \\
\hline $\mathrm{C}(54)$ & $35(6)$ & $43(6)$ & $21(5)$ & $4(4)$ & $19(4)$ & $-6(5)$ \\
\hline$C(55)$ & $17(5)$ & $40(6)$ & $34(5)$ & $-3(5)$ & $10(4)$ & $-9(4)$ \\
\hline
\end{tabular}




\begin{tabular}{|lcccccc|}
\hline $\mathrm{C}(56)$ & $30(5)$ & $30(5)$ & $29(5)$ & $9(4)$ & $13(4)$ & $-6(4)$ \\
\hline $\mathrm{C}(57)$ & $26(5)$ & $26(5)$ & $35(6)$ & $-2(4)$ & $16(4)$ & $-14(4)$ \\
\hline $\mathrm{C}(58)$ & $9(4)$ & $33(5)$ & $50(6)$ & $-1(5)$ & $5(4)$ & $-7(4)$ \\
\hline $\mathrm{C}(59)$ & $8(4)$ & $39(6)$ & $46(6)$ & $6(5)$ & $5(4)$ & $-5(4)$ \\
\hline $\mathrm{C}(60)$ & $18(5)$ & $41(6)$ & $44(6)$ & $6(5)$ & $20(4)$ & $-3(4)$ \\
\hline $\mathrm{CA}$ & $76(10)$ & $45(7)$ & $93(11)$ & $-2(7)$ & $37(8)$ & $-4(7)$ \\
\hline SA & $74(3)$ & $94(4)$ & $374(11)$ & $-30(5)$ & $8(5)$ & $-10(3)$ \\
\hline SAA & $128(4)$ & $72(3)$ & $69(3)$ & $14(2)$ & $0(2)$ & $12(3)$ \\
\hline CB & $450(50)$ & $120(18)$ & $96(17)$ & $-1(14)$ & $90(20)$ & $-10(20)$ \\
\hline SB & $248(10)$ & $256(11)$ & $282(12)$ & $84(9)$ & $87(9)$ & $-45(8)$ \\
\hline SBB & $580(30)$ & $336(15)$ & $229(12)$ & $119(11)$ & $186(13)$ & $49(15)$ \\
\hline CC & $180(20)$ & $123(16)$ & $99(15)$ & $27(12)$ & $72(14)$ & $-4(15)$ \\
\hline SC & $434(15)$ & $314(11)$ & $172(7)$ & $115(8)$ & $-134(9)$ & $-275(11)$ \\
\hline SCC & $191(6)$ & $248(8)$ & $91(4)$ & $44(5)$ & $28(4)$ & $112(6)$ \\
\hline CD & $77(10)$ & $84(10)$ & $67(9)$ & $4(8)$ & $3(8)$ & $25(8)$ \\
\hline SD & $143(4)$ & $126(4)$ & $82(3)$ & $-12(3)$ & $-7(3)$ & $31(3)$ \\
\hline SDD & $122(4)$ & $97(3)$ & $81(3)$ & $15(2)$ & $10(3)$ & $24(3)$ \\
\hline
\end{tabular}


Table S7. Atomic coordinates $\left(\times 10^{4}\right)$ and equivalent isotropic displacement parameters $\left(\AA^{2} \times 10^{3}\right)$ for 5 . $\mathrm{U}(\mathrm{eq})$ is defined as one third of the trace of the orthogonalized Uij tensor.

\begin{tabular}{|c|c|c|c|c|}
\hline & $\mathrm{x}$ & $\mathrm{y}$ & $\mathrm{Z}$ & $\mathrm{U}(\mathrm{eq})$ \\
\hline $\operatorname{Ir}(1)$ & $5950(1)$ & $2760(1)$ & $3872(1)$ & $22(1)$ \\
\hline $\operatorname{Ir}(2)$ & $5562(1)$ & $3672(1)$ & $4636(1)$ & $21(1)$ \\
\hline $\operatorname{Ir}(3))$ & 6703(1) & 3181(1) & $5760(1)$ & $24(1)$ \\
\hline $\operatorname{Ir}(4)$ & $7045(1)$ & $2358(1)$ & $5038(1)$ & $27(1)$ \\
\hline $\mathrm{C}(100)$ & $6595(8)$ & $3159(6)$ & 4771(5) & $31(3)$ \\
\hline $\mathrm{C}(200)$ & $7130(11)$ & $4582(6)$ & $5807(7)$ & $47(4)$ \\
\hline $\mathrm{C}(300)$ & $8356(9)$ & $3962(8)$ & $5580(7)$ & $49(4)$ \\
\hline $\mathrm{C}(400)$ & $8217(9)$ & $3997(7)$ & $6809(6)$ & $41(4)$ \\
\hline $\mathrm{P}(2)$ & 7401(3) & $1478(2)$ & $4858(2)$ & $34(1)$ \\
\hline $\mathrm{C}(500)$ & $8427(10)$ & 1418(7) & $4907(7)$ & $44(4)$ \\
\hline $\mathrm{C}(600)$ & $7340(11)$ & $929(6)$ & $5379(7)$ & $49(5)$ \\
\hline $\mathrm{C}(700)$ & 6911(11) & $1195(7)$ & $4076(7)$ & $49(4)$ \\
\hline $\mathrm{P}(3)$ & $7551(3)$ & $2447(2)$ & $6115(2)$ & $34(1)$ \\
\hline $\mathrm{C}(800)$ & $8597(10)$ & 2571(7) & $6487(7)$ & $49(5)$ \\
\hline $\mathrm{C}(900)$ & $7439(11)$ & 1968(6) & $6689(7)$ & $45(4)$ \\
\hline $\mathrm{C}(1 \mathrm{~A})$ & $5789(9)$ & $2285(5)$ & $3186(6)$ & $31(3)$ \\
\hline $\mathrm{O}(1 \mathrm{~A})$ & $5689(8)$ & 1999(5) & 2764(5) & $58(3))$ \\
\hline $\mathrm{C}(2 \mathrm{~A})$ & $4885(9)$ & $4200(6)$ & $4753(6)$ & $30(3)$ \\
\hline $\mathrm{O}(2 \mathrm{~A})$ & $4443(6)$ & $4535(4)$ & $4805(5)$ & $39(3)$ \\
\hline $\mathrm{C}(3 \mathrm{~A})$ & $6478(9)$ & $3378(6$ & 6491(7) & $36(4)$ \\
\hline $\mathrm{O}(3 \mathrm{~A})$ & 6374(7) & $3520(5)$ & 6941(4) & $48(3)$ \\
\hline $\mathrm{N}(1)$ & $8501(9)$ & 2791(6) & $4753(7)$ & $54(4)$ \\
\hline $\mathrm{C}(101)$ & $9854(10)$ & $3045(9)$ & $5093(8)$ & $86(7)$ \\
\hline $\mathrm{C}(102)$ & 10191(15) & $3554(9)$ & $5079(10)$ & 174(16) \\
\hline $\mathrm{C}(103)$ & $10831(15)$ & $3727(8)$ & 5594(13) & $280(30)$ \\
\hline $\mathrm{C}(104)$ & $11135(11)$ & 3391(10) & 6121(10) & $140(12)$ \\
\hline $\mathrm{C}(105)$ & $10798(12)$ & 2881(9) & $6135(8)$ & 104(9) \\
\hline $\mathrm{C}(106)$ & $10158(12)$ & $2708(7)$ & $5620(10)$ & 132(11) \\
\hline $\mathrm{C}(107)$ & $9151(10)$ & 2951(10) & $4555(9)$ & $66(6)$ \\
\hline $\mathrm{C}(108)$ & 7987(9) & $2631(6)$ & $4865(6)$ & $33(3)$ \\
\hline $\mathrm{C}\left(1^{\prime}\right)$ & $6025(8)$ & $4270(5)$ & $4129(5)$ & 21(3) \\
\hline$C\left(2^{\prime}\right)$ & $5405(9)$ & $3936(6)$ & $3693(6)$ & $28(3)$ \\
\hline$C\left(3^{\prime}\right)$ & $5612(8)$ & $3483(5)$ & $3326(5)$ & $21(3)$ \\
\hline$C\left(4^{\prime}\right)$ & $6443(8)$ & $3382(5)$ & $3404(5)$ & $20(3)$ \\
\hline$C\left(5^{\prime}\right)$ & 7039(8) & 3794(5) & $3772(5)$ & $24(3)$ \\
\hline$C\left(6^{\prime}\right)$ & $6847(8)$ & 4204(5) & $4105(5)$ & $24(3)$ \\
\hline$C\left(7^{\prime}\right)$ & 7189(8) & $4740(6)$ & $4147(6)$ & $29(3)$ \\
\hline$C\left(8^{\prime}\right)$ & $6620(9)$ & $5150(5)$ & $4139(5)$ & $29(3)$ \\
\hline $\mathrm{C}\left(9^{\prime}\right)$ & 5889(9) & $4886(5)$ & $4087(6)$ & $25(3)$ \\
\hline $\mathrm{C}\left(10^{\prime}\right)$ & 5177(9) & $5106(5)$ & $3692(6)$ & $27(3)$ \\
\hline $\mathrm{C}\left(11^{\prime}\right)$ & 4573(9) & $4755(6)$ & $3268(6)$ & $30(3)$ \\
\hline $\mathrm{C}\left(12^{\prime}\right)$ & $4697(8)$ & $4202(5)$ & $3241(5)$ & $26(3)$ \\
\hline $\mathrm{C}\left(13^{\prime}\right)$ & $4448(8)$ & $3918(6)$ & $2649(5)$ & $28(3)$ \\
\hline $\mathrm{C}\left(14^{\prime}\right)$ & $5015(8)$ & $3512(6)$ & $2667(6)$ & $43(10)$ \\
\hline $\mathrm{C}\left(15^{\prime}\right)$ & $5223(8)$ & $3387(5)$ & $2142(5)$ & $24(3)$ \\
\hline $\mathrm{C}\left(16^{\prime}\right)$ & 6035(9) & $3299(5)$ & $2214(6)$ & $28(3)$ \\
\hline $\mathrm{C}\left(17^{\prime}\right)$ & $6629(9)$ & $3322(5)$ & $2804(6)$ & $26(3)$ \\
\hline $\mathrm{C}\left(18^{\prime}\right)$ & $7353(8)$ & $3609(6)$ & $2869(6)$ & $28(3)$ \\
\hline $\mathrm{C}\left(19^{\prime}\right)$ & $7607(8)$ & $3901(6)$ & $3466(6)$ & $29(3)$ \\
\hline $\mathrm{C}\left(20^{\prime}\right)$ & $7982(8)$ & $4405(6)$ & $3536(6)$ & $33(3)$ \\
\hline $\mathrm{C}\left(21^{\prime}\right)$ & 7764(9) & $4844(6)$ & $3879(6)$ & $37(4)$ \\
\hline $\mathrm{C}\left(22^{\prime}\right)$ & $7764(10))$ & $5358(6)$ & $3557(6)$ & $40(4)$ \\
\hline $\mathrm{C}\left(23^{\prime}\right)$ & $7188(10)$ & $5754(6)$ & $3528(7)$ & $41(4)$ \\
\hline
\end{tabular}




\begin{tabular}{|c|c|c|c|c|}
\hline $\mathrm{C}\left(24^{\prime}\right)$ & $6629(10)$ & $5653(6)$ & $3834(6)$ & $37(4)$ \\
\hline $\mathrm{C}\left(25^{\prime}\right)$ & $5885(10)$ & $5890(6)$ & $3441(7)$ & $38(4)$ \\
\hline $\mathrm{C}\left(26^{\prime}\right)$ & $5189(9)$ & $5616(6)$ & $3374(6)$ & $30(3)$ \\
\hline $\mathrm{C}\left(27^{\prime}\right)$ & $4574(9)$ & $5588(6)$ & 2751(6) & $35(4)$ \\
\hline $\mathrm{C}\left(29^{\prime}\right)$ & $3948(9)$ & $4786(6)$ & $2105(6)$ & $33(3)$ \\
\hline $\mathrm{C}\left(30^{\prime}\right)$ & $4065(8)$ & $4205(6)$ & $2080(6)$ & $30(3)$ \\
\hline $\mathrm{C}\left(31^{\prime}\right)$ & $4286(8)$ & $4084(6)$ & 1527(6) & $29(3)$ \\
\hline $\mathrm{C}\left(32^{\prime}\right)$ & 4832(9) & $3687(6)$ & $1562(6)$ & $28(3)$ \\
\hline $\mathrm{C}\left(33^{\prime}\right)$ & 5431(9) & $3785(6)$ & $1266(6)$ & $30(3)$ \\
\hline $\mathrm{C}\left(34^{\prime}\right)$ & $6169(9)$ & $3542(5)$ & $1670(6)$ & $28(3)$ \\
\hline $\mathrm{C}\left(35^{\prime}\right)$ & $6850(9)$ & $3809(6)$ & 1723(6) & $34(4)$ \\
\hline $\mathrm{C}\left(36^{\prime}\right)$ & $7472(9)$ & $3837(6)$ & $2343(7)$ & $34(3)$ \\
\hline $\mathrm{C}\left(37^{\prime}\right)$ & 7858(9) & $4372(7)$ & 2402(7) & $39(4)$ \\
\hline $\mathrm{C}\left(38^{\prime}\right)$ & 8103(9) & $4646(7)$ & 2987(7) & $37(4)$ \\
\hline $\mathrm{C}\left(39^{\prime}\right)$ & $7968(9)$ & $5233(7)$ & $3001(7)$ & $42(4)$ \\
\hline $\mathrm{C}\left(40^{\prime}\right)$ & $7603(10)$ & $5526(7)$ & $2434(7)$ & $44(4)$ \\
\hline $\mathrm{C}\left(41^{\prime}\right)$ & $7008(10)$ & $5943(6)$ & 2403(7) & $40(4)$ \\
\hline $\mathrm{C}\left(42^{\prime}\right)$ & 6818(11) & $6046(6)$ & $2946(7)$ & $42(4)$ \\
\hline $\mathrm{C}\left(43^{\prime}\right)$ & $6006(10)$ & $6135(6)$ & $2890(7)$ & $39(4)$ \\
\hline $\mathrm{C}\left(44^{\prime}\right)$ & $5411(11)$ & $6112(6)$ & $2293(7)$ & $41(4)$ \\
\hline $\mathrm{C}\left(45^{\prime}\right)$ & $4695(10)$ & $5833(6)$ & $2228(6)$ & $38(4)$ \\
\hline $\mathrm{C}\left(46^{\prime}\right)$ & $4442(9)$ & $5537(6)$ & $1627(6)$ & $34(3)$ \\
\hline $\mathrm{C}\left(47^{\prime}\right)$ & 4077(9) & $5033(6)$ & $1562(6)$ & $36(4)$ \\
\hline $\mathrm{C}\left(48^{\prime}\right)$ & $4271(9)$ & $4599(6)$ & $1206(6)$ & $34(4)$ \\
\hline $\mathrm{C}\left(49^{\prime}\right)$ & $4841(10)$ & $4692(6)$ & $915(6)$ & $40(4)$ \\
\hline $\mathrm{C}\left(50^{\prime}\right)$ & $5417(9)$ & $4275(6)$ & $945(5)$ & $30(3)$ \\
\hline $\mathrm{C}\left(51^{\prime}\right)$ & $6152(10)$ & $4551(6)$ & 1021(6) & $35(4)$ \\
\hline $\mathrm{C}\left(52^{\prime}\right)$ & $6865(10)$ & $4327(6)$ & $1405(6)$ & $37(4)$ \\
\hline $\mathrm{C}\left(53^{\prime}\right)$ & $7460(10)$ & $4672(7)$ & 1814(7) & $39(4)$ \\
\hline$C\left(54^{\prime}\right)$ & $7337(10)$ & $5239(7)$ & $1826(7)$ & $42(4)$ \\
\hline$C\left(55^{\prime}\right)$ & $6599(11)$ & $5476(7)$ & $1434(7)$ & $44(4)$ \\
\hline $\mathrm{C}\left(56^{\prime}\right)$ & $6398(11)$ & $5915(6)$ & 1790(6) & $40(4)$ \\
\hline$C\left(57^{\prime}\right)$ & $5617(11)$ & $5987(6)$ & 1736(6) & $38(4)$ \\
\hline$C\left(58^{\prime}\right)$ & $4998(10)$ & $5641(6)$ & 1321(6) & $40(4)$ \\
\hline$C\left(59^{\prime}\right)$ & $5200(9)$ & $5220(6)$ & 971(6) & $35(4)$ \\
\hline $\mathrm{C}\left(60^{\prime}\right)$ & $6025(10)$ & $5140(6)$ & 1037(6) & $37(4)$ \\
\hline $\mathrm{C}(1)$ & $5406(9)$ & $2175(5)$ & $4338(5)$ & $27(3)$ \\
\hline $\mathrm{C}(2)$ & $4861(8)$ & $2605(5)$ & $4029(5)$ & $21(3)$ \\
\hline$C(3)$ & $4657(8)$ & $3048(5)$ & $4402(6)$ & $24(3)$ \\
\hline $\mathrm{C}(4)$ & $5083(8)$ & $3049(5)$ & $5101(6)$ & $25(3)$ \\
\hline $\mathrm{C}(5)$ & $5693(8)$ & $2636(5)$ & $5455(5)$ & $24(3)$ \\
\hline$C(6)$ & $5872(8)$ & $2170(5)$ & $5053(6)$ & $22(3)$ \\
\hline$C(7)$ & $5120(2)$ & $7843(18)$ & $5378(9)$ & $27(9)$ \\
\hline $\mathrm{C}(8)$ & $5354(9)$ & $1268(6)$ & $4692(6)$ & $34(3)$ \\
\hline $\mathrm{C}(9)$ & $5140(9)$ & 1614(5) & 4130(6) & $28(3)$ \\
\hline $\mathrm{C}(10)$ & $4459(9)$ & 1494(5) & $3623(6)$ & $29(3)$ \\
\hline $\mathrm{C}(11)$ & $3923(9)$ & 1937(6) & $3313(6)$ & $28(3)$ \\
\hline $\mathrm{C}(12)$ & 4102(8) & $2465(6)$ & $3524(6)$ & $27(3)$ \\
\hline $\mathrm{C}(13)$ & $3508(8)$ & 2832(6) & $3582(6)$ & $27(3)$ \\
\hline $\mathrm{C}(14)$ & $3828(8)$ & $3169(6)$ & 4129(6) & $26(3)$ \\
\hline $\mathrm{C}(15)$ & $3396(9)$ & $3312(5)$ & 4498(6) & $28(3)$ \\
\hline $\mathrm{C}(16)$ & $3763(8)$ & 3311(5) & $5187(6)$ & $26(3)$ \\
\hline $\mathrm{C}(17)$ & $4535(9)$ & $3161(5)$ & $5465(6)$ & $26(3)$ \\
\hline $\mathrm{C}(18)$ & $4769(9)$ & $2798(6)$ & $6009(6)$ & $30(3)$ \\
\hline $\mathrm{C}(19)$ & $5400(8)$ & $2448(5)$ & 5972(5) & $23(3)$ \\
\hline $\mathrm{C}(20)$ & $5427(8)$ & 1909(5) & $6180(5)$ & $25(3)$ \\
\hline $\mathrm{C}(21)$ & $5588(9)$ & 1469(6) & $5796(6)$ & $32(3)$ \\
\hline
\end{tabular}




\begin{tabular}{|c|c|c|c|c|}
\hline $\mathrm{C}(22)$ & $5122(10)$ & $1006(6)$ & $5820(6)$ & $39(4)$ \\
\hline $\mathrm{C}(23)$ & $4786(10)$ & $664(6)$ & $5296(7)$ & $38(4)$ \\
\hline $\mathrm{C}(24)$ & $4907(10)$ & $795(6)$ & $4710(7)$ & $39(4)$ \\
\hline $\mathrm{C}(25)$ & $4201(10)$ & $679(5)$ & $4184(6)$ & $38(4)$ \\
\hline $\mathrm{C}(26)$ & $3971(10)$ & $1025(6)$ & $3662(6)$ & $36(4)$ \\
\hline $\mathrm{C}(27)$ & $3150(11)$ & 1174(6) & $3370(7)$ & $42(4)$ \\
\hline $\mathrm{C}(28)$ & $3118(9)$ & $1738(6)$ & $3149(6)$ & $28(3)$ \\
\hline $\mathrm{C}(29)$ & 2533(9) & $2088(6)$ & $3189(6)$ & $33(3)$ \\
\hline $\mathrm{C}(30)$ & 2713(9) & $2643(6)$ & $3406(6)$ & $31(3)$ \\
\hline $\mathrm{C}(31)$ & 2264(9) & 2791(6) & $3798(7)$ & $34(3)$ \\
\hline $\mathrm{C}(32)$ & 2589(9) & $3116(6)$ & 4331(6) & $32(3)$ \\
\hline $\mathrm{C}(33)$ & $2463(8)$ & $2986(6)$ & $4923(7)$ & $33(3)$ \\
\hline $\mathrm{C}(34)$ & $3191(9)$ & $3106(6)$ & $5449(6)$ & $32(3)$ \\
\hline $\mathrm{C}(35)$ & $3415(9)$ & $2770(6)$ & $5992(6)$ & $33(3)$ \\
\hline $\mathrm{C}(36)$ & $4227(9)$ & $2615(6)$ & $6275(6)$ & $30(3)$ \\
\hline $\mathrm{C}(37)$ & $4260(10)$ & $2050(6)$ & $6489(6)$ & $36(4)$ \\
\hline $\mathrm{C}(38)$ & $4844(10)$ & $1710(6)$ & $6427(6)$ & $34(4)$ \\
\hline $\mathrm{C}(39)$ & $4658(10)$ & 1149(6) & $6221(6)$ & $37(4)$ \\
\hline $\mathrm{C}(40)$ & $3876(10)$ & $958(6)$ & $6055(6)$ & $38(4)$ \\
\hline $\mathrm{C}(41)$ & $3535(11)$ & $603(6)$ & $5504(7)$ & $45(4)$ \\
\hline $\mathrm{C}(42)$ & $4009(12)$ & $458(6)$ & $5140(7)$ & $48(5)$ \\
\hline $\mathrm{C}(43)$ & $3618(11)$ & $478(6)$ & $4439(7)$ & $43(4)$ \\
\hline $\mathrm{C}(44)$ & $2843(11)$ & $623(6)$ & $4167(7)$ & $41(4)$ \\
\hline $\mathrm{C}(45)$ & $2609(11)$ & $977(6)$ & $3609(7)$ & $46(4)$ \\
\hline $\mathrm{C}(46)$ & 1994(11) & 1338(7) & $3655(7)$ & $46(4)$ \\
\hline $\mathrm{C}(47)$ & 1969(9) & 1884(7) & $3452(6)$ & $42(4)$ \\
\hline $\mathrm{C}(48)$ & 1791(10) & $2325(7)$ & $3827(7)$ & $43(4)$ \\
\hline $\mathrm{C}(49)$ & 1660(9) & $2200(7)$ & $4398(7)$ & $45(4)$ \\
\hline $\mathrm{C}(50)$ & $2010(10)$ & $2537(7)$ & 4959(7) & $42(4)$ \\
\hline $\mathrm{C}(51)$ & $2239(10)$ & $2188(7)$ & $5506(7)$ & $42(4)$ \\
\hline $\mathrm{C}(52)$ & $2932(9)$ & $2300(7)$ & $6017(6)$ & $38(4)$ \\
\hline $\mathrm{C}(53)$ & $3464(10)$ & $1855(6)$ & $6318(6)$ & $38(4)$ \\
\hline $\mathrm{C}(54)$ & $3280(11)$ & $1317(7)$ & 6108(6) & $43(4)$ \\
\hline $\mathrm{C}(56)$ & $2735(11)$ & $759(6)$ & $5213(7)$ & $42(4)$ \\
\hline $\mathrm{C}(57)$ & $2385(11)$ & $770(7)$ & $4560(8)$ & $49(5)$ \\
\hline $\mathrm{C}(58)$ & 1859(12) & $1218(7)$ & $4244(8)$ & $54(5)$ \\
\hline $\mathrm{C}(59)$ & $1686(10)$ & $1633(7)$ & $4608(7)$ & $46(4)$ \\
\hline $\mathrm{C}(60)$ & $2058(10)$ & $1624(7)$ & $5296(7)$ & $43(4)$ \\
\hline $\mathrm{C}(1 \mathrm{X})$ & $2868(12)$ & $9385(9)$ & $2485(10)$ & $68(6)$ \\
\hline$S(1 X)$ & $2422(5)$ & 9127(4) & $1842(4)$ & $121(3)$ \\
\hline $\mathrm{S}(1 \mathrm{Y})$ & $3227(5)$ & $9639(4)$ & $3134(4)$ & $124(3)$ \\
\hline $\mathrm{C}(2 \mathrm{X})$ & $8846(15)$ & 2447(9) & $2833(10)$ & $47(5)$ \\
\hline $\mathrm{S}(2 \mathrm{X})$ & $8182(10)$ & $2363(7)$ & $2826(8)$ & $173(6)$ \\
\hline $\mathrm{S}(2 \mathrm{Y})$ & $9609(12)$ & $2642(8)$ & $3095(10)$ & $215(8)$ \\
\hline $\mathrm{C}(901)$ & $9825(18)$ & 5343(13) & $6782(16)$ & $196(18)$ \\
\hline $\mathrm{C}(902)$ & $10000(19)$ & 4881(18) & $6495(10)$ & $360(40)$ \\
\hline $\mathrm{C}(903)$ & $10262(17)$ & $4406(13)$ & $6847(15)$ & 204(19) \\
\hline $\mathrm{C}(904)$ & $10349(14)$ & 4393(9) & $7485(15)$ & 184(17) \\
\hline $\mathrm{C}(905)$ & $10173(13)$ & $4856(12)$ & $7773(10)$ & 109(9) \\
\hline $\mathrm{C}(906)$ & $9911(15)$ & $5331(9)$ & $7421(16)$ & $240(20)$ \\
\hline $\mathrm{Cl}(1)$ & $9220(20)$ & $5878(15)$ & $6320(16)$ & $520(20)$ \\
\hline $\mathrm{Cl}(2)$ & $9877(13)$ & $5037(9)$ & $5665(10)$ & $320(10)$ \\
\hline
\end{tabular}


Table S8. Bond lengths $[\AA]$ for 5 .

\begin{tabular}{|c|c|c|c|}
\hline $\operatorname{Ir}(1)-C(1 \mathrm{~A})$ & $1.869(13)$ & $\operatorname{Ir}(1)-C\left(3^{\prime}\right)$ & $2.114(13)$ \\
\hline $\operatorname{Ir}(1)-C(2)$ & $2.158(13)$ & $\operatorname{Ir}(1)-C(100)$ & $2.182(12)$ \\
\hline $\operatorname{Ir}(1)-C(1)$ & $2.196(12)$ & $\operatorname{Ir}(1)-C\left(4^{\prime}\right)$ & $2.204(11)$ \\
\hline $\operatorname{Ir}(1)-\operatorname{Ir}(4)$ & $2.8574(7)$ & $\operatorname{Ir}(1)-\operatorname{Ir}(2)$ & $3.0388(7)$ \\
\hline $\operatorname{Ir}(2)-C(2 A)$ & $1.858(16)$ & $\operatorname{Ir}(2)-C\left(2^{\prime}\right)$ & $2.137(11)$ \\
\hline $\operatorname{Ir}(2)-C(3)$ & $2.165(12)$ & $\operatorname{Ir}(2)-C(100)$ & $2.185(14)$ \\
\hline $\operatorname{Ir}(2)-C(4)$ & $2.188(12)$ & $\operatorname{Ir}(2)-C\left(1^{\prime}\right)$ & $2.190(12)$ \\
\hline $\operatorname{Ir}(2)-\operatorname{Ir}(3)$ & $2.9116(7)$ & $\operatorname{Ir}(3)-C(3 A)$ & $1.887(15)$ \\
\hline $\operatorname{Ir}(3)-C(100)$ & $2.164(11)$ & $\operatorname{Ir}(3)-C(5)$ & $2.173(13)$ \\
\hline $\operatorname{Ir}(3)-P(3)$ & $2.313(4)$ & $\operatorname{Ir}(3)-P(1)$ & $2.372(4)$ \\
\hline $\operatorname{Ir}(3)-\operatorname{Ir}(4)$ & $2.7819(7)$ & $\operatorname{Ir}(4)-C(108)$ & $1.994(16)$ \\
\hline $\operatorname{Ir}(4)-C(100)$ & $2.122(15)$ & $\operatorname{Ir}(4)-C(6)$ & $2.188(13)$ \\
\hline $\operatorname{Ir}(4)-P(3)$ & $2.284(3)$ & $\operatorname{Ir}(4)-P(2)$ & $2.318(4)$ \\
\hline $\mathrm{P}(1)-\mathrm{C}(400)$ & $1.825(13)$ & $\mathrm{P}(1)-\mathrm{C}(200)$ & $1.833(16)$ \\
\hline $\mathrm{P}(1)-\mathrm{C}(300)$ & $1.845(16)$ & $\mathrm{P}(2)-\mathrm{C}(600)$ & $1.807(15)$ \\
\hline $\mathrm{P}(2)-\mathrm{C}(700)$ & $1.809(15)$ & $\mathrm{P}(2)-\mathrm{C}(500)$ & $1.832(17)$ \\
\hline $\mathrm{P}(3)-\mathrm{C}(900)$ & $1.804(15)$ & $\mathrm{P}(3)-\mathrm{C}(800)$ & $1.813(17)$ \\
\hline $\mathrm{C}(1 \mathrm{~A})-\mathrm{O}(1 \mathrm{~A})$ & $1.140(16)$ & $\mathrm{C}(2 \mathrm{~A})-\mathrm{O}(2 \mathrm{~A})$ & $1.178(17)$ \\
\hline $\mathrm{C}(3 \mathrm{~A})-\mathrm{O}(3 \mathrm{~A})$ & $1.146(16)$ & $\mathrm{N}(1)-\mathrm{C}(108)$ & $1.116(19$ \\
\hline $\mathrm{N}(1)-\mathrm{C}(107)$ & $1.45(2)$ & $\mathrm{C}(101)-\mathrm{C}(102)$ & 1.3900 \\
\hline $\mathrm{C}(101)-\mathrm{C}(106)$ & 1.3900 & $\mathrm{C}(101)-\mathrm{C}(107)$ & $1.44(2)$ \\
\hline$C(102)-C(103)$ & 1.3900 & $\mathrm{C}(103)-\mathrm{C}(104)$ & 1.3900 \\
\hline$C(104)-C(105)$ & 1.3900 & $\mathrm{C}(105)-\mathrm{C}(106)$ & 1.3900 \\
\hline $\mathrm{C}\left(1^{\prime}\right)-\mathrm{C}\left(2^{\prime}\right)$ & $1.458(18)$ & $C\left(1^{\prime}\right)-C\left(6^{\prime}\right)$ & $1.520(18)$ \\
\hline $\mathrm{C}\left(1^{\prime}\right)-\mathrm{C}\left(9^{\prime}\right)$ & $1.521(17)$ & $\mathrm{C}\left(2^{\prime}\right)-\mathrm{C}\left(12^{\prime}\right)$ & $1.482(18)$ \\
\hline $\mathrm{C}\left(2^{\prime}\right)-\mathrm{C}\left(3^{\prime}\right)$ & $1.501(17)$ & $C\left(3^{\prime}\right)-C\left(4^{\prime}\right)$ & $1.477(18)$ \\
\hline $\mathrm{C}\left(3^{\prime}\right)-\mathrm{C}\left(14^{\prime}\right)$ & $1.504(17)$ & $C\left(4^{\prime}\right)-C\left(5^{\prime}\right)$ & $1.498(17)$ \\
\hline$C\left(4^{\prime}\right)-C\left(17^{\prime}\right)$ & $1.507(16)$ & $C\left(5^{\prime}\right)-C\left(6^{\prime}\right)$ & $1.364(17)$ \\
\hline $\mathrm{C}\left(5^{\prime}\right)-\mathrm{C}\left(19^{\prime}\right)$ & $1.448(18)$ & $C\left(6^{\prime}\right)-C\left(7^{\prime}\right)$ & $1.436(19)$ \\
\hline $\mathrm{C}\left(7^{\prime}\right)-\mathrm{C}\left(21^{\prime}\right)$ & $1.40(2)$ & $C\left(7^{\prime}\right)-C\left(8^{\prime}\right)$ & $1.43(2)$ \\
\hline $\mathrm{C}\left(8^{\prime}\right)-\mathrm{C}\left(24^{\prime}\right)$ & $1.408(19)$ & $\mathrm{C}\left(8^{\prime}\right)-\mathrm{C}\left(9^{\prime}\right)$ & $1.443(19)$ \\
\hline $\mathrm{C}\left(9^{\prime}\right)-\mathrm{C}\left(10^{\prime}\right)$ & $1.395(19)$ & $\mathrm{C}\left(10^{\prime}\right)-\mathrm{C}\left(26^{\prime}\right)$ & $1.439(18)$ \\
\hline $\mathrm{C}\left(10^{\prime}\right)-\mathrm{C}\left(11^{\prime}\right)$ & $1.454(19)$ & $\mathrm{C}\left(11^{\prime}\right)-\mathrm{C}\left(12^{\prime}\right)$ & $1.373(18)$ \\
\hline $\mathrm{C}\left(11^{\prime}\right)-\mathrm{C}\left(28^{\prime}\right)$ & $1.439(19)$ & $\mathrm{C}\left(12^{\prime}\right)-\mathrm{C}\left(13^{\prime}\right)$ & $1.428(17)$ \\
\hline $\mathrm{C}\left(13^{\prime}\right)-\mathrm{C}\left(30^{\prime}\right)$ & $1.411(17)$ & $\mathrm{C}\left(13^{\prime}\right)-\mathrm{C}\left(14^{\prime}\right)$ & $1.417(19)$ \\
\hline $\mathrm{C}\left(14^{\prime}\right)-\mathrm{C}\left(15^{\prime}\right)$ & $1.391(17)$ & $C\left(15^{\prime}\right)-C\left(16^{\prime}\right)$ & $1.440(19)$ \\
\hline $\mathrm{C}\left(15^{\prime}\right)-\mathrm{C}\left(32^{\prime}\right)$ & $1.449(17)$ & $\mathrm{C}\left(16^{\prime}\right)-\mathrm{C}\left(17^{\prime}\right)$ & $1.390(19)$ \\
\hline $\mathrm{C}\left(16^{\prime}\right)-\mathrm{C}\left(34^{\prime}\right)$ & $1.453(17)$ & $\mathrm{C}\left(17^{\prime}\right)-\mathrm{C}\left(18^{\prime}\right)$ & $1.451(19)$ \\
\hline $\mathrm{C}\left(18^{\prime}\right)-\mathrm{C}\left(36^{\prime}\right)$ & $1.390(18)$ & $\mathrm{C}\left(18^{\prime}\right)-\mathrm{C}\left(19^{\prime}\right)$ & $1.445(18)$ \\
\hline $\mathrm{C}\left(19^{\prime}\right)-\mathrm{C}\left(20^{\prime}\right)$ & $1.39(2)$ & $\mathrm{C}\left(20^{\prime}\right)-\mathrm{C}\left(38^{\prime}\right)$ & $1.450(19)$ \\
\hline $\mathrm{C}\left(20^{\prime}\right)-\mathrm{C}\left(21^{\prime}\right)$ & $1.45(2)$ & $\mathrm{C}\left(21^{\prime}\right)-\mathrm{C}\left(22^{\prime}\right)$ & $1.45(2)$ \\
\hline $\mathrm{C}\left(22^{\prime}\right)-\mathrm{C}\left(23^{\prime}\right)$ & $1.41(2)$ & $\mathrm{C}\left(22^{\prime}\right)-\mathrm{C}\left(39^{\prime}\right)$ & $1.45(2)$ \\
\hline $\left.\mathrm{C}\left(23^{\prime}\right)-\mathrm{C}\left(24^{\prime}\right)\right)$ & $1.43(2)$ & $\left.\mathrm{C}\left(23^{\prime}\right)-\mathrm{C}\left(42^{\prime}\right)\right)$ & $1.44(2)$ \\
\hline $\left.\mathrm{C}\left(24^{\prime}\right)-\mathrm{C}\left(25^{\prime}\right)\right)$ & $1.45(2)$ & $\mathrm{C}\left(25^{\prime}\right)-\mathrm{C}\left(26^{\prime}\right)$ & $1.39(2)$ \\
\hline $\mathrm{C}\left(25^{\prime}\right)-\mathrm{C}\left(43^{\prime}\right)$ & $1.46(2)$ & $\mathrm{C}\left(26^{\prime}\right)-\mathrm{C}\left(27^{\prime}\right)$ & $1.458(19)$ \\
\hline $\mathrm{C}\left(27^{\prime}\right)-\mathrm{C}\left(45^{\prime}\right)$ & $1.402(19)$ & $\mathrm{C}\left(27^{\prime}\right)-\mathrm{C}\left(28^{\prime}\right)$ & $1.44(2)$ \\
\hline $\mathrm{C}\left(28^{\prime}\right)-\mathrm{C}\left(29^{\prime}\right)$ & $1.404(19)$ & $\mathrm{C}\left(29^{\prime}\right)-\mathrm{C}\left(30^{\prime}\right)$ & $1.44(2)$ \\
\hline $\mathrm{C}\left(29^{\prime}\right)-\mathrm{C}\left(47^{\prime}\right)$ & $1.450(19)$ & $\mathrm{C}\left(30^{\prime}\right)-\mathrm{C}\left(31^{\prime}\right)$ & $1.464(18)$ \\
\hline $\mathrm{C}\left(31^{\prime}\right)-\mathrm{C}\left(32^{\prime}\right)$ & $1.368(19)$ & $\mathrm{C}\left(31^{\prime}\right)-\mathrm{C}\left(48^{\prime}\right)$ & $1.445(19)$ \\
\hline $\mathrm{C}\left(32^{\prime}\right)-\mathrm{C}\left(33^{\prime}\right)$ & $1.476(19)$ & $\mathrm{C}\left(33^{\prime}\right)-\mathrm{C}\left(50^{\prime}\right)$ & $1.393(18)$ \\
\hline $\mathrm{C}\left(33^{\prime}\right)-\mathrm{C}\left(34^{\prime}\right)$ & $1.46(2)$ & $\mathrm{C}\left(34^{\prime}\right)-\mathrm{C}\left(35^{\prime}\right)$ & $1.36(2)$ \\
\hline $\mathrm{C}\left(35^{\prime}\right)-\mathrm{C}\left(52^{\prime}\right)$ & $1.456(19)$ & $\mathrm{C}\left(35^{\prime}\right)-\mathrm{C}\left(36^{\prime}\right)$ & $1.46(2)$ \\
\hline $\mathrm{C}\left(36^{\prime}\right)-\mathrm{C}\left(37^{\prime}\right)$ & $1.47(2)$ & $\mathrm{C}\left(37^{\prime}\right)-\mathrm{C}\left(38^{\prime}\right)$ & $1.40(2)$ \\
\hline $\mathrm{C}\left(37^{\prime}\right)-\mathrm{C}\left(53^{\prime}\right)$ & $1.46(2)$ & $\mathrm{C}\left(38^{\prime}\right)-\mathrm{C}\left(39^{\prime}\right)$ & $1.45(2)$ \\
\hline $\mathrm{C}\left(39^{\prime}\right)-\mathrm{C}\left(40^{\prime}\right)$ & $1.41(2)$ & $\mathrm{C}\left(40^{\prime}\right)-\mathrm{C}\left(54^{\prime}\right)$ & $1.46(2)$ \\
\hline
\end{tabular}




\begin{tabular}{|c|c|c|c|}
\hline $\mathrm{C}\left(40^{\prime}\right)-\mathrm{C}\left(41^{\prime}\right)$ & $1.47(2)$ & $\mathrm{C}\left(41^{\prime}\right)-\mathrm{C}\left(42^{\prime}\right)$ & $1.40(2)$ \\
\hline $\mathrm{C}\left(41^{\prime}\right)-\mathrm{C}\left(56^{\prime}\right)$ & $1.44(2)$ & $\mathrm{C}\left(42^{\prime}\right)-\mathrm{C}\left(43^{\prime}\right)$ & $1.45(2)$ \\
\hline $\mathrm{C}\left(43^{\prime}\right)-\mathrm{C}\left(44^{\prime}\right)$ & $1.40(2)$ & $\mathrm{C}\left(44^{\prime}\right)-\mathrm{C}\left(45^{\prime}\right)$ & $1.43(2)$ \\
\hline $\mathrm{C}\left(44^{\prime}\right)-\mathrm{C}\left(57^{\prime}\right)$ & $1.459(19)$ & $\mathrm{C}\left(45^{\prime}\right)-\mathrm{C}\left(46^{\prime}\right)$ & $1.460(19)$ \\
\hline $\mathrm{C}\left(46^{\prime}\right)-\mathrm{C}\left(47^{\prime}\right)$ & $1.38(2)$ & $\mathrm{C}\left(46^{\prime}\right)-\mathrm{C}\left(58^{\prime}\right)$ & $1.54(4)$ \\
\hline $\mathrm{C}\left(47^{\prime}\right)-\mathrm{C}\left(48^{\prime}\right)$ & $1.44(2)$ & $\mathrm{C}\left(48^{\prime}\right)-\mathrm{C}\left(49^{\prime}\right)$ & $1.42(2)$ \\
\hline $\mathrm{C}\left(49^{\prime}\right)-\mathrm{C}\left(59^{\prime}\right)$ & $1.43(2)$ & $\mathrm{C}\left(49^{\prime}\right)-\mathrm{C}\left(50^{\prime}\right)$ & $1.44(2)$ \\
\hline $\mathrm{C}\left(50^{\prime}\right)-\mathrm{C}\left(51^{\prime}\right)$ & $1.45(2)$ & $\mathrm{C}\left(51^{\prime}\right)-\mathrm{C}\left(52^{\prime}\right)$ & $1.39(2)$ \\
\hline $\mathrm{C}\left(51^{\prime}\right)-\mathrm{C}\left(60^{\prime}\right)$ & $1.46(2)$ & $\mathrm{C}\left(52^{\prime}\right)-\mathrm{C}\left(53^{\prime}\right)$ & $1.43(2)$ \\
\hline $\mathrm{C}\left(53^{\prime}\right)-\mathrm{C}\left(54^{\prime}\right)$ & $1.40(2)$ & $\mathrm{C}\left(54^{\prime}\right)-\mathrm{C}\left(55^{\prime}\right)$ & $1.44(2)$ \\
\hline $\mathrm{C}\left(55^{\prime}\right)-\mathrm{C}\left(60^{\prime}\right)$ & $1.38(2)$ & $\mathrm{C}\left(55^{\prime}\right)-\mathrm{C}\left(56^{\prime}\right)$ & $1.46(2)$ \\
\hline $\mathrm{C}\left(56^{\prime}\right)-\mathrm{C}\left(57^{\prime}\right)$ & $1.39(2)$ & $\mathrm{C}\left(57^{\prime}\right)-\mathrm{C}\left(58^{\prime}\right)$ & $1.45(2)$ \\
\hline $\mathrm{C}\left(58^{\prime}\right)-\mathrm{C}\left(59^{\prime}\right)$ & $1.42(2)$ & $\mathrm{C}\left(59^{\prime}\right)-\mathrm{C}\left(60^{\prime}\right)$ & $1.47(2)$ \\
\hline$C(1)-C(2)$ & $1.442(19)$ & $\mathrm{C}(1)-\mathrm{C}(9)$ & $1.473(17)$ \\
\hline$C(1)-C(6)$ & $1.535(16)$ & $\mathrm{C}(2)-\mathrm{C}(12)$ & $1.489(18)$ \\
\hline$C(2)-C(3)$ & $1.492(16)$ & $\mathrm{C}(3)-\mathrm{C}(14)$ & $1.443(19)$ \\
\hline$C(3)-C(4)$ & $1.491(17)$ & $C(4)-C(5)$ & $1.503(19)$ \\
\hline$C(4)-C(17)$ & $1.514(16)$ & $\mathrm{C}(5)-\mathrm{C}(19)$ & $1.506(17)$ \\
\hline$C(5)-C(6)$ & $1.554(17)$ & $C(6)-C(7)$ & $1.494(18)$ \\
\hline $\mathrm{C}(7)-\mathrm{C}(21)$ & $1.397(18)$ & $\mathrm{C}(7)-\mathrm{C}(8)$ & $1.426(18)$ \\
\hline $\mathrm{C}(8)-\mathrm{C}(24)$ & $1.42(2)$ & $\mathrm{C}(8)-\mathrm{C}(9)$ & $1.456(18)$ \\
\hline $\mathrm{C}(9)-\mathrm{C}(10)$ & $1.389(19)$ & $\mathrm{C}(10)-\mathrm{C}(11)$ & $1.459(19)$ \\
\hline $\mathrm{C}(10)-\mathrm{C}(26)$ & $1.468(19)$ & $\mathrm{C}(11)-\mathrm{C}(12)$ & $1.372(18)$ \\
\hline $\mathrm{C}(11)-\mathrm{C}(28)$ & $1.46(2)$ & $\mathrm{C}(12)-\mathrm{C}(13)$ & $1.441(19)$ \\
\hline $\mathrm{C}(13)-\mathrm{C}(14)$ & $1.423(17)$ & $\mathrm{C}(13)-\mathrm{C}(30)$ & $1.433(19)$ \\
\hline $\mathrm{C}(14)-\mathrm{C}(15)$ & $1.370(18)$ & $\mathrm{C}(15)-\mathrm{C}(16)$ & $1.458(17)$ \\
\hline $\mathrm{C}(15)-\mathrm{C}(32)$ & $1.46(2)$ & $\mathrm{C}(16)-\mathrm{C}(17)$ & $1.372(19)$ \\
\hline $\mathrm{C}(16)-\mathrm{C}(34)$ & $1.446(19)$ & $\mathrm{C}(17)-\mathrm{C}(18)$ & $1.448(17)$ \\
\hline $\mathrm{C}(18)-\mathrm{C}(36)$ & $1.388(19)$ & $\mathrm{C}(18)-\mathrm{C}(19)$ & $1.455(19)$ \\
\hline $\mathrm{C}(19)-\mathrm{C}(20)$ & $1.389(18)$ & $\mathrm{C}(20)-\mathrm{C}(38)$ & $1.439(19)$ \\
\hline $\mathrm{C}(20)-\mathrm{C}(21)$ & $1.470(18)$ & $\mathrm{C}(21)-\mathrm{C}(22)$ & $1.42(2)$ \\
\hline $\mathrm{C}(22)-\mathrm{C}(23)$ & $1.40(2)$ & $\mathrm{C}(22)-\mathrm{C}(39)$ & $1.47(2)$ \\
\hline $\mathrm{C}(23)-\mathrm{C}(42)$ & $1.42(2)$ & $\mathrm{C}(23)-\mathrm{C}(24)$ & $1.443(18)$ \\
\hline $\mathrm{C}(24)-\mathrm{C}(25)$ & $1.44(2)$ & $\mathrm{C}(25)-\mathrm{C}(26)$ & $1.387(19)$ \\
\hline $\mathrm{C}(25)-\mathrm{C}(43)$ & $1.45(2)$ & $\mathrm{C}(26)-\mathrm{C}(27)$ & $1.45(2)$ \\
\hline $\mathrm{C}(27)-\mathrm{C}(45)$ & $1.36(2)$ & $\mathrm{C}(27)-\mathrm{C}(28)$ & $1.46(2)$ \\
\hline $\mathrm{C}(28)-\mathrm{C}(29)$ & $1.39(2)$ & $\mathrm{C}(29)-\mathrm{C}(47)$ & $1.44(2)$ \\
\hline $\mathrm{C}(29)-\mathrm{C}(30)$ & $1.44(2)$ & $\mathrm{C}(30)-\mathrm{C}(31)$ & $1.437(19)$ \\
\hline $\mathrm{C}(31)-\mathrm{C}(32)$ & $1.387(18)$ & $\mathrm{C}(31)-\mathrm{C}(48)$ & $1.44(2)$ \\
\hline $\mathrm{C}(32)-\mathrm{C}(33)$ & $1.461(18)$ & $\mathrm{C}(33)-\mathrm{C}(50)$ & $1.39(2)$ \\
\hline $\mathrm{C}(33)-\mathrm{C}(34)$ & $1.47(2)$ & $\mathrm{C}(34)-\mathrm{C}(35)$ & $1.409(19)$ \\
\hline $\mathrm{C}(35)-\mathrm{C}(36)$ & $1.44(2)$ & $(35)-C(52)$ & $1.46(2)$ \\
\hline $\mathrm{C}(36)-\mathrm{C}(37)$ & $1.454(19)$ & $\mathrm{C}(37)-\mathrm{C}(38)$ & $1.39(2)$ \\
\hline $\mathrm{C}(37)-\mathrm{C}(53)$ & $1.44(2)$ & $\mathrm{C}(38)-\mathrm{C}(39)$ & $1.45(2)$ \\
\hline $\mathrm{C}(39)-\mathrm{C}(40)$ & $1.41(2)$ & $\mathrm{C}(40)-\mathrm{C}(54)$ & $1.43(2)$ \\
\hline $\mathrm{C}(40)-\mathrm{C}(41)$ & $1.46(2)$ & $\mathrm{C}(41)-\mathrm{C}(42)$ & $1.42(2)$ \\
\hline $\mathrm{C}(41)-\mathrm{C}(56)$ & $1.42(2)$ & $\mathrm{C}(42)-\mathrm{C}(43)$ & $1.49(2)$ \\
\hline $\mathrm{C}(43)-\mathrm{C}(44)$ & $1.37(2)$ & $\mathrm{C}(44)-\mathrm{C}(57)$ & $1.45(2)$ \\
\hline $\mathrm{C}(44)-\mathrm{C}(45)$ & $1.46(2$ & $\mathrm{C}(45)-\mathrm{C}(46)$ & $1.45(2)$ \\
\hline $\mathrm{C}(46)-\mathrm{C}(47)$ & $1.40(2)$ & $\mathrm{C}(46)-\mathrm{C}(58)$ & $1.46(2)$ \\
\hline $\mathrm{C}(47)-\mathrm{C}(48)$ & $1.47(2)$ & $\mathrm{C}(48)-\mathrm{C}(49)$ & $1.42(2)$ \\
\hline $\mathrm{C}(49)-\mathrm{C}(50)$ & $1.45(2)$ & $\mathrm{C}(49)-\mathrm{C}(59)$ & $1.46(2)$ \\
\hline $\mathrm{C}(50)-\mathrm{C}(51)$ & $1.43(2)$ & $\mathrm{C}(51)-\mathrm{C}(52)$ & $1.40(2)$ \\
\hline $\mathrm{C}(51)-\mathrm{C}(60)$ & $1.46(2)$ & $\mathrm{C}(52)-\mathrm{C}(53)$ & $1.45(2)$ \\
\hline $\mathrm{C}(53)-\mathrm{C}(54)$ & $1.39(2)$ & $\mathrm{C}(54)-\mathrm{C}(55)$ & $1.44(2)$ \\
\hline $\mathrm{C}(55)-\mathrm{C}(60)$ & $1.38(2)$ & $\mathrm{C}(55)-\mathrm{C}(56)$ & $1.46(2)$ \\
\hline $\mathrm{C}(56)-\mathrm{C}(57)$ & $1.38(2)$ & $\mathrm{C}(57)-\mathrm{C}(58)$ & $1.46(3)$ \\
\hline
\end{tabular}




\begin{tabular}{|l|l|l|l|}
\hline $\mathrm{C}(58)-\mathrm{C}(59)$ & $1.40(2)$ & $\mathrm{C}(59)-\mathrm{C}(60)$ & $1.46(2)$ \\
\hline $\mathrm{C}(1 \mathrm{X})-\mathrm{S}(1 \mathrm{Y})$ & $1.51(2)$ & $\mathrm{C}(1 \mathrm{X})-\mathrm{S}(1 \mathrm{X})$ & $1.53(2)$ \\
\hline $\mathrm{C}(2 \mathrm{X})-\mathrm{S}(2 \mathrm{X})$ & $1.22(3)$ & $\mathrm{C}(2 \mathrm{X})-\mathrm{S}(2 \mathrm{Y})$ & $1.39(3)$ \\
\hline $\mathrm{S}(2 \mathrm{X})-\mathrm{S}(2 \mathrm{Y})$ & $2.54(3)$ & $\mathrm{C}(901)-\mathrm{C}(902)$ & 1.3900 \\
\hline $\mathrm{C}(901)-\mathrm{C}(906)$ & 1.3900 & $\mathrm{C}(901)-\mathrm{Cl}(1)$ & $1.79(4)$ \\
\hline $\mathrm{C}(902)-\mathrm{C}(903)$ & 1.3900 & $\mathrm{C}(902)-\mathrm{Cl}(2)$ & $1.84(3)$ \\
\hline $\mathrm{C}(903)-\mathrm{C}(904)$ & 1.3900 & $\mathrm{C}(904)-\mathrm{C}(905)$ & 1.3900 \\
\hline $\mathrm{C}(905)-\mathrm{C}(906)$ & 1.3900 & & \\
\hline
\end{tabular}


Table S9. Bond angles [deg] for 5 .

\begin{tabular}{|c|c|c|c|}
\hline $\mathrm{C}(1 \mathrm{~A})-\operatorname{Ir}(1)-\mathrm{C}\left(3^{\prime}\right)$ & $96.2(5)$ & $\mathrm{C}(1 \mathrm{~A})-\operatorname{Ir}(1)-\mathrm{C}(2)$ & $97.8(5)$ \\
\hline $\mathrm{C}\left(3^{\prime}\right)-\operatorname{Ir}(1)-\mathrm{C}(2)$ & $98.3(5)$ & $\mathrm{C}(1 \mathrm{~A})-\operatorname{Ir}(1)-\mathrm{C}(100)$ & 157.1(6) \\
\hline$C\left(3^{\prime}\right)-\operatorname{Ir}(1)-C(100)$ & $96.9(5)$ & $\mathrm{C}(2)-\operatorname{Ir}(1)-\mathrm{C}(100)$ & $98.9(5)$ \\
\hline $\mathrm{C}(1 \mathrm{~A})-\operatorname{Ir}(1)-\mathrm{C}(1)$ & $91.3(5)$ & $\mathrm{C}\left(3^{\prime}\right)-\operatorname{Ir}(1)-\mathrm{C}(1)$ & $136.9(5)$ \\
\hline$C(2)-\operatorname{Ir}(1)-C(1)$ & $38.7(5)$ & $\mathrm{C}(100)-\operatorname{Ir}(1)-\mathrm{C}(1)$ & $91.9(5)$ \\
\hline $\mathrm{C}(1 \mathrm{~A})-\operatorname{Ir}(1)-\mathrm{C}\left(4^{\prime}\right)$ & $90.4(5)$ & $\mathrm{C}\left(3^{\prime}\right)-\operatorname{Ir}(1)-\mathrm{C}\left(4^{\prime}\right)$ & $39.9(5)$ \\
\hline$C(2)-\operatorname{Ir}(1)-C\left(4^{\prime}\right)$ & $138.2(5)$ & $\mathrm{C}(100)-\operatorname{Ir}(1)-\mathrm{C}\left(4^{\prime}\right)$ & $87.6(5)$ \\
\hline$C(1)-\operatorname{Ir}(1)-C\left(4^{\prime}\right)$ & 176.7(5) & $\mathrm{C}(1 \mathrm{~A})-\operatorname{Ir}(1)-\operatorname{Ir}(4)$ & $113.8(4)$ \\
\hline$C\left(3^{\prime}\right)-\operatorname{Ir}(1)-\operatorname{Ir}(4)$ & $142.0(3)$ & $\mathrm{C}(2)-\operatorname{Ir}(1)-\operatorname{Ir}(4)$ & $100.0(3)$ \\
\hline $\mathrm{C}(100)-\operatorname{Ir}(1)-\operatorname{Ir}(4)$ & $47.5(4)$ & $\mathrm{C}(1)-\operatorname{Ir}(1)-\operatorname{Ir}(4)$ & $67.9(4)$ \\
\hline$C\left(4^{\prime}\right)-\operatorname{Ir}(1)-\operatorname{Ir}(4)$ & $113.9(3)$ & $\mathrm{C}(1 \mathrm{~A})-\operatorname{Ir}(1)-\operatorname{Ir}(2)$ & $156.9(5)$ \\
\hline$C\left(3^{\prime}\right)-\operatorname{Ir}(1)-\operatorname{Ir}(2)$ & $68.9(3)$ & $\mathrm{C}(2)-\operatorname{Ir}(1)-\operatorname{Ir}(2)$ & $68.4(3)$ \\
\hline $\mathrm{C}(100)-\operatorname{Ir}(1)-\operatorname{Ir}(2)$ & $45.9(4)$ & $\mathrm{C}(1)-\operatorname{Ir}(1)-\operatorname{Ir}(2)$ & $88.6(3)$ \\
\hline$C\left(4^{\prime}\right)-\operatorname{Ir}(1)-\operatorname{Ir}(2)$ & $88.7(3)$ & $\operatorname{Ir}(4)-\operatorname{Ir}(1)-\operatorname{Ir}(2)$ & $87.47(2)$ \\
\hline $\mathrm{C}(2 \mathrm{~A})-\operatorname{Ir}(2)-\mathrm{C}\left(2^{\prime}\right)$ & $93.7(5)$ & $\mathrm{C}(2 \mathrm{~A})-\operatorname{Ir}(2)-\mathrm{C}(3)$ & $92.2(5)$ \\
\hline$C\left(2^{\prime}\right)-\operatorname{Ir}(2)-C(3)$ & $98.1(5)$ & $\mathrm{C}(2 \mathrm{~A})-\operatorname{Ir}(2)-\mathrm{C}(100)$ & $162.4(5)$ \\
\hline $\mathrm{C}\left(2^{\prime}\right)-\operatorname{Ir}(2)-\mathrm{C}(100)$ & $97.0(5)$ & $\mathrm{C}(3)-\operatorname{Ir}(2)-\mathrm{C}(100)$ & $100.0(6)$ \\
\hline $\mathrm{C}(2 \mathrm{~A})-\operatorname{Ir}(2)-\mathrm{C}(4)$ & $91.4(5)$ & $C\left(2^{\prime}\right)-\operatorname{Ir}(2)-C(4)$ & $138.1(5)$ \\
\hline$C(3)-\operatorname{Ir}(2)-C(4)$ & $40.1(4)$ & $C(100)-\operatorname{Ir}(2)-C(4)$ & $90.0(5)$ \\
\hline $\mathrm{C}(2 \mathrm{~A})-\operatorname{Ir}(2)-\mathrm{C}\left(1^{\prime}\right)$ & $90.2(5)$ & $\mathrm{C}\left(2^{\prime}\right)-\operatorname{Ir}(2)-\mathrm{C}\left(1^{\prime}\right)$ & $39.4(5)$ \\
\hline$C(3)-\operatorname{Ir}(2)-C\left(1^{\prime}\right)$ & $137.5(4)$ & $\mathrm{C}(100)-\operatorname{Ir}(2)-\mathrm{C}\left(1^{\prime}\right)$ & $89.3(5)$ \\
\hline$C(4)-\operatorname{Ir}(2)-C\left(1^{\prime}\right)$ & 177.1(4) & $\mathrm{C}(2 \mathrm{~A})-\operatorname{Ir}(2)-\operatorname{Ir}(3)$ & $118.0(4)$ \\
\hline$C\left(2^{\prime}\right)-\operatorname{Ir}(2)-\operatorname{Ir}(3)$ & $142.6(4)$ & $\mathrm{C}(3)-\operatorname{Ir}(2)-\operatorname{Ir}(3)$ & $99.9(4)$ \\
\hline $\mathrm{C}(100)-\operatorname{Ir}(2)-\operatorname{Ir}(3)$ & $47.7(3)$ & $\mathrm{C}(4)-\operatorname{Ir}(2)-\operatorname{Ir}(3)$ & $65.2(4)$ \\
\hline$C\left(1^{\prime}\right)-\operatorname{Ir}(2)-\operatorname{Ir}(3)$ & 116.1(3) & $\mathrm{C}(2 \mathrm{~A})-\operatorname{Ir}(2)-\operatorname{Ir}(1)$ & $151.7(4)$ \\
\hline$C\left(2^{\prime}\right)-\operatorname{Ir}(2)-\operatorname{Ir}(1)$ & $68.7(4)$ & $\mathrm{C}(3)-\operatorname{Ir}(2)-\operatorname{Ir}(1)$ & $69.7(3)$ \\
\hline $\mathrm{C}(100)-\operatorname{Ir}(2)-\operatorname{Ir}(1)$ & $45.9(3)$ & $\mathrm{C}(4)-\operatorname{Ir}(2)-\operatorname{Ir}(1)$ & $88.3(3)$ \\
\hline$C\left(1^{\prime}\right)-\operatorname{Ir}(2)-\operatorname{Ir}(1)$ & $89.3(3)$ & $\operatorname{Ir}(3)-\operatorname{Ir}(2)-\operatorname{Ir}(1)$ & $87.41(2)$ \\
\hline$C(3 A)-\operatorname{Ir}(3)-C(100)$ & $158.5(6)$ & $\mathrm{C}(3 \mathrm{~A})-\operatorname{Ir}(3)-\mathrm{C}(5)$ & $91.0(6)$ \\
\hline $\mathrm{C}(100)-\operatorname{Ir}(3)-\mathrm{C}(5)$ & $84.0(5)$ & $\mathrm{C}(3 \mathrm{~A})-\operatorname{Ir}(3)-\mathrm{P}(3)$ & $102.4(4)$ \\
\hline $\mathrm{C}(100)-\operatorname{Ir}(3)-\mathrm{P}(3)$ & $98.6(4)$ & $\mathrm{C}(5)-\operatorname{Ir}(3)-\mathrm{P}(3)$ & $91.3(4)$ \\
\hline $\mathrm{C}(3 \mathrm{~A})-\operatorname{Ir}(3)-\mathrm{P}(1)$ & $88.8(5)$ & $\mathrm{C}(100)-\operatorname{Ir}(3)-\mathrm{P}(1)$ & $91.9(4)$ \\
\hline $\mathrm{C}(5)-\operatorname{Ir}(3)-\mathrm{P}(1)$ & $168.2(4)$ & $\mathrm{P}(3)-\operatorname{Ir}(3)-\mathrm{P}(1)$ & $100.20(15)$ \\
\hline $\mathrm{C}(3 \mathrm{~A})-\operatorname{Ir}(3)-\operatorname{Ir}(4)$ & 148.3(4) & $C(100)-\operatorname{Ir}(3)-\operatorname{Ir}(4)$ & $48.9(4)$ \\
\hline$C(5)-\operatorname{Ir}(3)-\operatorname{Ir}(4)$ & $73.1(3)$ & $\mathrm{P}(3)-\operatorname{Ir}(3)-\operatorname{Ir}(4)$ & $52.28(9)$ \\
\hline$P(1)-\operatorname{Ir}(3)-\operatorname{Ir}(4)$ & $112.27(10)$ & $\mathrm{C}(3 \mathrm{~A})-\operatorname{Ir}(3)-\operatorname{Ir}(2)$ & $110.3(4)$ \\
\hline $\mathrm{C}(100)-\operatorname{Ir}(3)-\operatorname{Ir}(2)$ & $48.3(4)$ & $\mathrm{C}(5)-\operatorname{Ir}(3)-\operatorname{Ir}(2)$ & $73.1(3)$ \\
\hline $\mathrm{P}(3)-\operatorname{Ir}(3)-\operatorname{Ir}(2)$ & $143.67(9)$ & $\mathrm{P}(1)-\operatorname{Ir}(3)-\operatorname{Ir}(2)$ & $95.91(9)$ \\
\hline $\operatorname{Ir}(4)-\operatorname{Ir}(3)-\operatorname{Ir}(2)$ & $91.47(2)$ & $\mathrm{C}(108)-\operatorname{Ir}(4)-\mathrm{C}(100)$ & $84.8(6)$ \\
\hline $\mathrm{C}(108)-\operatorname{Ir}(4)-\mathrm{C}(6)$ & $167.6(5)$ & $\mathrm{C}(100)-\operatorname{Ir}(4)-\mathrm{C}(6)$ & $85.2(5)$ \\
\hline $\mathrm{C}(108)-\operatorname{Ir}(4)-\mathrm{P}(3)$ & $96.8(4)$ & $\mathrm{C}(100)-\operatorname{Ir}(4)-\mathrm{P}(3)$ & $100.7(3)$ \\
\hline $\mathrm{C}(6)-\operatorname{Ir}(4)-\mathrm{P}(3)$ & $92.3(3)$ & $\mathrm{C}(108)-\operatorname{Ir}(4)-\mathrm{P}(2)$ & $88.0(4)$ \\
\hline $\mathrm{C}(100)-\operatorname{Ir}(4)-\mathrm{P}(2)$ & 155.1(3) & $\mathrm{C}(6)-\operatorname{Ir}(4)-\mathrm{P}(2)$ & $98.0(3)$ \\
\hline $\mathrm{P}(3)-\operatorname{Ir}(4)-\mathrm{P}(2)$ & 103.83(13) & 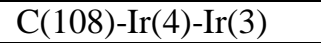 & 104.6(4) \\
\hline $\begin{array}{l}\mathrm{C}(100)-\operatorname{Ir}(4)-\operatorname{Ir}(3) \\
\end{array}$ & $50.2(3)$ & $\mathrm{C}(6)-\operatorname{Ir}(4)-\operatorname{Ir}(3)$ & $74.2(3)$ \\
\hline $\mathrm{P}(3)-\operatorname{Ir}(4)-\operatorname{Ir}(3)$ & $53.25(10)$ & $\mathrm{P}(2)-\operatorname{Ir}(4)-\operatorname{Ir}(3)$ & $154.35(9)$ \\
\hline $\mathrm{C}(108)-\operatorname{Ir}(4)-\operatorname{Ir}(1)$ & $94.4(4)$ & $\mathrm{C}(100)-\operatorname{Ir}(4)-\operatorname{Ir}(1)$ & $49.3(3)$ \\
\hline $\mathrm{C}(6)-\operatorname{Ir}(4)-\operatorname{Ir}(1)$ & $73.5(3)$ & P(3)-Ir(4)-Ir(1) & $146.76(10)$ \\
\hline $\mathrm{P}(2)-\operatorname{Ir}(4)-\operatorname{Ir}(1)$ & $107.75(9)$ & $\operatorname{Ir}(3)-\operatorname{Ir}(4)-\operatorname{Ir}(1)$ & 93.64(2) \\
\hline $\operatorname{Ir}(4)-C(100)-\operatorname{Ir}(3)$ & $80.9(5)$ & $\operatorname{Ir}(4)-C(100)-\operatorname{Ir}(1)$ & $83.2(5)$ \\
\hline $\operatorname{Ir}(3)-C(100)-\operatorname{Ir}(1)$ & $142.3(8)$ & $\operatorname{Ir}(4)-C(100)-\operatorname{Ir}(2)$ & $142.5(8)$ \\
\hline $\operatorname{Ir}(3)-C(100)-\operatorname{Ir}(2)$ & $84.1(5)$ & $\operatorname{Ir}(1)-C(100)-\operatorname{Ir}(2)$ & $88.2(5)$ \\
\hline $\mathrm{C}(400)-\mathrm{P}(1)-\mathrm{C}(200)$ & $100.6(7)$ & $\mathrm{C}(400)-\mathrm{P}(1)-\mathrm{C}(300)$ & $102.4(8)$ \\
\hline $\mathrm{C}(200)-\mathrm{P}(1)-\mathrm{C}(300)$ & $103.0(8)$ & $\mathrm{C}(400)-\mathrm{P}(1)-\operatorname{Ir}(3)$ & $114.7(5)$ \\
\hline $\mathrm{C}(200)-\mathrm{P}(1)-\operatorname{Ir}(3)$ & $112.0(6)$ & $\mathrm{C}(300)-\mathrm{P}(1)-\operatorname{Ir}(3)$ & $121.7(6)$ \\
\hline
\end{tabular}




\begin{tabular}{|c|c|c|c|}
\hline $\mathrm{C}(600)-\mathrm{P}(2)-\mathrm{C}(700)$ & $103.2(8)$ & $\mathrm{C}(600)-\mathrm{P}(2)-\mathrm{C}(500)$ & $101.0(8)$ \\
\hline $\mathrm{C}(700)-\mathrm{P}(2)-\mathrm{C}(500)$ & $100.0(7)$ & $\mathrm{C}(600)-\mathrm{P}(2)-\operatorname{Ir}(4)$ & $119.3(5)$ \\
\hline $\mathrm{C}(700)-\mathrm{P}(2)-\operatorname{Ir}(4)$ & $116.7(5)$ & $\mathrm{C}(500)-\mathrm{P}(2)-\operatorname{Ir}(4)$ & $113.7(6)$ \\
\hline $\mathrm{C}(900)-\mathrm{P}(3)-\mathrm{C}(800)$ & $98.0(8)$ & $\mathrm{C}(900)-\mathrm{P}(3)-\operatorname{Ir}(4)$ & $126.4(5)$ \\
\hline $\mathrm{C}(800)-\mathrm{P}(3)-\operatorname{Ir}(4)$ & $118.4(5)$ & $\mathrm{C}(900)-\mathrm{P}(3)-\operatorname{Ir}(3)$ & $121.4(6)$ \\
\hline $\mathrm{C}(800)-\mathrm{P}(3)-\operatorname{Ir}(3)$ & $119.6(6)$ & $\operatorname{Ir}(4)-\mathrm{P}(3)-\operatorname{Ir}(3)$ & $74.48(11)$ \\
\hline $\mathrm{O}(1 \mathrm{~A})-\mathrm{C}(1 \mathrm{~A})-\operatorname{Ir}(1)$ & $179.3(12)$ & $\mathrm{O}(2 \mathrm{~A})-\mathrm{C}(2 \mathrm{~A})-\operatorname{Ir}(2)$ & $177.8(11)$ \\
\hline $\mathrm{O}(3 \mathrm{~A})-\mathrm{C}(3 \mathrm{~A})-\operatorname{Ir}(3)$ & 176.1(15) & $\mathrm{C}(108)-\mathrm{N}(1)-\mathrm{C}(107)$ & $173.6(19)$ \\
\hline $\mathrm{C}(102)-\mathrm{C}(101)-\mathrm{C}(106)$ & 120.0 & $\mathrm{C}(102)-\mathrm{C}(101)-\mathrm{C}(107)$ & 113.1(18) \\
\hline $\mathrm{C}(106)-\mathrm{C}(101)-\mathrm{C}(107)$ & $126.6(18)$ & $\mathrm{C}(101)-\mathrm{C}(102)-\mathrm{C}(103)$ & 120.0 \\
\hline $\mathrm{C}(102)-\mathrm{C}(103)-\mathrm{C}(104)$ & 120.0 & $\mathrm{C}(105)-\mathrm{C}(104)-\mathrm{C}(103)$ & 120.0 \\
\hline $\mathrm{C}(106)-\mathrm{C}(105)-\mathrm{C}(104)$ & 120.0 & $\mathrm{C}(105)-\mathrm{C}(106)-\mathrm{C}(101)$ & 120.0 \\
\hline $\mathrm{C}(101)-\mathrm{C}(107)-\mathrm{N}(1)$ & 111.4(16) & $\mathrm{N}(1)-\mathrm{C}(108)-\operatorname{Ir}(4)$ & 178.0(13) \\
\hline $\mathrm{C}\left(2^{\prime}\right)-\mathrm{C}\left(1^{\prime}\right)-\mathrm{C}\left(6^{\prime}\right)$ & $117.0(10)$ & $\mathrm{C}\left(2^{\prime}\right)-\mathrm{C}\left(1^{\prime}\right)-\mathrm{C}\left(9^{\prime}\right)$ & 116.1(11) \\
\hline $\mathrm{C}\left(6^{\prime}\right)-\mathrm{C}\left(1^{\prime}\right)-\mathrm{C}\left(9^{\prime}\right)$ & $104.0(11)$ & $C\left(2^{\prime}\right)-C\left(1^{\prime}\right)-\operatorname{Ir}(2)$ & $68.4(6)$ \\
\hline$C\left(6^{\prime}\right)-C\left(1^{\prime}\right)-\operatorname{Ir}(2)$ & $120.5(8)$ & $\mathrm{C}\left(9^{\prime}\right)-\mathrm{C}\left(1^{\prime}\right)-\operatorname{Ir}(2)$ & 127.4(9) \\
\hline $\mathrm{C}\left(1^{\prime}\right)-\mathrm{C}\left(2^{\prime}\right)-\mathrm{C}\left(12^{\prime}\right)$ & $119.9(12)$ & $\mathrm{C}\left(1^{\prime}\right)-\mathrm{C}\left(2^{\prime}\right)-\mathrm{C}\left(3^{\prime}\right)$ & 119.9(12) \\
\hline $\mathrm{C}\left(12^{\prime}\right)-\mathrm{C}\left(2^{\prime}\right)-\mathrm{C}\left(3^{\prime}\right)$ & $105.5(10)$ & $\mathrm{C}\left(1^{\prime}\right)-\mathrm{C}\left(2^{\prime}\right)-\operatorname{Ir}(2)$ & $72.2(6)$ \\
\hline $\mathrm{C}\left(12^{\prime}\right)-\mathrm{C}\left(2^{\prime}\right)-\operatorname{Ir}(2)$ & 126.7(9) & $\mathrm{C}\left(3^{\prime}\right)-\mathrm{C}\left(2^{\prime}\right)-\operatorname{Ir}(2)$ & $110.6(8)$ \\
\hline $\mathrm{C}\left(4^{\prime}\right)-\mathrm{C}\left(3^{\prime}\right)-\mathrm{C}\left(2^{\prime}\right)$ & $119.8(11)$ & $\mathrm{C}\left(4^{\prime}\right)-\mathrm{C}\left(3^{\prime}\right)-\mathrm{C}\left(14^{\prime}\right)$ & $118.8(10)$ \\
\hline $\mathrm{C}\left(2^{\prime}\right)-\mathrm{C}\left(3^{\prime}\right)-\mathrm{C}\left(14^{\prime}\right)$ & $106.0(11)$ & $\mathrm{C}\left(4^{\prime}\right)-\mathrm{C}\left(3^{\prime}\right)-\operatorname{Ir}(1)$ & 73.3(7) \\
\hline$C\left(2^{\prime}\right)-C\left(3^{\prime}\right)-\operatorname{Ir}(1)$ & $111.8(8)$ & $\mathrm{C}\left(14^{\prime}\right)-\mathrm{C}\left(3^{\prime}\right)-\operatorname{Ir}(1)$ & 125.2(9) \\
\hline $\mathrm{C}\left(3^{\prime}\right)-\mathrm{C}\left(4^{\prime}\right)-\mathrm{C}\left(5^{\prime}\right)$ & 117.7(11) & $\mathrm{C}\left(3^{\prime}\right)-\mathrm{C}\left(4^{\prime}\right)-\mathrm{C}\left(17^{\prime}\right)$ & $116.5(11)$ \\
\hline $\mathrm{C}\left(5^{\prime}\right)-\mathrm{C}\left(4^{\prime}\right)-\mathrm{C}\left(17^{\prime}\right)$ & $102.5(10)$ & $\mathrm{C}\left(3^{\prime}\right)-\mathrm{C}\left(4^{\prime}\right)-\operatorname{Ir}(1)$ & $66.7(6)$ \\
\hline$C\left(5^{\prime}\right)-C\left(4^{\prime}\right)-\operatorname{Ir}(1)$ & $122.2(8)$ & $\mathrm{C}\left(17^{\prime}\right)-\mathrm{C}\left(4^{\prime}\right)-\operatorname{Ir}(1)$ & $127.9(8)$ \\
\hline $\mathrm{C}\left(6^{\prime}\right)-\mathrm{C}\left(5^{\prime}\right)-\mathrm{C}\left(19^{\prime}\right)$ & $119.2(12)$ & $\mathrm{C}\left(6^{\prime}\right)-\mathrm{C}\left(5^{\prime}\right)-\mathrm{C}\left(4^{\prime}\right)$ & $121.5(12)$ \\
\hline $\mathrm{C}\left(19^{\prime}\right)-\mathrm{C}\left(5^{\prime}\right)-\mathrm{C}\left(4^{\prime}\right)$ & $110.7(10)$ & $\mathrm{C}\left(5^{\prime}\right)-\mathrm{C}\left(6^{\prime}\right)-\mathrm{C}\left(7^{\prime}\right)$ & 121.1(12) \\
\hline $\mathrm{C}\left(5^{\prime}\right)-\mathrm{C}\left(6^{\prime}\right)-\mathrm{C}\left(1^{\prime}\right)$ & $122.5(12)$ & $\mathrm{C}\left(7^{\prime}\right)-\mathrm{C}\left(6^{\prime}\right)-\mathrm{C}\left(1^{\prime}\right)$ & $108.0(11)$ \\
\hline $\mathrm{C}\left(21^{\prime}\right)-\mathrm{C}\left(7^{\prime}\right)-\mathrm{C}\left(8^{\prime}\right)$ & $120.7(13)$ & $\mathrm{C}\left(21^{\prime}\right)-\mathrm{C}\left(7^{\prime}\right)-\mathrm{C}\left(6^{\prime}\right)$ & $120.5(13)$ \\
\hline $\mathrm{C}\left(8^{\prime}\right)-\mathrm{C}\left(7^{\prime}\right)-\mathrm{C}\left(6^{\prime}\right)$ & $109.9(12)$ & $\mathrm{C}\left(24^{\prime}\right)-\mathrm{C}\left(8^{\prime}\right)-\mathrm{C}\left(7^{\prime}\right)$ & $118.9(13)$ \\
\hline $\mathrm{C}\left(24^{\prime}\right)-\mathrm{C}\left(8^{\prime}\right)-\mathrm{C}\left(9^{\prime}\right)$ & $121.0(14)$ & $\mathrm{C}\left(7^{\prime}\right)-\mathrm{C}\left(8^{\prime}\right)-\mathrm{C}\left(9^{\prime}\right)$ & $109.2(11)$ \\
\hline $\mathrm{C}\left(10^{\prime}\right)-\mathrm{C}\left(9^{\prime}\right)-\mathrm{C}\left(8^{\prime}\right)$ & $120.2(12)$ & $\mathrm{C}\left(10^{\prime}\right)-\mathrm{C}\left(9^{\prime}\right)-\mathrm{C}\left(1^{\prime}\right)$ & $120.8(12)$ \\
\hline $\mathrm{C}\left(8^{\prime}\right)-\mathrm{C}\left(9^{\prime}\right)-\mathrm{C}\left(1^{\prime}\right)$ & $108.1(12)$ & $\mathrm{C}\left(9^{\prime}\right)-\mathrm{C}\left(10^{\prime}\right)-\mathrm{C}\left(26^{\prime}\right)$ & $118.5(13)$ \\
\hline $\mathrm{C}\left(9^{\prime}\right)-\mathrm{C}\left(10^{\prime}\right)-\mathrm{C}\left(11^{\prime}\right)$ & $120.9(11)$ & $\mathrm{C}\left(26^{\prime}\right)-\mathrm{C}\left(10^{\prime}\right)-\mathrm{C}\left(11^{\prime}\right)$ & $108.7(11)$ \\
\hline $\mathrm{C}\left(12^{\prime}\right)-\mathrm{C}\left(11^{\prime}\right)-\mathrm{C}\left(28^{\prime}\right)$ & $119.9(12)$ & $\mathrm{C}\left(12^{\prime}\right)-\mathrm{C}\left(11^{\prime}\right)-\mathrm{C}\left(10^{\prime}\right)$ & $120.5(13)$ \\
\hline $\mathrm{C}\left(28^{\prime}\right)-\mathrm{C}\left(11^{\prime}\right)-\mathrm{C}\left(10^{\prime}\right)$ & $107.5(12)$ & $\mathrm{C}\left(11^{\prime}\right)-\mathrm{C}\left(12^{\prime}\right)-\mathrm{C}\left(13^{\prime}\right)$ & $120.9(11)$ \\
\hline $\mathrm{C}\left(11^{\prime}\right)-\mathrm{C}\left(12^{\prime}\right)-\mathrm{C}\left(2^{\prime}\right)$ & $121.2(13)$ & $\mathrm{C}\left(13^{\prime}\right)-\mathrm{C}\left(12^{\prime}\right)-\mathrm{C}\left(2^{\prime}\right)$ & $110.2(11)$ \\
\hline $\mathrm{C}\left(30^{\prime}\right)-\mathrm{C}\left(13^{\prime}\right)-\mathrm{C}\left(14^{\prime}\right)$ & $119.8(11)$ & $\mathrm{C}\left(30^{\prime}\right)-\mathrm{C}\left(13^{\prime}\right)-\mathrm{C}\left(12^{\prime}\right)$ & $120.0(12)$ \\
\hline $\mathrm{C}\left(14^{\prime}\right)-\mathrm{C}\left(13^{\prime}\right)-\mathrm{C}\left(12^{\prime}\right)$ & $108.7(11)$ & $\mathrm{C}\left(15^{\prime}\right)-\mathrm{C}\left(14^{\prime}\right)-\mathrm{C}\left(13^{\prime}\right)$ & $122.5(12)$ \\
\hline $\mathrm{C}\left(15^{\prime}\right)-\mathrm{C}\left(14^{\prime}\right)-\mathrm{C}\left(3^{\prime}\right)$ & $120.7(12)$ & $\mathrm{C}\left(13^{\prime}\right)-\mathrm{C}\left(14^{\prime}\right)-\mathrm{C}\left(3^{\prime}\right)$ & 109.1(11) \\
\hline $\mathrm{C}\left(14^{\prime}\right)-\mathrm{C}\left(15^{\prime}\right)-\mathrm{C}\left(16^{\prime}\right)$ & $120.3(11)$ & $\mathrm{C}\left(14^{\prime}\right)-\mathrm{C}\left(15^{\prime}\right)-\mathrm{C}\left(32^{\prime}\right)$ & $117.4(12)$ \\
\hline $\mathrm{C}\left(16^{\prime}\right)-\mathrm{C}\left(15^{\prime}\right)-\mathrm{C}\left(32^{\prime}\right)$ & $109.9(11)$ & $\mathrm{C}\left(17^{\prime}\right)-\mathrm{C}\left(16^{\prime}\right)-\mathrm{C}\left(15^{\prime}\right)$ & $121.7(11)$ \\
\hline $\mathrm{C}\left(17^{\prime}\right)-\mathrm{C}\left(16^{\prime}\right)-\mathrm{C}\left(34^{\prime}\right)$ & 119.1(13) & $\mathrm{C}\left(15^{\prime}\right)-\mathrm{C}\left(16^{\prime}\right)-\mathrm{C}\left(34^{\prime}\right)$ & $107.9(12)$ \\
\hline $\mathrm{C}\left(16^{\prime}\right)-\mathrm{C}\left(17^{\prime}\right)-\mathrm{C}\left(18^{\prime}\right)$ & $119.4(11)$ & $\mathrm{C}\left(16^{\prime}\right)-\mathrm{C}\left(17^{\prime}\right)-\mathrm{C}\left(4^{\prime}\right)$ & $121.2(12)$ \\
\hline $\mathrm{C}\left(18^{\prime}\right)-\mathrm{C}\left(17^{\prime}\right)-\mathrm{C}\left(4^{\prime}\right)$ & $109.9(11)$ & $\mathrm{C}\left(36^{\prime}\right)-\mathrm{C}\left(18^{\prime}\right)-\mathrm{C}\left(19^{\prime}\right)$ & $120.0(13)$ \\
\hline $\mathrm{C}\left(36^{\prime}\right)-\mathrm{C}\left(18^{\prime}\right)-\mathrm{C}\left(17^{\prime}\right)$ & $120.6(13)$ & $\mathrm{C}\left(19^{\prime}\right)-\mathrm{C}\left(18^{\prime}\right)-\mathrm{C}\left(17^{\prime}\right)$ & $108.5(11)$ \\
\hline $\mathrm{C}\left(20^{\prime}\right)-\mathrm{C}\left(19^{\prime}\right)-\mathrm{C}\left(18^{\prime}\right)$ & $121.8(12)$ & $\mathrm{C}\left(20^{\prime}\right)-\mathrm{C}\left(19^{\prime}\right)-\mathrm{C}\left(5^{\prime}\right)$ & $120.4(12)$ \\
\hline $\mathrm{C}\left(18^{\prime}\right)-\mathrm{C}\left(19^{\prime}\right)-\mathrm{C}\left(5^{\prime}\right)$ & 107.6(11) & $\mathrm{C}\left(19^{\prime}\right)-\mathrm{C}\left(20^{\prime}\right)-\mathrm{C}\left(38^{\prime}\right)$ & $118.4(13)$ \\
\hline $\mathrm{C}\left(19^{\prime}\right)-\mathrm{C}\left(20^{\prime}\right)-\mathrm{C}\left(21^{\prime}\right)$ & $120.0(13)$ & $\mathrm{C}\left(38^{\prime}\right)-\mathrm{C}\left(20^{\prime}\right)-\mathrm{C}\left(21^{\prime}\right)$ & 107.7(13) \\
\hline $\mathrm{C}\left(7^{\prime}\right)-\mathrm{C}\left(21^{\prime}\right)-\mathrm{C}\left(22^{\prime}\right)$ & $120.1(15)$ & $\mathrm{C}\left(7^{\prime}\right)-\mathrm{C}\left(21^{\prime}\right)-\mathrm{C}\left(20^{\prime}\right)$ & $118.6(13)$ \\
\hline $\mathrm{C}\left(22^{\prime}\right)-\mathrm{C}\left(21^{\prime}\right)-\mathrm{C}\left(20^{\prime}\right)$ & $108.9(13)$ & $\mathrm{C}\left(23^{\prime}\right)-\mathrm{C}\left(22^{\prime}\right)-\mathrm{C}\left(21^{\prime}\right)$ & $119.3(14)$ \\
\hline $\mathrm{C}\left(23^{\prime}\right)-\mathrm{C}\left(22^{\prime}\right)-\mathrm{C}\left(39^{\prime}\right)$ & $120.7(15)$ & $\mathrm{C}\left(21^{\prime}\right)-\mathrm{C}\left(22^{\prime}\right)-\mathrm{C}\left(39^{\prime}\right)$ & 106.9(14) \\
\hline $\mathrm{C}\left(22^{\prime}\right)-\mathrm{C}\left(23^{\prime}\right)-\mathrm{C}\left(24^{\prime}\right)$ & $119.9(14)$ & $\mathrm{C}\left(22^{\prime}\right)-\mathrm{C}\left(23^{\prime}\right)-\mathrm{C}\left(42^{\prime}\right)$ & $119.3(15)$ \\
\hline $\mathrm{C}\left(24^{\prime}\right)-\mathrm{C}\left(23^{\prime}\right)-\mathrm{C}\left(42^{\prime}\right)$ & $109.7(15)$ & $\mathrm{C}\left(8^{\prime}\right)-\mathrm{C}\left(24^{\prime}\right)-\mathrm{C}\left(23^{\prime}\right)$ & $120.9(14)$ \\
\hline $\mathrm{C}\left(8^{\prime}\right)-\mathrm{C}\left(24^{\prime}\right)-\mathrm{C}\left(25^{\prime}\right)$ & $118.5(14)$ & $\mathrm{C}\left(23^{\prime}\right)-\mathrm{C}\left(24^{\prime}\right)-\mathrm{C}\left(25^{\prime}\right)$ & $107.7(13)$ \\
\hline $\mathrm{C}\left(26^{\prime}\right)-\mathrm{C}\left(25^{\prime}\right)-\mathrm{C}\left(24^{\prime}\right)$ & $119.6(13)$ & $\mathrm{C}\left(26^{\prime}\right)-\mathrm{C}\left(25^{\prime}\right)-\mathrm{C}\left(43^{\prime}\right)$ & $120.2(14)$ \\
\hline $\mathrm{C}\left(24^{\prime}\right)-\mathrm{C}\left(25^{\prime}\right)-\mathrm{C}\left(43^{\prime}\right)$ & $107.4(14)$ & $\mathrm{C}\left(25^{\prime}\right)-\mathrm{C}\left(26^{\prime}\right)-\mathrm{C}\left(10^{\prime}\right)$ & $122.1(13)$ \\
\hline
\end{tabular}




\begin{tabular}{|c|c|c|c|}
\hline $\mathrm{C}\left(25^{\prime}\right)-\mathrm{C}\left(26^{\prime}\right)-\mathrm{C}\left(27^{\prime}\right)$ & 119.4(13) & $\mathrm{C}\left(10^{\prime}\right)-\mathrm{C}\left(26^{\prime}\right)-\mathrm{C}\left(27^{\prime}\right)$ & $107.3(12)$ \\
\hline $\mathrm{C}\left(45^{\prime}\right)-\mathrm{C}\left(27^{\prime}\right)-\mathrm{C}\left(28^{\prime}\right)$ & $120.7(13)$ & $\mathrm{C}\left(45^{\prime}\right)-\mathrm{C}\left(27^{\prime}\right)-\mathrm{C}\left(26^{\prime}\right)$ & $119.6(15)$ \\
\hline $\mathrm{C}\left(28^{\prime}\right)-\mathrm{C}\left(27^{\prime}\right)-\mathrm{C}\left(26^{\prime}\right)$ & 108.1(12) & $\mathrm{C}\left(29^{\prime}\right)-\mathrm{C}\left(28^{\prime}\right)-\mathrm{C}\left(11^{\prime}\right)$ & $120.1(13)$ \\
\hline $\mathrm{C}\left(29^{\prime}\right)-\mathrm{C}\left(28^{\prime}\right)-\mathrm{C}\left(27^{\prime}\right)$ & $119.8(13)$ & $\mathrm{C}\left(11^{\prime}\right)-\mathrm{C}\left(28^{\prime}\right)-\mathrm{C}\left(27^{\prime}\right)$ & 108.4(13) \\
\hline $\mathrm{C}\left(28^{\prime}\right)-\mathrm{C}\left(29^{\prime}\right)-\mathrm{C}\left(30^{\prime}\right)$ & $119.8(12)$ & $\mathrm{C}\left(28^{\prime}\right)-\mathrm{C}\left(29^{\prime}\right)-\mathrm{C}\left(47^{\prime}\right)$ & $120.1(14)$ \\
\hline $\mathrm{C}\left(30^{\prime}\right)-\mathrm{C}\left(29^{\prime}\right)-\mathrm{C}\left(47^{\prime}\right)$ & $107.9(12)$ & $\mathrm{C}\left(13^{\prime}\right)-\mathrm{C}\left(30^{\prime}\right)-\mathrm{C}\left(29^{\prime}\right)$ & $119.2(12)$ \\
\hline $\mathrm{C}\left(13^{\prime}\right)-\mathrm{C}\left(30^{\prime}\right)-\mathrm{C}\left(31^{\prime}\right)$ & $118.3(12)$ & $\mathrm{C}\left(29^{\prime}\right)-\mathrm{C}\left(30^{\prime}\right)-\mathrm{C}\left(31^{\prime}\right)$ & $108.6(12)$ \\
\hline $\mathrm{C}\left(32^{\prime}\right)-\mathrm{C}\left(31^{\prime}\right)-\mathrm{C}\left(48^{\prime}\right)$ & 122.1(13) & $\mathrm{C}\left(32^{\prime}\right)-\mathrm{C}\left(31^{\prime}\right)-\mathrm{C}\left(30^{\prime}\right)$ & $120.0(12)$ \\
\hline $\mathrm{C}\left(48^{\prime}\right)-\mathrm{C}\left(31^{\prime}\right)-\mathrm{C}\left(30^{\prime}\right)$ & $106.7(12)$ & $\mathrm{C}\left(31^{\prime}\right)-\mathrm{C}\left(32^{\prime}\right)-\mathrm{C}\left(15^{\prime}\right)$ & $121.9(12)$ \\
\hline $\mathrm{C}\left(31^{\prime}\right)-\mathrm{C}\left(32^{\prime}\right)-\mathrm{C}\left(33^{\prime}\right)$ & $119.3(12)$ & $\mathrm{C}\left(15^{\prime}\right)-\mathrm{C}\left(32^{\prime}\right)-\mathrm{C}\left(33^{\prime}\right)$ & $106.2(12)$ \\
\hline $\mathrm{C}\left(50^{\prime}\right)-\mathrm{C}\left(33^{\prime}\right)-\mathrm{C}\left(34^{\prime}\right)$ & $121.3(13)$ & $\mathrm{C}\left(50^{\prime}\right)-\mathrm{C}\left(33^{\prime}\right)-\mathrm{C}\left(32^{\prime}\right)$ & $119.3(13)$ \\
\hline $\mathrm{C}\left(34^{\prime}\right)-\mathrm{C}\left(33^{\prime}\right)-\mathrm{C}\left(32^{\prime}\right)$ & $108.3(11)$ & $\mathrm{C}\left(35^{\prime}\right)-\mathrm{C}\left(34^{\prime}\right)-\mathrm{C}\left(16^{\prime}\right)$ & $122.2(12)$ \\
\hline $\mathrm{C}\left(35^{\prime}\right)-\mathrm{C}\left(34^{\prime}\right)-\mathrm{C}\left(33^{\prime}\right)$ & $117.9(12)$ & $\mathrm{C}\left(16^{\prime}\right)-\mathrm{C}\left(34^{\prime}\right)-\mathrm{C}\left(33^{\prime}\right)$ & $107.7(12)$ \\
\hline $\mathrm{C}\left(34^{\prime}\right)-\mathrm{C}\left(35^{\prime}\right)-\mathrm{C}\left(52^{\prime}\right)$ & $122.8(14)$ & $\mathrm{C}\left(34^{\prime}\right)-\mathrm{C}\left(35^{\prime}\right)-\mathrm{C}\left(36^{\prime}\right)$ & $118.8(11)$ \\
\hline $\mathrm{C}\left(52^{\prime}\right)-\mathrm{C}\left(35^{\prime}\right)-\mathrm{C}\left(36^{\prime}\right)$ & $106.7(13)$ & $\mathrm{C}\left(18^{\prime}\right)-\mathrm{C}\left(36^{\prime}\right)-\mathrm{C}\left(35^{\prime}\right)$ & $119.8(13)$ \\
\hline $\mathrm{C}\left(18^{\prime}\right)-\mathrm{C}\left(36^{\prime}\right)-\mathrm{C}\left(37^{\prime}\right)$ & $119.2(13)$ & $\mathrm{C}\left(35^{\prime}\right)-\mathrm{C}\left(36^{\prime}\right)-\mathrm{C}\left(37^{\prime}\right)$ & $108.4(13)$ \\
\hline $\mathrm{C}\left(38^{\prime}\right)-\mathrm{C}\left(37^{\prime}\right)-\mathrm{C}\left(53^{\prime}\right)$ & $120.4(15)$ & $\mathrm{C}\left(38^{\prime}\right)-\mathrm{C}\left(37^{\prime}\right)-\mathrm{C}\left(36^{\prime}\right)$ & $119.8(13)$ \\
\hline $\mathrm{C}\left(53^{\prime}\right)-\mathrm{C}\left(37^{\prime}\right)-\mathrm{C}\left(36^{\prime}\right)$ & $107.0(14)$ & $\mathrm{C}\left(37^{\prime}\right)-\mathrm{C}\left(38^{\prime}\right)-\mathrm{C}\left(20^{\prime}\right)$ & $120.8(14)$ \\
\hline $\mathrm{C}\left(37^{\prime}\right)-\mathrm{C}\left(38^{\prime}\right)-\mathrm{C}\left(39^{\prime}\right)$ & $119.2(14)$ & $\mathrm{C}\left(20^{\prime}\right)-\mathrm{C}\left(38^{\prime}\right)-\mathrm{C}\left(39^{\prime}\right)$ & $107.6(13)$ \\
\hline $\mathrm{C}\left(40^{\prime}\right)-\mathrm{C}\left(39^{\prime}\right)-\mathrm{C}\left(22^{\prime}\right)$ & $119.3(16)$ & $\mathrm{C}\left(40^{\prime}\right)-\mathrm{C}\left(39^{\prime}\right)-\mathrm{C}\left(38^{\prime}\right)$ & $120.6(14)$ \\
\hline $\mathrm{C}\left(22^{\prime}\right)-\mathrm{C}\left(39^{\prime}\right)-\mathrm{C}\left(38^{\prime}\right)$ & $108.8(14)$ & $\mathrm{C}\left(39^{\prime}\right)-\mathrm{C}\left(40^{\prime}\right)-\mathrm{C}\left(54^{\prime}\right)$ & $120.1(15)$ \\
\hline $\mathrm{C}\left(39^{\prime}\right)-\mathrm{C}\left(40^{\prime}\right)-\mathrm{C}\left(41^{\prime}\right)$ & $120.1(14)$ & $\mathrm{C}\left(54^{\prime}\right)-\mathrm{C}\left(40^{\prime}\right)-\mathrm{C}\left(41^{\prime}\right)$ & $106.8(15)$ \\
\hline $\mathrm{C}\left(42^{\prime}\right)-\mathrm{C}\left(41^{\prime}\right)-\mathrm{C}\left(56^{\prime}\right)$ & 120.1(16) & $\mathrm{C}\left(42^{\prime}\right)-\mathrm{C}\left(41^{\prime}\right)-\mathrm{C}\left(40^{\prime}\right)$ & $118.9(14)$ \\
\hline $\mathrm{C}\left(56^{\prime}\right)-\mathrm{C}\left(41^{\prime}\right)-\mathrm{C}\left(40^{\prime}\right)$ & $108.8(14)$ & $\mathrm{C}\left(41^{\prime}\right)-\mathrm{C}\left(42^{\prime}\right)-\mathrm{C}\left(23^{\prime}\right)$ & $121.7(16)$ \\
\hline $\mathrm{C}\left(41^{\prime}\right)-\mathrm{C}\left(42^{\prime}\right)-\mathrm{C}\left(43^{\prime}\right)$ & $120.1(15)$ & $\mathrm{C}\left(23^{\prime}\right)-\mathrm{C}\left(42^{\prime}\right)-\mathrm{C}\left(43^{\prime}\right)$ & $107.0(14)$ \\
\hline $\mathrm{C}\left(44^{\prime}\right)-\mathrm{C}\left(43^{\prime}\right)-\mathrm{C}\left(42^{\prime}\right)$ & $119.9(14)$ & $\mathrm{C}\left(44^{\prime}\right)-\mathrm{C}\left(43^{\prime}\right)-\mathrm{C}\left(25^{\prime}\right)$ & $120.4(15)$ \\
\hline $\mathrm{C}\left(42^{\prime}\right)-\mathrm{C}\left(43^{\prime}\right)-\mathrm{C}\left(25^{\prime}\right)$ & $108.2(14)$ & $\mathrm{C}\left(43^{\prime}\right)-\mathrm{C}\left(44^{\prime}\right)-\mathrm{C}\left(45^{\prime}\right)$ & $119.1(13)$ \\
\hline $\mathrm{C}\left(43^{\prime}\right)-\mathrm{C}\left(44^{\prime}\right)-\mathrm{C}\left(57^{\prime}\right)$ & $119.3(16)$ & $\mathrm{C}\left(45^{\prime}\right)-\mathrm{C}\left(44^{\prime}\right)-\mathrm{C}\left(57^{\prime}\right)$ & $107.9(14)$ \\
\hline $\mathrm{C}\left(27^{\prime}\right)-\mathrm{C}\left(45^{\prime}\right)-\mathrm{C}\left(44^{\prime}\right)$ & $121.3(14)$ & $\mathrm{C}\left(27^{\prime}\right)-\mathrm{C}\left(45^{\prime}\right)-\mathrm{C}\left(46^{\prime}\right)$ & $118.3(14)$ \\
\hline $\mathrm{C}\left(44^{\prime}\right)-\mathrm{C}\left(45^{\prime}\right)-\mathrm{C}\left(46^{\prime}\right)$ & $108.2(13)$ & $\mathrm{C}\left(47^{\prime}\right)-\mathrm{C}\left(46^{\prime}\right)-\mathrm{C}\left(58^{\prime}\right)$ & $120.1(14)$ \\
\hline $\mathrm{C}\left(47^{\prime}\right)-\mathrm{C}\left(46^{\prime}\right)-\mathrm{C}\left(45^{\prime}\right)$ & $121.6(13)$ & $\mathrm{C}\left(58^{\prime}\right)-\mathrm{C}\left(46^{\prime}\right)-\mathrm{C}\left(45^{\prime}\right)$ & $108.1(14)$ \\
\hline $\mathrm{C}\left(46^{\prime}\right)-\mathrm{C}\left(47^{\prime}\right)-\mathrm{C}\left(48^{\prime}\right)$ & $120.7(14)$ & $\mathrm{C}\left(46^{\prime}\right)-\mathrm{C}\left(47^{\prime}\right)-\mathrm{C}\left(29^{\prime}\right)$ & $119.4(13)$ \\
\hline $\mathrm{C}\left(48^{\prime}\right)-\mathrm{C}\left(47^{\prime}\right)-\mathrm{C}\left(29^{\prime}\right)$ & $107.8(13)$ & $\mathrm{C}\left(49^{\prime}\right)-\mathrm{C}\left(48^{\prime}\right)-\mathrm{C}\left(47^{\prime}\right)$ & $119.7(14)$ \\
\hline $\mathrm{C}\left(49^{\prime}\right)-\mathrm{C}\left(48^{\prime}\right)-\mathrm{C}\left(31^{\prime}\right)$ & $118.6(14)$ & $\mathrm{C}\left(47^{\prime}\right)-\mathrm{C}\left(48^{\prime}\right)-\mathrm{C}\left(31^{\prime}\right)$ & $109.0(12)$ \\
\hline $\mathrm{C}\left(48^{\prime}\right)-\mathrm{C}\left(49^{\prime}\right)-\mathrm{C}\left(59^{\prime}\right)$ & $119.0(14)$ & $\mathrm{C}\left(48^{\prime}\right)-\mathrm{C}\left(49^{\prime}\right)-\mathrm{C}\left(50^{\prime}\right)$ & $119.8(13)$ \\
\hline $\mathrm{C}\left(59^{\prime}\right)-\mathrm{C}\left(49^{\prime}\right)-\mathrm{C}\left(50^{\prime}\right)$ & $109.3(14)$ & $\mathrm{C}\left(33^{\prime}\right)-\mathrm{C}\left(50^{\prime}\right)-\mathrm{C}\left(49^{\prime}\right)$ & $120.8(13)$ \\
\hline $\mathrm{C}\left(33^{\prime}\right)-\mathrm{C}\left(50^{\prime}\right)-\mathrm{C}\left(51^{\prime}\right)$ & $119.1(13)$ & $\mathrm{C}\left(49^{\prime}\right)-\mathrm{C}\left(50^{\prime}\right)-\mathrm{C}\left(51^{\prime}\right)$ & $107.5(13)$ \\
\hline $\mathrm{C}\left(52^{\prime}\right)-\mathrm{C}\left(51^{\prime}\right)-\mathrm{C}\left(50^{\prime}\right)$ & $120.5(13)$ & $\mathrm{C}\left(52^{\prime}\right)-\mathrm{C}\left(51^{\prime}\right)-\mathrm{C}\left(60^{\prime}\right)$ & $119.6(14)$ \\
\hline $\mathrm{C}\left(50^{\prime}\right)-\mathrm{C}\left(51^{\prime}\right)-\mathrm{C}\left(60^{\prime}\right)$ & $108.2(13)$ & $\mathrm{C}\left(51^{\prime}\right)-\mathrm{C}\left(52^{\prime}\right)-\mathrm{C}\left(53^{\prime}\right)$ & $119.9(14)$ \\
\hline $\mathrm{C}\left(51^{\prime}\right)-\mathrm{C}\left(52^{\prime}\right)-\mathrm{C}\left(35^{\prime}\right)$ & $118.3(15)$ & $\mathrm{C}\left(53^{\prime}\right)-\mathrm{C}\left(52^{\prime}\right)-\mathrm{C}\left(35^{\prime}\right)$ & $109.6(13)$ \\
\hline $\mathrm{C}\left(54^{\prime}\right)-\mathrm{C}\left(53^{\prime}\right)-\mathrm{C}\left(52^{\prime}\right)$ & $120.4(15)$ & $\mathrm{C}\left(54^{\prime}\right)-\mathrm{C}\left(53^{\prime}\right)-\mathrm{C}\left(37^{\prime}\right)$ & $120.4(14)$ \\
\hline $\mathrm{C}\left(52^{\prime}\right)-\mathrm{C}\left(53^{\prime}\right)-\mathrm{C}\left(37^{\prime}\right)$ & $108.3(13)$ & $\mathrm{C}\left(53^{\prime}\right)-\mathrm{C}\left(54^{\prime}\right)-\mathrm{C}\left(55^{\prime}\right)$ & $120.2(15)$ \\
\hline $\mathrm{C}\left(53^{\prime}\right)-\mathrm{C}\left(54^{\prime}\right)-\mathrm{C}\left(40^{\prime}\right)$ & $119.2(15)$ & $\mathrm{C}\left(55^{\prime}\right)-\mathrm{C}\left(54^{\prime}\right)-\mathrm{C}\left(40^{\prime}\right)$ & $108.3(15)$ \\
\hline $\mathrm{C}\left(60^{\prime}\right)-\mathrm{C}\left(55^{\prime}\right)-\mathrm{C}\left(54^{\prime}\right)$ & $119.3(15)$ & $\mathrm{C}\left(60^{\prime}\right)-\mathrm{C}\left(55^{\prime}\right)-\mathrm{C}\left(56^{\prime}\right)$ & $120.9(16)$ \\
\hline $\mathrm{C}\left(54^{\prime}\right)-\mathrm{C}\left(55^{\prime}\right)-\mathrm{C}\left(56^{\prime}\right)$ & $108.4(14)$ & $\mathrm{C}\left(57^{\prime}\right)-\mathrm{C}\left(56^{\prime}\right)-\mathrm{C}\left(41^{\prime}\right)$ & $120.0(13)$ \\
\hline $\mathrm{C}\left(57^{\prime}\right)-\mathrm{C}\left(56^{\prime}\right)-\mathrm{C}\left(55^{\prime}\right)$ & 119.1(15) & $\mathrm{C}\left(41^{\prime}\right)-\mathrm{C}\left(56^{\prime}\right)-\mathrm{C}\left(55^{\prime}\right)$ & $107.7(15)$ \\
\hline $\mathrm{C}\left(56^{\prime}\right)-\mathrm{C}\left(57^{\prime}\right)-\mathrm{C}\left(58^{\prime}\right)$ & $121.3(14)$ & $\mathrm{C}\left(56^{\prime}\right)-\mathrm{C}\left(57^{\prime}\right)-\mathrm{C}\left(44^{\prime}\right)$ & $120.6(14)$ \\
\hline $\mathrm{C}\left(58^{\prime}\right)-\mathrm{C}\left(57^{\prime}\right)-\mathrm{C}\left(44^{\prime}\right)$ & $107.5(15)$ & $\mathrm{C}\left(59^{\prime}\right)-\mathrm{C}\left(58^{\prime}\right)-\mathrm{C}\left(46^{\prime}\right)$ & $120.0(14)$ \\
\hline $\mathrm{C}\left(59^{\prime}\right)-\mathrm{C}\left(58^{\prime}\right)-\mathrm{C}\left(57^{\prime}\right)$ & 119.1(15) & $\mathrm{C}\left(46^{\prime}\right)-\mathrm{C}\left(58^{\prime}\right)-\mathrm{C}\left(57^{\prime}\right)$ & 108.2(13) \\
\hline $\mathrm{C}\left(58^{\prime}\right)-\mathrm{C}\left(59^{\prime}\right)-\mathrm{C}\left(49^{\prime}\right)$ & $120.3(14)$ & $\mathrm{C}\left(58^{\prime}\right)-\mathrm{C}\left(59^{\prime}\right)-\mathrm{C}\left(60^{\prime}\right)$ & $119.5(14)$ \\
\hline $\mathrm{C}\left(49^{\prime}\right)-\mathrm{C}\left(59^{\prime}\right)-\mathrm{C}\left(60^{\prime}\right)$ & $107.9(14)$ & $\mathrm{C}\left(55^{\prime}\right)-\mathrm{C}\left(60^{\prime}\right)-\mathrm{C}\left(51^{\prime}\right)$ & $120.6(15)$ \\
\hline $\mathrm{C}\left(55^{\prime}\right)-\mathrm{C}\left(60^{\prime}\right)-\mathrm{C}\left(59^{\prime}\right)$ & $120.1(14)$ & $\mathrm{C}\left(51^{\prime}\right)-\mathrm{C}\left(60^{\prime}\right)-\mathrm{C}\left(59^{\prime}\right)$ & 107.1(13) \\
\hline $\mathrm{C}(2)-\mathrm{C}(1)-\mathrm{C}(9)$ & $115.3(12)$ & $C(2)-C(1)-C(6)$ & $123.1(10)$ \\
\hline $\mathrm{C}(9)-\mathrm{C}(1)-\mathrm{C}(6)$ & $109.0(10)$ & $\mathrm{C}(2)-\mathrm{C}(1)-\operatorname{Ir}(1)$ & $69.2(7)$ \\
\hline $\mathrm{C}(9)-\mathrm{C}(1)-\operatorname{Ir}(1)$ & $127.2(8)$ & $\mathrm{C}(6)-\mathrm{C}(1)-\operatorname{Ir}(1)$ & $109.2(8)$ \\
\hline $\mathrm{C}(1)-\mathrm{C}(2)-\mathrm{C}(12)$ & $119.9(11)$ & $\mathrm{C}(1)-\mathrm{C}(2)-\mathrm{C}(3)$ & $121.2(10)$ \\
\hline $\mathrm{C}(12)-\mathrm{C}(2)-\mathrm{C}(3)$ & $104.5(11)$ & $C(1)-C(2)-\operatorname{Ir}(1)$ & 72.1(7) \\
\hline
\end{tabular}




\begin{tabular}{|c|c|c|c|}
\hline $\mathrm{C}(12)-\mathrm{C}(2)-\operatorname{Ir}(1)$ & $124.9(8)$ & $\mathrm{C}(3)-\mathrm{C}(2)-\operatorname{Ir}(1)$ & $112.6(8)$ \\
\hline $\mathrm{C}(14)-\mathrm{C}(3)-\mathrm{C}(4)$ & $122.2(11)$ & $\mathrm{C}(14)-\mathrm{C}(3)-\mathrm{C}(2)$ & 109.4(10) \\
\hline $\mathrm{C}(4)-\mathrm{C}(3)-\mathrm{C}(2)$ & $117.0(12)$ & $\mathrm{C}(14)-\mathrm{C}(3)-\operatorname{Ir}(2)$ & $123.4(9)$ \\
\hline$C(4)-C(3)-\operatorname{Ir}(2)$ & $70.8(7)$ & $\mathrm{C}(2)-\mathrm{C}(3)-\operatorname{Ir}(2)$ & $109.3(8)$ \\
\hline$C(3)-C(4)-C(5)$ & $125.1(10)$ & $\mathrm{C}(3)-\mathrm{C}(4)-\mathrm{C}(17)$ & $111.8(12)$ \\
\hline$C(5)-C(4)-C(17)$ & $109.6(10)$ & $C(3)-C(4)-\operatorname{Ir}(2)$ & $69.2(7)$ \\
\hline$C(5)-C(4)-\operatorname{Ir}(2)$ & $112.1(9)$ & $\mathrm{C}(17)-\mathrm{C}(4)-\operatorname{Ir}(2)$ & $125.1(9)$ \\
\hline $\mathrm{C}(4)-\mathrm{C}(5)-\mathrm{C}(19)$ & $102.7(11)$ & $\mathrm{C}(4)-\mathrm{C}(5)-\mathrm{C}(6)$ & $116.4(10)$ \\
\hline$C(19)-C(5)-C(6)$ & $115.2(10)$ & $C(4)-C(5)-\operatorname{Ir}(3)$ & $98.2(8)$ \\
\hline $\mathrm{C}(19)-\mathrm{C}(5)-\operatorname{Ir}(3)$ & $115.3(8)$ & $C(6)-C(5)-\operatorname{Ir}(3)$ & 107.9(9) \\
\hline$C(7)-C(6)-C(1)$ & $101.8(10)$ & $C(7)-C(6)-C(5)$ & $114.6(10)$ \\
\hline$C(1)-C(6)-C(5)$ & $117.0(11)$ & $\mathrm{C}(7)-\mathrm{C}(6)-\operatorname{Ir}(4)$ & $118.6(9)$ \\
\hline $\mathrm{C}(1)-\mathrm{C}(6)-\operatorname{Ir}(4)$ & $99.7(8)$ & $\mathrm{C}(5)-\mathrm{C}(6)-\operatorname{Ir}(4)$ & $104.8(8)$ \\
\hline $\mathrm{C}(21)-\mathrm{C}(7)-\mathrm{C}(8)$ & $117.8(13)$ & $\mathrm{C}(21)-\mathrm{C}(7)-\mathrm{C}(6)$ & $125.0(12)$ \\
\hline$C(8)-C(7)-C(6)$ & $111.9(11)$ & $C(24)-C(8)-C(7)$ & $122.6(12)$ \\
\hline $\mathrm{C}(24)-\mathrm{C}(8)-\mathrm{C}(9)$ & $120.9(13)$ & $C(7)-C(8)-C(9)$ & $108.3(12)$ \\
\hline$C(10)-C(9)-C(8)$ & $118.9(12)$ & $\mathrm{C}(10)-\mathrm{C}(9)-\mathrm{C}(1)$ & $123.8(13)$ \\
\hline $\mathrm{C}(8)-\mathrm{C}(9)-\mathrm{C}(1)$ & $107.6(11)$ & $\mathrm{C}(9)-\mathrm{C}(10)-\mathrm{C}(11)$ & $119.5(12)$ \\
\hline $\mathrm{C}(9)-\mathrm{C}(10)-\mathrm{C}(26)$ & $119.9(12)$ & $C(11)-C(10)-C(26)$ & $106.8(13)$ \\
\hline $\mathrm{C}(12)-\mathrm{C}(11)-\mathrm{C}(10)$ & $119.4(12)$ & $\mathrm{C}(12)-\mathrm{C}(11)-\mathrm{C}(28)$ & $119.6(13)$ \\
\hline $\mathrm{C}(10)-\mathrm{C}(11)-\mathrm{C}(28)$ & $108.5(12)$ & $\mathrm{C}(11)-\mathrm{C}(12)-\mathrm{C}(13)$ & $121.4(13)$ \\
\hline $\mathrm{C}(11)-\mathrm{C}(12)-\mathrm{C}(2)$ & $121.6(12)$ & $\mathrm{C}(13)-\mathrm{C}(12)-\mathrm{C}(2)$ & $108.1(11)$ \\
\hline $\mathrm{C}(14)-\mathrm{C}(13)-\mathrm{C}(30)$ & $119.6(12)$ & $\mathrm{C}(14)-\mathrm{C}(13)-\mathrm{C}(12)$ & $110.1(12)$ \\
\hline $\mathrm{C}(30)-\mathrm{C}(13)-\mathrm{C}(12)$ & $119.2(12)$ & $C(15)-C(14)-C(13)$ & $121.5(12)$ \\
\hline$C(15)-C(14)-C(3)$ & $121.6(11)$ & $C(13)-C(14)-C(3)$ & $107.6(12)$ \\
\hline$C(14)-C(15)-C(16)$ & $119.7(13)$ & $\mathrm{C}(14)-\mathrm{C}(15)-\mathrm{C}(32)$ & $119.6(12)$ \\
\hline$C(16)-C(15)-C(32)$ & $108.6(11)$ & $\mathrm{C}(17)-\mathrm{C}(16)-\mathrm{C}(34)$ & $119.1(12)$ \\
\hline$C(17)-C(16)-C(15)$ & $120.2(12)$ & $C(34)-C(16)-C(15)$ & $107.8(12)$ \\
\hline$C(16)-C(17)-C(18)$ & $120.0(12)$ & $C(16)-C(17)-C(4)$ & $124.1(11)$ \\
\hline $\mathrm{C}(18)-\mathrm{C}(17)-\mathrm{C}(4)$ & $107.0(12)$ & $\mathrm{C}(36)-\mathrm{C}(18)-\mathrm{C}(17)$ & $121.1(13)$ \\
\hline$C(36)-C(18)-C(19)$ & $121.6(12)$ & $\mathrm{C}(17)-\mathrm{C}(18)-\mathrm{C}(19)$ & $108.4(11)$ \\
\hline $\mathrm{C}(20)-\mathrm{C}(19)-\mathrm{C}(18)$ & $118.2(12)$ & $\mathrm{C}(20)-\mathrm{C}(19)-\mathrm{C}(5)$ & $124.6(11)$ \\
\hline $\mathrm{C}(18)-\mathrm{C}(19)-\mathrm{C}(5)$ & 111.1(11) & $\mathrm{C}(19)-\mathrm{C}(20)-\mathrm{C}(38)$ & $120.4(13)$ \\
\hline$C(19)-C(20)-C(21)$ & $118.9(11)$ & $\mathrm{C}(38)-\mathrm{C}(20)-\mathrm{C}(21)$ & $107.6(12)$ \\
\hline$C(7)-C(21)-C(22)$ & $120.5(12)$ & $C(7)-C(21)-C(20)$ & $119.0(12)$ \\
\hline$C(22)-C(21)-C(20)$ & $108.3(12)$ & $C(23)-C(22)-C(21)$ & $122.2(12)$ \\
\hline$C(23)-C(22)-C(39)$ & $118.8(15)$ & $C(21)-C(22)-C(39)$ & $108.1(12)$ \\
\hline$C(22)-C(23)-C(42)$ & $121.6(15)$ & $C(22)-C(23)-C(24)$ & $118.4(13)$ \\
\hline$C(42)-C(23)-C(24)$ & $107.8(14)$ & $C(8)-C(24)-C(25)$ & $119.4(13)$ \\
\hline$C(8)-C(24)-C(23)$ & $118.4(13)$ & $C(25)-C(24)-C(23)$ & $109.4(14)$ \\
\hline$C(26)-C(25)-C(24)$ & $119.8(13)$ & $C(26)-C(25)-C(43)$ & $119.5(16)$ \\
\hline$C(24)-C(25)-C(43)$ & $107.7(12)$ & $C(25)-C(26)-C(27)$ & $119.7(14)$ \\
\hline$C(25)-C(26)-C(10)$ & $120.9(14)$ & $C(27)-C(26)-C(10)$ & $108.9(13)$ \\
\hline$C(45)-C(27)-C(26)$ & $120.1(15)$ & $\mathrm{C}(45)-\mathrm{C}(27)-\mathrm{C}(28)$ & $121.3(16)$ \\
\hline$C(26)-C(27)-C(28)$ & $107.7(14)$ & $C(29)-C(28)-C(27)$ & $120.0(13)$ \\
\hline$C(29)-C(28)-C(11)$ & $120.0(13)$ & $\mathrm{C}(27)-\mathrm{C}(28)-\mathrm{C}(11)$ & $108.0(13)$ \\
\hline $\mathrm{C}(28)-\mathrm{C}(29)-\mathrm{C}(47)$ & $118.9(14)$ & $\mathrm{C}(28)-\mathrm{C}(29)-\mathrm{C}(30)$ & $120.8(14)$ \\
\hline $\mathrm{C}(47)-\mathrm{C}(29)-\mathrm{C}(30)$ & $107.2(13)$ & $\mathrm{C}(13)-\mathrm{C}(30)-\mathrm{C}(31)$ & $118.7(12)$ \\
\hline $\mathrm{C}(13)-\mathrm{C}(30)-\mathrm{C}(29)$ & $119.0(14)$ & $\mathrm{C}(31)-\mathrm{C}(30)-\mathrm{C}(29)$ & $109.5(12)$ \\
\hline $\mathrm{C}(32)-\mathrm{C}(31)-\mathrm{C}(30)$ & $120.8(13)$ & $\mathrm{C}(32)-\mathrm{C}(31)-\mathrm{C}(48)$ & $119.6(13)$ \\
\hline $\mathrm{C}(30)-\mathrm{C}(31)-\mathrm{C}(48)$ & $107.6(13)$ & $C(31)-C(32)-C(15)$ & $119.8(13)$ \\
\hline $\mathrm{C}(31)-\mathrm{C}(32)-\mathrm{C}(33)$ & $120.6(13)$ & $\mathrm{C}(15)-\mathrm{C}(32)-\mathrm{C}(33)$ & $107.3(11)$ \\
\hline $\mathrm{C}(50)-\mathrm{C}(33)-\mathrm{C}(32)$ & $120.5(13)$ & $\mathrm{C}(50)-\mathrm{C}(33)-\mathrm{C}(34)$ & $119.8(13)$ \\
\hline $\mathrm{C}(32)-\mathrm{C}(33)-\mathrm{C}(34)$ & $108.0(12)$ & $\mathrm{C}(35)-\mathrm{C}(34)-\mathrm{C}(16)$ & $121.4(14)$ \\
\hline $\mathrm{C}(35)-\mathrm{C}(34)-\mathrm{C}(33)$ & $119.4(13)$ & $\mathrm{C}(16)-\mathrm{C}(34)-\mathrm{C}(33)$ & $108.3(11)$ \\
\hline $\mathrm{C}(34)-\mathrm{C}(35)-\mathrm{C}(36)$ & $118.7(13)$ & $\mathrm{C}(34)-\mathrm{C}(35)-\mathrm{C}(52)$ & $119.7(13)$ \\
\hline $\mathrm{C}(36)-\mathrm{C}(35)-\mathrm{C}(52)$ & $108.4(13)$ & $\mathrm{C}(18)-\mathrm{C}(36)-\mathrm{C}(35)$ & $119.6(12)$ \\
\hline
\end{tabular}




\begin{tabular}{|c|c|c|c|}
\hline $\mathrm{C}(18)-\mathrm{C}(36)-\mathrm{C}(37)$ & $119.6(13)$ & $C(35)-C(36)-C(37)$ & $108.2(13)$ \\
\hline $\mathrm{C}(38)-\mathrm{C}(37)-\mathrm{C}(53)$ & $120.3(14)$ & $\mathrm{C}(38)-\mathrm{C}(37)-\mathrm{C}(36)$ & $118.6(13)$ \\
\hline $\mathrm{C}(53)-\mathrm{C}(37)-\mathrm{C}(36)$ & $107.6(14)$ & $\mathrm{C}(37)-\mathrm{C}(38)-\mathrm{C}(20)$ & $121.6(13)$ \\
\hline $\mathrm{C}(37)-\mathrm{C}(38)-\mathrm{C}(39)$ & $119.7(15)$ & $\mathrm{C}(20)-\mathrm{C}(38)-\mathrm{C}(39)$ & $108.5(13)$ \\
\hline $\mathrm{C}(40)-\mathrm{C}(39)-\mathrm{C}(38)$ & $119.8(15)$ & $\mathrm{C}(40)-\mathrm{C}(39)-\mathrm{C}(22)$ & $119.6(13)$ \\
\hline $\mathrm{C}(38)-\mathrm{C}(39)-\mathrm{C}(22)$ & $107.4(13)$ & $\mathrm{C}(39)-\mathrm{C}(40)-\mathrm{C}(54)$ & 119.7(14) \\
\hline $\mathrm{C}(39)-\mathrm{C}(40)-\mathrm{C}(41)$ & $120.6(15)$ & $\mathrm{C}(54)-\mathrm{C}(40)-\mathrm{C}(41)$ & $108.9(15)$ \\
\hline $\mathrm{C}(42)-\mathrm{C}(41)-\mathrm{C}(56)$ & $121.8(14)$ & $\mathrm{C}(42)-\mathrm{C}(41)-\mathrm{C}(40)$ & $118.2(16)$ \\
\hline $\mathrm{C}(56)-\mathrm{C}(41)-\mathrm{C}(40)$ & $107.1(15)$ & $\mathrm{C}(41)-\mathrm{C}(42)-\mathrm{C}(23)$ & 121.1(14) \\
\hline $\mathrm{C}(41)-\mathrm{C}(42)-\mathrm{C}(43)$ & $116.2(17)$ & $\mathrm{C}(23)-\mathrm{C}(42)-\mathrm{C}(43)$ & $108.5(14)$ \\
\hline$C(44)-C(43)-C(25)$ & $120.7(14)$ & $\mathrm{C}(44)-\mathrm{C}(43)-\mathrm{C}(42)$ & $121.2(16)$ \\
\hline$C(25)-C(43)-C(42)$ & $106.5(14)$ & $\mathrm{C}(43)-\mathrm{C}(44)-\mathrm{C}(57)$ & $120.5(14)$ \\
\hline $\mathrm{C}(43)-\mathrm{C}(44)-\mathrm{C}(45)$ & $118.9(15)$ & $\mathrm{C}(57)-\mathrm{C}(44)-\mathrm{C}(45)$ & $108.6(16)$ \\
\hline $\mathrm{C}(27)-\mathrm{C}(45)-\mathrm{C}(46)$ & $119.5(15)$ & $\mathrm{C}(27)-\mathrm{C}(45)-\mathrm{C}(44)$ & $120.9(17)$ \\
\hline$C(46)-C(45)-C(44)$ & $107.4(14)$ & $\mathrm{C}(47)-\mathrm{C}(46)-\mathrm{C}(45)$ & $119.4(15)$ \\
\hline $\mathrm{C}(47)-\mathrm{C}(46)-\mathrm{C}(58)$ & $119.3(15)$ & $\mathrm{C}(45)-\mathrm{C}(46)-\mathrm{C}(58)$ & $108.6(16)$ \\
\hline $\mathrm{C}(46)-\mathrm{C}(47)-\mathrm{C}(29)$ & $121.0(16)$ & $\mathrm{C}(46)-\mathrm{C}(47)-\mathrm{C}(48)$ & $119.8(14)$ \\
\hline $\mathrm{C}(29)-\mathrm{C}(47)-\mathrm{C}(48)$ & $108.2(14)$ & $\mathrm{C}(49)-\mathrm{C}(48)-\mathrm{C}(31)$ & $120.0(14)$ \\
\hline $\mathrm{C}(49)-\mathrm{C}(48)-\mathrm{C}(47)$ & $120.1(15)$ & $\mathrm{C}(31)-\mathrm{C}(48)-\mathrm{C}(47)$ & $107.5(13)$ \\
\hline $\mathrm{C}(48)-\mathrm{C}(49)-\mathrm{C}(50)$ & $120.3(15)$ & $\mathrm{C}(48)-\mathrm{C}(49)-\mathrm{C}(59)$ & $120.0(16)$ \\
\hline $\mathrm{C}(50)-\mathrm{C}(49)-\mathrm{C}(59)$ & $107.4(13)$ & $\mathrm{C}(33)-\mathrm{C}(50)-\mathrm{C}(51)$ & $121.2(14)$ \\
\hline $\mathrm{C}(33)-\mathrm{C}(50)-\mathrm{C}(49)$ & $119.0(14)$ & $\mathrm{C}(51)-\mathrm{C}(50)-\mathrm{C}(49)$ & $108.6(14)$ \\
\hline $\mathrm{C}(52)-\mathrm{C}(51)-\mathrm{C}(50)$ & $119.8(14)$ & $\mathrm{C}(52)-\mathrm{C}(51)-\mathrm{C}(60)$ & 119.1(16) \\
\hline $\mathrm{C}(50)-\mathrm{C}(51)-\mathrm{C}(60)$ & $108.5(13)$ & $\mathrm{C}(51)-\mathrm{C}(52)-\mathrm{C}(53)$ & $119.8(15)$ \\
\hline $\mathrm{C}(51)-\mathrm{C}(52)-\mathrm{C}(35)$ & $120.1(13)$ & $\mathrm{C}(53)-\mathrm{C}(52)-\mathrm{C}(35)$ & $107.0(13)$ \\
\hline $\mathrm{C}(54)-\mathrm{C}(53)-\mathrm{C}(37)$ & $120.1(15)$ & $\mathrm{C}(54)-\mathrm{C}(53)-\mathrm{C}(52)$ & $120.1(15)$ \\
\hline $\mathrm{C}(37)-\mathrm{C}(53)-\mathrm{C}(52)$ & $108.7(13)$ & $\mathrm{C}(53)-\mathrm{C}(54)-\mathrm{C}(40)$ & $120.4(15)$ \\
\hline $\mathrm{C}(53)-\mathrm{C}(54)-\mathrm{C}(55)$ & $119.9(16)$ & $\mathrm{C}(40)-\mathrm{C}(54)-\mathrm{C}(55)$ & $107.8(13)$ \\
\hline $\mathrm{C}(60)-\mathrm{C}(55)-\mathrm{C}(54)$ & $120.4(15)$ & $\mathrm{C}(60)-\mathrm{C}(55)-\mathrm{C}(56)$ & 121.1(14) \\
\hline $\mathrm{C}(54)-\mathrm{C}(55)-\mathrm{C}(56)$ & $107.6(16)$ & $C(57)-C(56)-C(41)$ & $120.8(15)$ \\
\hline $\mathrm{C}(57)-\mathrm{C}(56)-\mathrm{C}(55)$ & $118.9(16)$ & $\mathrm{C}(41)-\mathrm{C}(56)-\mathrm{C}(55)$ & $108.5(14)$ \\
\hline $\mathrm{C}(56)-\mathrm{C}(57)-\mathrm{C}(44)$ & $119.5(17)$ & $\mathrm{C}(56)-\mathrm{C}(57)-\mathrm{C}(58)$ & $120.8(16)$ \\
\hline $\mathrm{C}(44)-\mathrm{C}(57)-\mathrm{C}(58)$ & $107.7(14)$ & $\mathrm{C}(59)-\mathrm{C}(58)-\mathrm{C}(46)$ & $121.8(16)$ \\
\hline $\mathrm{C}(59)-\mathrm{C}(58)-\mathrm{C}(57)$ & $119.7(15)$ & $\mathrm{C}(46)-\mathrm{C}(58)-\mathrm{C}(57)$ & $107.7(16)$ \\
\hline $\mathrm{C}(58)-\mathrm{C}(59)-\mathrm{C}(60)$ & $119.5(17)$ & $\mathrm{C}(58)-\mathrm{C}(59)-\mathrm{C}(49)$ & $119.0(14)$ \\
\hline $\mathrm{C}(60)-\mathrm{C}(59)-\mathrm{C}(49)$ & $108.1(14)$ & $\mathrm{C}(55)-\mathrm{C}(60)-\mathrm{C}(51)$ & $120.7(15)$ \\
\hline $\mathrm{C}(55)-\mathrm{C}(60)-\mathrm{C}(59)$ & $120.0(15)$ & $\mathrm{C}(51)-\mathrm{C}(60)-\mathrm{C}(59)$ & $107.4(15)$ \\
\hline$S(1 Y)-C(1 X)-S(1 X)$ & 173.9(17) & $\mathrm{S}(2 \mathrm{X})-\mathrm{C}(2 \mathrm{X})-\mathrm{S}(2 \mathrm{Y})$ & $154(2)$ \\
\hline$C(2 X)-S(2 X)-S(2 Y)$ & 13.7(13) & $C(2 X)-S(2 Y)-S(2 X)$ & $12.0(11)$ \\
\hline $\mathrm{C}(902)-\mathrm{C}(901)-\mathrm{C}(906)$ & 120.0 & $\mathrm{C}(902)-\mathrm{C}(901)-\mathrm{Cl}(1)$ & 121(3) \\
\hline $\mathrm{C}(906)-\mathrm{C}(901)-\mathrm{Cl}(1)$ & $116(3)$ & $\mathrm{C}(901)-\mathrm{C}(902)-\mathrm{C}(903)$ & 120.0 \\
\hline $\mathrm{C}(901)-\mathrm{C}(902)-\mathrm{Cl}(2)$ & $110(3)$ & $\mathrm{C}(903)-\mathrm{C}(902)-\mathrm{Cl}(2)$ & $130(3)$ \\
\hline $\mathrm{C}(902)-\mathrm{C}(903)-\mathrm{C}(904)$ & 120.0 & $\mathrm{C}(905)-\mathrm{C}(904)-\mathrm{C}(903)$ & 120.0 \\
\hline $\mathrm{C}(904)-\mathrm{C}(905)-\mathrm{C}(906)$ & 120.0 & $\mathrm{C}(905)-\mathrm{C}(906)-\mathrm{C}(901)$ & 120.0 \\
\hline
\end{tabular}

